\title{
Portfolio Diversification Across Segmented Financial Markets
}

A Thesis
Presented to
the faculty of the School of Engineering and Applied Science
University of Virginia
in partial fulfillment
of the requirements for the degree
Master of Science
by
Derek Thomas Anderson

August 2017 


\section{APPROVAL SHEET}

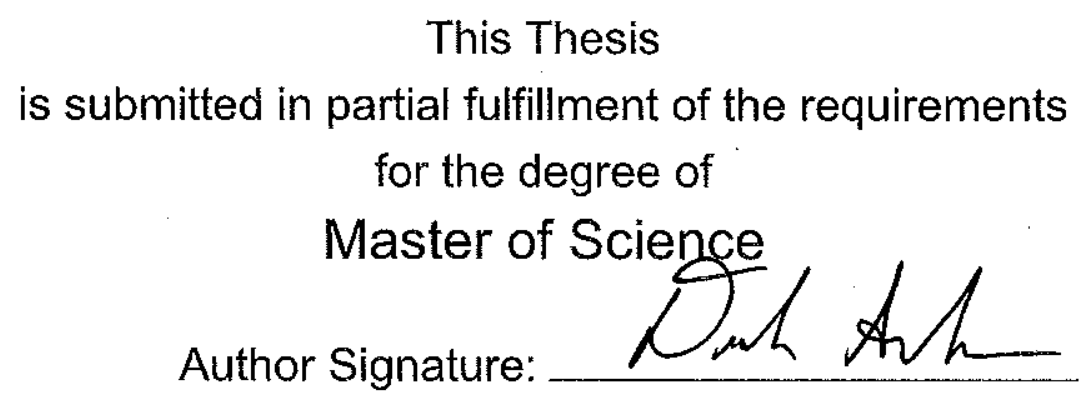

This Thesis has been read and approved by the examining committee:

Advisor: William Scherer

Committee Member: Reid Bailey

Committee Member: Steve Peterson

Committee Member:

Committee Member:

Committee Member:

Accepted for the School of Engineering and Applied Science:

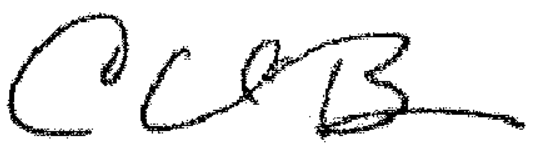

Craig H. Benson, School of Engineering and Applied Science

August 2017 


\title{
UNIVERSITY OF VIRGINIA
}

\author{
Abstract \\ Reid Bailey \\ Steve Peterson \\ William Scherer \\ Systems and Information Engineering Department \\ Master of Science

\section{Portfolio Diversification Across Segmented Financial Markets} \\ by Derek ANDERSON \\ Regional price to earnings ratios, aggregated at the industry level for a \\ country or geographic region, possess forward-looking information regarding \\ volatility-reducing diversification based on a test-control paired experiment \\ using random selection to form portfolios. Market segmentation theory pro- \\ poses that segmented financial markets are subject to different shocks than in- \\ ternationally integrated financial markets. Multiple performance metrics are \\ analyzed, and correlation of diversification holdings with pre-existing assets \\ varies directly with increased growth opportunities and segmentation mea- \\ sures as defined by Bekaert, Harvey, Lundblad, and Siegel (2007 and 2011). \\ The randomized portfolio experiment developed in this work is ripe for exten- \\ sion and customization as a tool to aid in portfolio management.
}





\section{Acknowledgements}

I would like to thank Bill Scherer, Reid Bailey, and Steve Peterson for serving as my advisory committee. I would also like to thank the University of Virginia Investment Management Company for their support of both in my academic endeavors and technical research requirements. 



\section{Contents}

$\begin{array}{ll}\text { Abstract } & \text { iii }\end{array}$

$\begin{array}{ll}\text { Acknowledgements } & \mathbf{v}\end{array}$

1 Introduction 1

1.1 Introduction . . . . . . . . . . . . . . . 1

1.1.1 Executive Summary . . . . . . . . . . . . . . 1

1.1.2 Framing the Question .............. 2

1.2 Literature Review . . . . . . . . . . . . . . . . . . . 3

1.2.1 International Capital Asset Pricing Model . . . . . . . . . . . 4

1.2.2 Correlation and Cointegration Structures . . . . . . . . 6

1.2.3 SEG, LGO, and GGO . . . . . . . . . . . . . . 6

1.2.4 Limitations of P/E Ratio Information Content . . . . . 8

1.2.5 Random Portfolio Analysis . . . . . . . . . . . . 9

2 Methodology and Assumptions $\quad 11$

2.1 Methodology ... . . . . . . . . . . . . . . 11

2.1.1 Calculating LGO, GGO, and SEG . . . . . . . . . . . . 11

2.1.2 Randomized Portfolio Experiment Framework . . . . . . 12

2.1.3 Randomized Portfolio Experiment Metrics . . . . . . . . 13

2.1.4 Regression Framework . . . . . . . . . . . . . . 16

2.2 Assumptions.......................... 18

2.3 Data . . . . . . . . . . . . . . . . . . . 19

3 Results and Interpretations $\quad 23$

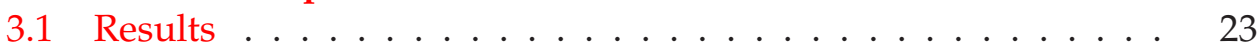

3.1.1 Macro Linkage Analysis . . . . . . . . . . . . . . . 24

3.1.2 Industry Contribution to SEG and LGO . . . . . . . . . 26

3.1.3 Visualizing the Random Portfolio Experiment Statistics . 29

3.1.4 Random Portfolio Experiment Regressions . . . . . . . . 29

3.2 Interpretations . . . . . . . . . . . . . . . 32

3.3 Directions for Future Work . . . . . . . . . . . . . . . . . . . 33

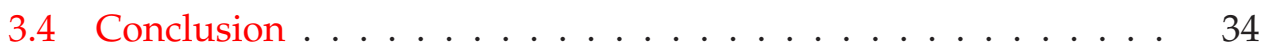

A A Valuation Model of P/E Ratios 35

B Return Indices and Higher Cross-Sectional Moments 37

C GDP and Investment Growth vs. LGO 49

$\begin{array}{ll}\text { D Random Portfolio Experiment Results } & 61\end{array}$ 
viii

Bibliography 


\section{List of Figures}

2.1 The indifference curves defined by the Sharpe ratio are presented in the left panel. The right panel shows the subdivision of the risk/return space into four quadrants around a particular observation. . . . . . . . . . . . . . . .

2.2 Cross-Sectional Equity Holdings Sample Moments for the United

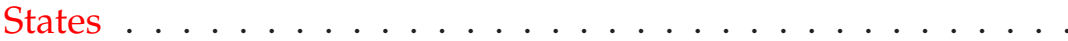

3.1 $S E G$ and $L G O$ over time. Note that $L G O$ has varied less as time progressed, especially since the crisis. $S E G$ shows more erratic behavior than $L G O \ldots \ldots \ldots \ldots \ldots \ldots$. . . . . . . . .

3.2 Left Panel: Base and Control Portfolios. Right Panel: Control and Test portfolios for diversification into the Middle East/North Africa region. . . . . . . . . . . . . . .

B.1 Cross-Sectional Equity Holdings Sample Moments for the United

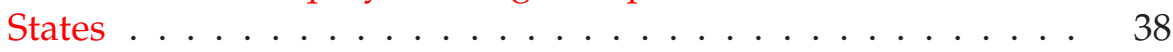

B.2 Cross-Sectional Equity Holdings Sample Moments for Canada . 38

B.3 Cross-Sectional Equity Holdings Sample Moments for France . 39

B.4 Cross-Sectional Equity Holdings Sample Moments for Germany 39

B.5 Cross-Sectional Equity Holdings Sample Moments for Italy . . . 40

B.6 Cross-Sectional Equity Holdings Sample Moments for Japan . . 40

B.7 Cross-Sectional Equity Holdings Sample Moments for the United Kingdom . . . . . . . . . . . . . . . . . 41

B.8 Cross-Sectional Equity Holdings Sample Moments for the Australia/New Zealand . . . . . . . . . . . . . . . . .

B.9 Cross-Sectional Equity Holdings Sample Moments for the Switzerland/Austria . . . . . . . . . . . . . . . 42

B.10 Cross-Sectional Equity Holdings Sample Moments for the Developed EU . . . . . . . . . . . . . . 42

B.11 Cross-Sectional Equity Holdings Sample Moments for Spain/Portugal 43

B.12 Cross-Sectional Equity Holdings Sample Moments for Scandinavia 43

B.13 Cross-Sectional Equity Holdings Sample Moments for Latin America ......................... 44

B.14 Cross-Sectional Equity Holdings Sample Moments for Korea . . 44

B.15 Cross-Sectional Equity Holdings Sample Moments for emerging Asia ............................. 45

B.16 Cross-Sectional Equity Holdings Sample Moments for emerging EU . . . . . . . . . . . . . . . . .

B.17 Cross-Sectional Equity Holdings Sample Moments for Middle

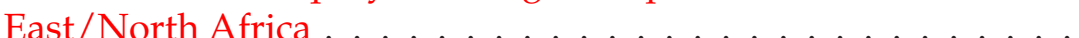


B.18 Cross-Sectional Equity Holdings Sample Moments for India/Sri Lanka . . . . . . . . . . . . . . . . . 46

B.19 Cross-Sectional Equity Holdings Sample Moments for South Africa 47 B.20 Cross-Sectional Equity Holdings Sample Moments for China . . 47 B.21 Cross-Sectional Equity Holdings Sample Moments for Taiwan . 48

C.1 GDP and Investment Growth versus LGO for the United States 50

C.2 GDP and Investment Growth versus LGO for Canada . . . . . . 50

C.3 GDP and Investment Growth versus LGO for France . . . . . . 51

C.4 GDP and Investment Growth versus LGO for Germany . . . . . 51

C.5 GDP and Investment Growth versus LGO for Italy . . . . . . . 52

C.6 GDP and Investment Growth versus LGO for Japan . . . . . . . 52

C.7 GDP and Investment Growth versus LGO for the United Kingdom 53

C.8 GDP and Investment Growth versus LGO for the Australia/New Zealand . . . . . . . . . . . . . . . . 53

C.9 GDP and Investment Growth versus LGO for the Switzerland/Austria 54

C.10 GDP and Investment Growth versus LGO for the Developed EU 54

C.11 GDP and Investment Growth versus LGO for Spain/Portugal . 55

C.12 GDP and Investment Growth versus LGO for Scandinavia . . . 55

C.13 GDP and Investment Growth versus LGO for Latin America . . 56

C.14 GDP and Investment Growth versus LGO for Korea . . . . . . . 56

C.15 GDP and Investment Growth versus LGO for emerging Asia . . 57

C.16 GDP and Investment Growth versus LGO for emerging EU . . . 57

C.17 GDP and Investment Growth versus LGO for Middle East/North Africa ........................... 58

C.18 GDP and Investment Growth versus LGO for India/Sri Lanka . 58

C.19 GDP and Investment Growth versus LGO for South Africa . . . 59

C.20 GDP and Investment Growth versus LGO for China . . . . . . . 59

C.21 GDP and Investment Growth versus LGO for Taiwan . . . . . . 60

D.1 Random Portfolio Experiment Results for Canada . . . . . . . . 62

D.2 Random Portfolio Experiment Results for France . . . . . . . . . 63

D.3 Random Portfolio Experiment Results for Germany . . . . . . . . 64

D.4 Random Portfolio Experiment Results for Italy . . . . . . . . . . 65

D.5 Random Portfolio Experiment Results for Japan . . . . . . . . . 66

D.6 Random Portfolio Experiment Results for the United Kingdom 67

D.7 Random Portfolio Experiment Results for the Australia/New Zealand . . . . . . . . . . . . . . . . . . 68

D.8 Random Portfolio Experiment Results for the Switzerland/Austria 69

D.9 Random Portfolio Experiment Results for the Developed EU . . 70

D.10 Random Portfolio Experiment Results for Spain/Portugal . . . 71

D.11 Random Portfolio Experiment Results for Scandinavia . . . . 72

D.12 Random Portfolio Experiment Results for Latin America . . . . 73

D.13 Random Portfolio Experiment Results for Korea . . . . . . . . . 74

D.14 Random Portfolio Experiment Results for emerging Asia . . . . 75

D.15 Random Portfolio Experiment Results for emerging EU . . . . . 76

D.16 Random Portfolio Experiment Results for Middle East/North

Africa . . . . . . . . . . . . . . . . 77 
D.17 Random Portfolio Experiment Results for India/Sri Lanka . . 78

D.18 Random Portfolio Experiment Results for South Africa . . . . . 79

D.19 Random Portfolio Experiment Results for China . . . . . . . . . . 80

D.20 Random Portfolio Experiment Results for Taiwan . . . . . . . . 81 



\section{List of Tables}

2.1 Regional Data Overview: Number of Return Series, Market Cap, and Market Cap Share . . . . . . . . . . . . . . . . . . 20

3.1 Regressing GDP growth on LGO . . . . . . . . . . . . . . . . . 24

3.2 Regressing Investment growth on LGO . . . . . . . . . . . . 25

3.3 Regressing GDP growth on GGO . . . . . . . . . . . . . 25

3.4 Regressing Investment growth on GGO . . . . . . . . . . . 25

3.5 Regressing excess GDP growth on LEGO . . . . . . . . . . . . . . 26

3.6 Contribution to $L G O$ by Industry, June $2016 \ldots \ldots \ldots$

3.7 Contribution to $S E G$ by Industry, June $2016 \ldots \ldots$. . . . . . . . . 28

3.8 Market Cap Share of Top 3 Industries by Region . . . . . . . . . 30

3.9 Coefficient Values from Regressions with Robust Standard Error Estimation. ${ }^{* * *}, * *$, and ${ }^{*}$ represent significance at $0.01,0.05$, and 0.10 significance, respectively. . . . . . . . . . . . . . 31 



\section{Chapter 1}

\section{Introduction}

\subsection{Introduction}

\subsubsection{Executive Summary}

Price to earnings $(\mathrm{P} / \mathrm{E})$ ratios contain forward-looking information for investors based in the United States about regional financial markets with assets that on average have less correlation with a pre-existing portfolio than other holdings available in US financial markets. The measures of market segmentation and growth opportunities proposed by Bekaert et al. (2011) and Bekaert et al. (2007) calculate industry-weighted $\mathrm{P} / \mathrm{E}$ ratios, using various weightings, to identify growth opportunities and segmentation levels for each region. A randomized portfolio experiment tests for the existence and significance of regional diversification premiums in portfolios held for three years. Cumulative returns, a measure of within-portfolio correlation, Conditional Value at Risk, and an additional metric combining total returns and three-year volatility are the metrics used to define portfolio performance in the experiment, conducted on a rolling 36-month window using 20 years of monthly data starting in February of 1996. This result is found using linear regressions with coefficient standard error estimation robust to clustered dependence over time and within regions. 


\subsubsection{Framing the Question}

A central tenet of Modern Portfolio Theory is that investors are risk averse, and construct portfolios by optimizing expected returns subject to constraints on the volatility of overall holdings ${ }^{1}$. Diversification possibilities are endlessinvestors choose to diversify across various asset classes, industries, factor model loadings, and regions of the world. Identifying diversification benefits across each of these methods, and more, are a major part of financial research, in both academia and industry.

International financial market segmentation is one source of potential diversification opportunities which can improve overall portfolio performance, as defined by risk associated with diversification into holdings that are positively correlated with an existing portfolio. This research shows that the $\mathrm{P} / \mathrm{E}$ ratio driven measures of segmentation and growth opportunities of Bekaert (henceforth BHLS) et al can indicate countries or geographical regions have assets that have lower correlation with assets in the US. This research does not endeavor to find an optimal diversification strategy, nor does it provide a predictive model of portfolio performance. These problems are better suited for active portfolio management. Test and control portfolio holdings of 50 total assets and the 3 year holding period length are chosen to emulate basic tenets of an arbitrary established investor with a medium term outlook. By randomly selecting these portfolios, a distribution of return streams can serve the purposes of analysis generally applied to overall market return indices. Sampling from this distribution of possible portfolios identifies general tendencies of regional markets.

In the next section, a literature review will serve to provide information on

\footnotetext{
${ }^{1}$ Markowitz (1952) is the seminal paper for Modern Portfolio Theory
} 
the path of research on international financial market segmentation. Following this, the experimental methodology and assumptions are explained for calculating and comparing the segmentation measures between the various regions, and the execution of the randomized portfolio diversification experiment. Finally, the results are analyzed, resulting in the conclusion that these three metrics together indicate regions which have assets with lower correlation to existing holdings than assets from U.S. markets. However, in this dataset they are statistically unrelated to future return premiums or reduction in tail risk events, as measured by conditional Value at Risk, implying that additional metrics and analysis are required for optimizing portfolio returns in active portfolio management.

\subsection{Literature Review}

International diversification is a well-studied topic, since it is justified only if there are gains from it. Many studies show that gains have existed historically for emerging and frontier markets, notably Jayasuriya and Shambora (2009). This paper shows that investors holding only US assets would have experienced higher (or constant) levels of return with lower risk by simply diversifying some of their portfolios to emerging and frontier markets. As the topic of international diversification has existed for a few decades, the gains from diversifying to emerging regions have been diminishing as more investors adopt this strategy, leading to a relatively focused vein of research on investing in frontier markets, which are financial markets in countries that are too small to be labeled emerging, yet still have a functional financial system for public equity holders. An overview of these economies can be found in Speidell and Khrone (2007). 
A great deal of academic research focuses on the topic of measuring international market segmentation. As US investors are searching out opportunities in even the smallest international markets, metrics hilighting diversification benefits in international markets become more and more useful. Kearney and Lucey (2004) provide a good overview of the field, and highlight three main threads of work;

... testing the segmentation of equity markets via the international Capital Asset Pricing Model (iCAPM), testing the extent and determinants of changes in the correlation or cointegration structure of markets, and the more recent literature that recognised the essentially static nature of these tests and derives time-varying measures of integration.

While this paper focuses specifically on a set of three time-varying measures, a brief overview of the research on static measures provides a foundation for understanding the methods employed.

\subsubsection{International Capital Asset Pricing Model}

The international CAPM is an extension of the well-known model of Sharpe (1964), which suggests that the individual assets in a financial market share a common set of risks. In the original Sharpe model, the volatility of an asset serves as a measure of riskiness, which must be considered as a constraint when maximizing total returns. The efficient frontier is defined as the set of assets which minimize variance with respect to a given level of excess returns over the risk free return rate. Jensen, Black, and Scholes (1972) further develop the CAPM, eliminating the need for the risk-free rate. Factor models are an extension of the CAPM within the dimension of a single financial market, 
but international markets add another dimension of possible variability. These models add various factors to the market return stream in a linear regression model. Assets with returns yielding coefficient values close to zero in time series regressions, indicating low levels of correlation with market returns, represent assets with low risks.

When the scope of analysis increases to more than a single market, a spectrum of assumptions exist between two extreme cases. The first extreme assumes all capital markets are integrated globally, and defines risk based on correlation with one global market return stream. The opposite extreme assumes an individual country's financial market is entirely segmented from the rest of the world, requiring the use of market return streams calculated for each region to identify risks.

The assumption sets that blend these two extremes allow for any given country's financial market to be partially correlated with other globalized markets, as in Errunza and Losq (1985) and Errunza, Losq, and Padmanabhan (1992). This an early application of data more granular than country-level aggregated index returns used to study market segmentation. Bekaert and Harvey (1995) use the same model framework, adding regime-switching techniques to estimate the probability of a market displaying either segmented or integrated behavior, based on the estimated local and global relative price of risk.

Carrieri, Errunza, and Hogan (2007) extend the analysis of Errunza and Losq by including a portfolio of country funds and American depositary receipts (ADRs) from integrated markets, which can serve as substitutes to international investors without access to local segmented markets. Carrieri et al clearly state that measuring financial market segmentation requires using data 
which is more granular than market-wide indices. Their index of integration identifies regions with market return rates that cannot be closely matched using holdings available to investors in globally integrated markets.

\subsubsection{Correlation and Cointegration Structures}

Examining correlation and cointegration structures between return streams is a slightly more technical (versus the theoretical CAPM) approach. The central assumption is that integrated markets exhibit more correlated return streams over time. Longin and Solnik (1995) focuses on correlation between index returns of major country financial markets by calculating covariance matrices over rolling windows. They find that the covariance matrices vary over time, implying that market integration a dynamic feature.

A slightly more complex analysis of these indices involves estimating the cointegration structure based on either the Engle-Granger methodology, such as work by Engle, Lilien, and Robins (1987) or Bollerslev, Engle, and Wooldridge (1988), or the more sophisticated Johansen multivariate approach, as found in Rangvid (1995), Aggarwal, Lucey, and Muckley (2009) or Bierens and Martins (2010). These studies recursively estimate cointegration vectors of international index returns and find that the number of cointegration vectors generally increases as time progresses. However, as these methods all depend on the analysis of aggregated index returns, they all suffer from the critique in Carrieri, Errunza, and Hogan (2007) by not using more granular data.

\subsubsection{SEG, LGO, and GGO}

The metrics developed in Bekaert et al. (2007) (henceforth BHLS07) and Bekaert et al. (2011) (henceforth BHLS11) are based on P/E ratios of industry portfolios. 
$\mathrm{P} / \mathrm{E}$ ratios are defined as the share price of a firm divided by the earnings per share in a given month. Campbell and Shiller (2001) dives deep into the information content of $\mathrm{P} / \mathrm{E}$ ratios. BHLS build on such logic and state their assumptions simply;

- The growth potential of a country is a function of the growth potential of its mix of industries

- $\mathrm{P} / \mathrm{E}$ ratios contain forward looking information about growth opportunities

The authors derive a model of growth opportunities by discounting future cash flows on an asset which pays out all earnings as dividends each period. An overview is available in Appendix A.

Market integration theory states that integrated markets enjoy free flow of capital, leading to equalization of $\mathrm{P} / \mathrm{E}$ ratios within industry groups. Industry portfolios are specified as the optimal lens for examining countries, as firms in the same country and industry will face very similar market conditions, and aggregating firms to the industry level reduces noisy signals from firm-level data. Local growth opportunities, as defined by BHLS07, are dependent upon a region's aggregated $\mathrm{P} / \mathrm{E}$ ratio, and convey information regarding growth opportunities for both globally integrated and segmented financial markets. Global growth opportunities, on the other hand, use global industry portfolio $\mathrm{P} / \mathrm{E}$ ratios, weighted by the industrial distribution of the specific country, will convey information regarding growth opportunities available to countries that are already integrated into the globalized market.

BHLS11 construct a measure of segmentation for a country based on it's industry-weighted sum of absolute deviations between the inverse of local and globalized industry portfolio $\mathrm{P} / \mathrm{E}$ ratios, also known as the earnings yield. 
While the concepts behind the construction of this segmentation measure are identical to that of the growth opportunity measures, the numerical methods are slightly different. The market segmentation measure weights absolute deviations from global industry portfolio earnings yields, versus measuring regions with only higher $\mathrm{P} / \mathrm{E}$ ratios. By weighting absolute devations, this metric identifies markets without growth opportunities which are still segmented from the globally integrated market.

\subsubsection{Limitations of P/E Ratio Information Content}

The model of BHLS shows that $\mathrm{P} / \mathrm{E}$ ratios are a function of both growth opportunities as well as industry-specific discount rates, which implies that changes in the discount rate could mask the effect of growth opportunities in observed values. However, Ang and Zhang (2011) show that most of the variation can be ascribed to changes in growth opportunities versus discount rates.

Weigand and Irons (2006) find that P/E ratios do not mean-revert fast enough (a central assumption of Campbell and Shiller (2001)) versus a model using the 10 -year treasury note as a better benchmark rate for reversion analysis ${ }^{2}$. Irons and $\mathrm{Wu}$ (2013) continue this research and argue that investors began indexing earnings yields to the 10-year treasury note since 1960, finding that the cointegration structure of $\mathrm{P} / \mathrm{E}$ ratios diminishes around this point in time. This analysis is primarily based upon P/E ratios of firms solely in the United States, however, so it is not completely at odds with the comparison of $\mathrm{P} / \mathrm{E}$ ratios between segmented international financial markets.

\footnotetext{
${ }^{2}$ This is known as the Fed Model, see Yardeni (2003), Asness (2003), Thomas and Zhang (2008)
} 


\subsubsection{Random Portfolio Analysis}

While portfolio choice is a widely studied subject, comparing the performance of multiple markets should involve more than a single optimal or index portfolio. Random portfolio selection stems from Malkiel (2011), a famous book called A Random Walk Down Wall Street, first written in 1973. Burns (2004) use randomly selected portfolios as a benchmark measure for investment skill. Lisi (2009) presents a mutual fund evaluation technique based on placing a particular fund's historical returns within a distribution of randomly selected portfolios from the same universe of holdings available to mutual funds. Arnott et al. (2013) presents a similar methodology with two different index portfolios - one weighted by market capitalization rates, and one equally rated of all stocks in their available dataset. This methodology is also employed by Stein (2014), by estimating factor models for mutual fund returns and placing these estimates in a distribution generated by forming random portfolios. 



\section{Chapter 2}

\section{Methodology and Assumptions}

\subsection{Methodology}

The calculations presented in this section are shown for a region $i$ of $G=21$

total countries and geographic regions that comprise global financial markets. 10 industries are identified within each region, defined by the sectors of the MSCI Global Industry Classification Standard (GICS). Weights for aggregating firm-level data to the industry portfolio level are based on market capitalization rates, henceforth referred to as market cap or cap-weighting. All returns are determined using price series denominated in US dollars. Market cap is also denominated in US dollars.

\subsubsection{Calculating LGO, GGO, and SEG}

For a country $i$, define $I W_{i, t}$ as a vector of industry weights calculated by the industry share of the entire region's market cap. Let $P E_{i, t}$ be a vector of industry portfolio $\mathrm{P} / \mathrm{E}$ ratios. Next, define local growth opportunities $L G O_{i, t}$ :

$$
L G O_{i, t}=\ln \left(I W_{i, t}^{\prime} P E_{i, t}\right)
$$

$L G O$ is the natural log of the market cap weighted country portfolio P/E ratio, and is capable of identifying growth opportunities in both segmented and globally integrated markets. 
Global growth opportunities $G G O_{i, t}$ are defined by the natural logarithm of the $\mathrm{P} / \mathrm{E}$ ratios of global industrial portfolios weighted by the $i^{\text {th }}$ country industry market cap. Define a vector of global industry portfolio P/E ratios $P E_{w, t}$.

$$
G G O_{i, t}=\ln \left(I W_{i, t}^{\prime} P E_{w, t}\right)
$$

BHLS07 state that GGO can identify growth opportunities available to countries that are part of the integrated global economy, but not for countries that are segmented, since only integrated economies should share industrial portfolio $\mathrm{P} / \mathrm{E}$ ratios over time.

$L G O$ and $G G O$ are constructed as forward looking signals for growth. However, an economy which is segmented is not necessarily also endowed with growth opportunities, and could still potentially reduce risk when added to an existing portfolio of US assets. $S E G$ is a measure of market segmentation based on earnings yields differentials, which are the inverse of the P/E ratio.

$$
S E G_{i, t}=I W_{i, t}^{\prime}\left|E Y_{i, t}-E Y_{w, t}\right|=I W_{i, t}^{\prime}\left|\frac{1}{P E_{i, t}}-\frac{1}{P E_{w, t}}\right|
$$

As the inverse of the $\mathrm{P} / \mathrm{E}$ ratio, using the earnings yield performs a similar task as the natural logarithm in $L G O$ and $G G O$ for minimizing the effect of high outliers in the $\mathrm{P} / \mathrm{E}$ ratio space.

\subsubsection{Randomized Portfolio Experiment Framework}

The growth opportunity and segmentation measures are compared to timeseries of portfolio performance metric differentials between randomized test and control portfolio pairs consisting of $N=50$ holdings each. All holdings are selected at random. Test and control pairs share $80 \%\left(N_{\text {base }}=40\right)$ of holdings in common. Statistical differences between the test and control portfolio 
performance is based on only $20 \%$ of the holdings $\left(N_{\text {div }}=10\right)$. Holdings in the US provide the universe of assets used for sampling the base of each portfolio pair, as well as the diversification holdings for the control portfolio. For the test portfolio, the diversification set is randomly selected from the universe of assets available within a particular test region. All $N=50$ assets are weighted equally in all portfolios, thus carrying weight $\frac{1}{N}$. For each region, 2000 pairs of portfolios are selected and rebalanced monthly. Let superscript $T, C$ represent both the test and control portfolios simultaneously, as the construction and metric calculation is identical across the testing pair.

Portfolios can be represented as a matrix $R^{C, T} \in \mathbb{R}^{50 \times 36}$. Each portfolio is a set of $N=50$ holdings, each with 36 months of US dollar denominated return observations.

$$
R^{C, T}=\frac{1}{50}\left[\begin{array}{cccc}
r_{1,1} & r_{1,2} & \ldots & r_{1,36} \\
r_{2,1} & r_{2,2} & \ldots & r_{2,36} \\
\vdots & & \ddots & \vdots \\
r_{50,1} & r_{50,2} & \ldots & r_{50,36}
\end{array}\right]
$$

Holdings 1 through 40 are from the base region, and holdings 41 through 50 are from either one of the test regions for the test portfolios, or from the United States again for the control portfolios.

\subsubsection{Randomized Portfolio Experiment Metrics}

Four measures of portfolio performance are compared between each pair to identify an average premium measure for each region. Cumulative (total) returns measure absolute performance, and are defined for each portfolio formed in period $t$ as

$$
T R_{T}^{C, T}=\prod_{t=T}^{T+35}\left(1+R_{T+t}^{C, T}\right)-1=\prod_{t=T}^{T+35}\left(1+\frac{1}{50} \sum_{i=1}^{50} r_{i, T+t}^{C, T}\right)-1
$$


This value is equal to the total growth (or loss) of the initial investment incurred over the 36 month period. The difference between each test and control portfolio total return is recorded for each of the test-control pairs. A Wilcoxon signed rank test identifies periods when the median total return difference is statistically nonzero.

The Pearson Correlation coefficient between the aggregated 40 base asset holdings and the aggregated set of 20 diversification holdings measures the degree to which the addition of diversification assets affects the volatility of overall portfolio. The expression for this measure is calculated

$$
\operatorname{Corr}_{T}=\frac{\mathbb{E}\left[R_{t}^{B} R_{t}^{C, T}\right]-\mathbb{E}\left[R_{t}^{B}\right] \mathbb{E}\left[R_{t}^{C, T}\right]}{\sigma^{B} \sigma^{C, T}}
$$

The combined performance of the base assets with the testing assets can be broken into two return streams - one for a portfolio of the $N_{\text {base }}=40$ assets, and a smaller portfolio of the $N_{d i v}=10$ holdings. The correlation between these two aggregated series is calculated to detect whether the addition of the test diversification region can decrease overall portfolio volatility by more than an arbitrary selection of US holdings.

Conditional Value at Risk (CVaR), as thoroughly explained in Acerbi and Tasche (2002), is an extension of another portfolio performance metric known as Value at Risk (VaR). The estimation of VaR requires knowledge of the distribution of returns, as it is defined as the most a portfolio can lose in one time period with probability $\alpha . \mathrm{CVaR}$ improves upon VaR as a risk measure primarily because it is subadditive, meaning that for two possible assets $A$ and $B$, we have

$$
C \operatorname{VaR}(A)+C \operatorname{VaR}(B) \leq C \operatorname{VaR}(A+B)
$$

CVaR is a tail mean, or in other words, a simple average of the worst $\alpha \%$ of 

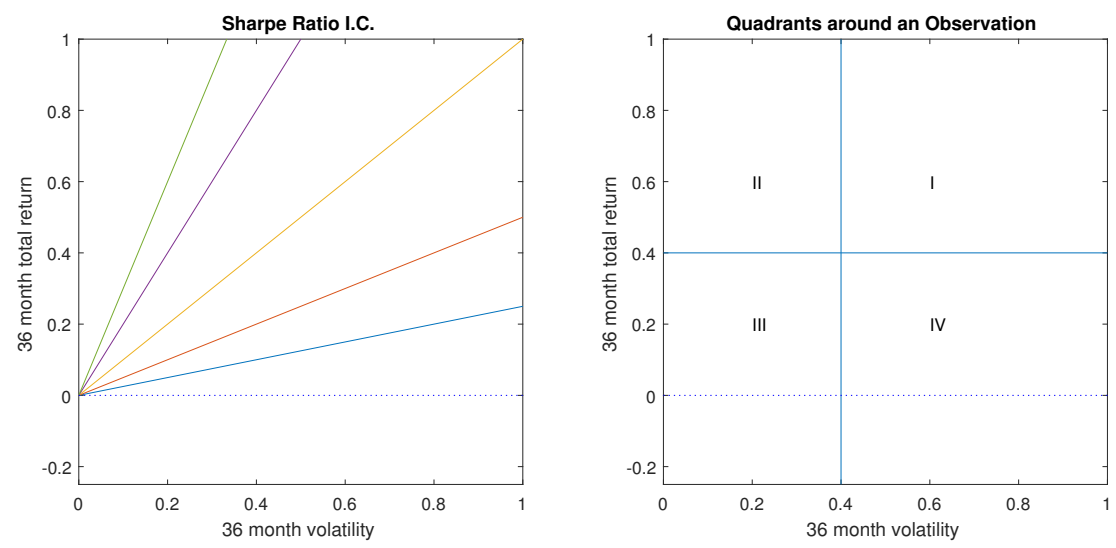

FIGURE 2.1: The indifference curves defined by the Sharpe ratio are presented in the left panel. The right panel shows the subdivision of the risk/return space into four quadrants around a particular observation.

observations. In this experiment, $\mathrm{CVaR}$ is calculated at $\alpha=8.33 \%\left(\frac{3}{36}\right)$ level, or the simple average of the three worst monthly returns observed over the 36 month period. Test $\mathrm{CVaR}$ minus control $\mathrm{CVaR}$ measures excess tail risk for the test diversification region.

The Sharpe ratio is a prevalent metric in financial analysis, which is defined by the cumulative return of an asset $T R_{T}^{C, T}$ divided by it's standard deviation $\sigma^{C, T}$ over a specified period of time, in this case 36 months. This ratio implies a set of indifference curves shown in Figure 2.1, which in turn define preferences for the tradeoff between increased returns while also increasing the risk of a portfolio. Also, negative values of the Sharpe ratio cannot be compared to positive values quantitatively, as increased volatility brings the Sharpe ratio closer to zero for assets with negative total returns, resulting in a 'better' metric observation.

Instead, note that the point representing the test portfolio will fall into one of the four quadrants relative to the control portfolio. Test portfolios in quadrant II dominate the control portfolio in both risk and return, and test portfolios in quadrant IV are dominated by the control portfolio in both risk and 
return. Counting the number of test portfolios in quadrant II relative to the control portfolio, and subtracting off the number of test portfolios in quadrant IV relative to the control portfolio yields a measure of the net absolute portfolio performance increase in the sample.

A central point of the distribution of each of the first three measures must be used to represent the average diversification benefits for each region over time. Since total returns and conditional value at risk are potentially unbounded, the median value over the 2000 observations each period is used to minimize the effect of extreme outliers. Since correlation is bounded between negative one and one, the mean correlation of diversification holdings and base holdings is used. The last metric is a simple count of test portfolios which dominate their paired control portfolio, so a measure of centrality is not necessary.

\subsubsection{Regression Framework}

Linear regression is a fundamental tool in financial time series analysis. The market risk of the CAPM is defined as the linear regression coefficient an asset return stream carries versus the market return stream. In time series analysis with multiple groups observed over a shared time period, simple ordinary least squares (OLS) regression results of can be improved upon by accounting for group behavior in the explanatory variables. The data from each group can be combined into what econometricians call a panel, and an OLS regression can be specified as

$$
Y_{i, t}=\alpha_{i}+X_{i, t} \beta+\epsilon_{i, t}
$$

Dummy variables for each region in the regressions account for country level constant effects $\alpha_{i}$ (also known as a fixed effect estimator). 
Thompson (2011) develops estimators for coefficient standard errors using data with correlation across regions and time. Petersen (2009) and Gow, Ormazabal, and Taylor (2010) present a comprehensive list of standard-error correction methodologies, and run tests based on simulations of data with firm and time effects present. Gow, Ormazabal, and Taylor (2010) find that the Thompson standard errors are the unequivocally best method for data including as few as 10 clusters.

For a single clustering of $G$ groups with $N_{g}$ observations each and $K$ explanatory variables, the covariance of the estimator for $\beta$ is given by

$$
\hat{V}(\hat{B})=\left(X^{\prime} X\right)^{-1} \hat{B}\left(X^{\prime} X\right)^{-1}
$$

where

$$
\hat{B}=\sum_{g=1}^{G} X_{g}^{\prime} u_{g} u_{g}^{\prime} X_{g}
$$

for $X_{g} \in \mathbb{R}^{N_{g} \times K}$ and $u_{g} \in \mathbb{R}^{N_{g}}$ are the residuals from the $g^{\text {th }}$ group observations.

This term can also be calculated with each group consisting of observations in a shared time period. The two-way cluster robust standard errors are defined by

$$
\hat{\operatorname{Var}}(\hat{\beta})=\hat{V}_{\text {region }}+\hat{V}_{\text {time }, 0}-\hat{V}_{\text {white }, 0}
$$

The term $\hat{V}_{w h i t e, 0}$ is the variance matrix used for the standard errors of White (1980). This heteroskedasticity-robust variance matrix is subtracted off from the tabulation, as these effects are counted both by the firm-specific and time period-specific clustering, avoiding double counting. 


\subsection{Assumptions}

Regional groups are primarily individual countries. Countries with smaller financial markets (fewer than 50 publicly available assets) are grouped regionally such that no group has less than 50 available holdings for the majority of observation dates. Regression results which are presented as a replication of a few experiments of BHLS calculate the world measures for $S E G_{i, t}$ and $G G O_{i, t}$ using the global aggregated industry portfolios. However, the randomized portfolio experiment is designed to measure diversification benefits beyond United States equity holdings, so $S E G_{i, t}$ and $G G O_{i, t}$ use the United States industrial portfolio as the definition of the 'global' measure.

Regional groups of small financial markets which do not explicitly state their country membership in the tables are: are aggregated in the following manner:

- G7: Canada, France, Germany, Italy, Japan, United States, and United Kingdom $^{1}$

- Developed EU: Belgium, the Netherlands, Denmark, and Ireland

- Scandinavia: Sweden, Finland, and Norway

- Latin America: Argentina, Brazil, Chile, Colombia, and Mexico

- Emerging Asia: Indonesia, Malaysia, Singapore, Bangladesh, Thailand, and Vietnam

- Emerging Europe: Bosnia and Herzigovina, Bulgaria, Croatia, Czech Republic, Estonia, Hungary, Greece, Lithuania, Poland, Serbia, Slovenia, and Ukraine

\footnotetext{
${ }^{1}$ Note that the G7 is not included in the random portfolio experiment, it is only shown in the tables exploring industry composition of $S E G$ and $L G O$.
} 
- Middle East/North Africa: Bahrain, Egypt, Jordan, Kuwait, Lebanon, Morocco, Oman, Qatar, Tunisia, Turkey, Pakistan, and Saudi Arabia

Developed economies, as defined by MSCI, include the G7 countries, Australia and New Zealand, Switzerland and Austria, Spain and Portugal, the Developed EU, and Scandinavia. The remaining regions are identified as emerging markets.

\subsection{Data}

The empirical work in this research primarily uses the Thompson-Reuters Worldscope dataset, which contains firm-level data for approximately $85 \%$ of global market capitalization. Firm-level data gathered monthly for this study included market cap, prices, and P/E ratios when available. Observations missing price data are excluded from analysis. The market segmentation and growth opportunity measures are based on industry cap-weighted P/E ratios. Table 2.1 presents the total number of holdings and total market cap for each region in the data in both the first and last year of the sample.

A least-squares regression of the monthly global aggregated index of all available Worldscope company $\mathrm{data}^{2}$ weighted by market cap rates on the MSCI All Country World Index yields a $\beta=1.01$ with a t-statistic of 12.4 , implying that the global market dynamics in the Worldscope data set are closely aligned with the MSCI measure, which is widely used as the global market return in many CAPM applications. The total market cap of the companies weighted in the MSCI All Country World Index is almost $\$ 40$ trillion US at the

\footnotetext{
${ }^{2}$ Firms with missing $\mathrm{P} / \mathrm{E}$ ratios, prices, or market cap rates were removed from the working data set. The total market cap of those firms missing prices or earnings information accounted for less than $1 \%$ of total market cap.
} 


\begin{tabular}{|c|c|c|c|c|c|c|}
\hline Region & $\begin{array}{c}\mathrm{N} \\
\text { Feb. } 1996\end{array}$ & $\begin{array}{l}\text { Market Cap. } \\
\text { (bil \$US) }\end{array}$ & Market Cap. Share & $\begin{array}{c}\text { N } \\
\text { Jun. } 2016\end{array}$ & $\begin{array}{l}\text { Market Cap. } \\
\text { (bil \$US) }\end{array}$ & Market Cap. Share \\
\hline Global & 9586 & 14,424 & $100 \%$ & 16344 & 57,089 & $100 \%$ \\
\hline G7 & 6570 & 11,837 & $82.1 \%$ & 8611 & 36,677 & $64.2 \%$ \\
\hline United States & 2849 & 6,014 & $41.7 \%$ & 3608 & 23,757 & $41.6 \%$ \\
\hline Canada & 304 & 234 & $1.6 \%$ & 590 & 1,396 & $2.5 \%$ \\
\hline France & 288 & 448 & $3.1 \%$ & 359 & 1,825 & $3.2 \%$ \\
\hline Germany & 101 & 338 & $2.4 \%$ & 289 & 1,482 & $2.6 \%$ \\
\hline Italy & 173 & 195 & $1.4 \%$ & 203 & 528 & $0.9 \%$ \\
\hline Japan & 2193 & 3,486 & $24.2 \%$ & 2795 & 4,888 & $8.6 \%$ \\
\hline United Kingdom & 662 & 1,119 & $7.8 \%$ & 767 & 2,797 & $4.9 \%$ \\
\hline Australia/New Zealand & 254 & 238 & $1.7 \%$ & 700 & 1,158 & $2.0 \%$ \\
\hline Switzerland/Austria & 157 & 306 & $2.1 \%$ & 186 & 1,423 & $2.5 \%$ \\
\hline Dev. EU & 212 & 321 & $2.2 \%$ & 252 & 1,237 & $2.2 \%$ \\
\hline Spain and Portugal & 120 & 141 & $1.0 \%$ & 131 & 696 & $1.2 \%$ \\
\hline Scandinavia & 205 & 169 & $1.2 \%$ & 459 & 955 & $1.7 \%$ \\
\hline Latin America & 225 & 180 & $1.3 \%$ & 186 & 846 & $1.5 \%$ \\
\hline Korea & 352 & 141 & $1.0 \%$ & 468 & 1,045 & $1.8 \%$ \\
\hline Emerging Asia & 763 & 539 & $3.7 \%$ & 683 & 1,342 & $2.4 \%$ \\
\hline Emerging EU & 112 & 38 & $0.3 \%$ & 98 & 179 & $0.3 \%$ \\
\hline Middle East/North Africa & 135 & 28 & $0.2 \%$ & 361 & 812 & $1.4 \%$ \\
\hline India/Sri Lanka & 87 & 40 & $0.3 \%$ & 386 & 1,275 & $2.2 \%$ \\
\hline South Africa & 181 & 187 & $1.3 \%$ & 111 & 362 & $0.6 \%$ \\
\hline China & 12 & 0.73 & $0.001 \%$ & 2037 & 5,387 & $9.4 \%$ \\
\hline Taiwan & 94 & 108 & 0.8 & 408 & 751 & $1.3 \%$ \\
\hline
\end{tabular}


end of the sample in June 2016. Data for this study, as seen in Table 2.1, had a total market cap of almost $\$ 60$ trillion.

While BHLS focused on a set of 39 industries for their analysis, this analysis is based on the GIC definitions which define 10 different industries: Energy, Materials, Industrials, Consumer Discretionary, Consumer Staples, Healthcare, Financials, Information Technology, Telecommunications, and Utilities. The recent addition of Real Estate (GIC 60) was not included in this dataset. Conducting the analysis with a smaller set of industry classifications did not affect the results found in BHLS07, which they conducted as a robustness check.

Figure 2.2 shows four time-varying measures of the cross-sectional distribution of available equity holding returns within the United States. The distribution of stock returns appears not to be normally distributed in any given time period, especially post-crisis, where higher moments clearly exist. Since the nature of these distributional shifts is not examined in this work, these charts are only included for every country in Appendix B. In most financial market segmentation analysis, only the first panel of information is considered, i.e. the regional market index return. While the higher moments do not factor directly into the randomized portfolio experiment, they show the evolution of asset price behavior in the United States over time. The higher moments appear to increase as time progresses, and the effect of the assets which contribute to these higher moments will affect the distribution of test and control portfolio metrics. 

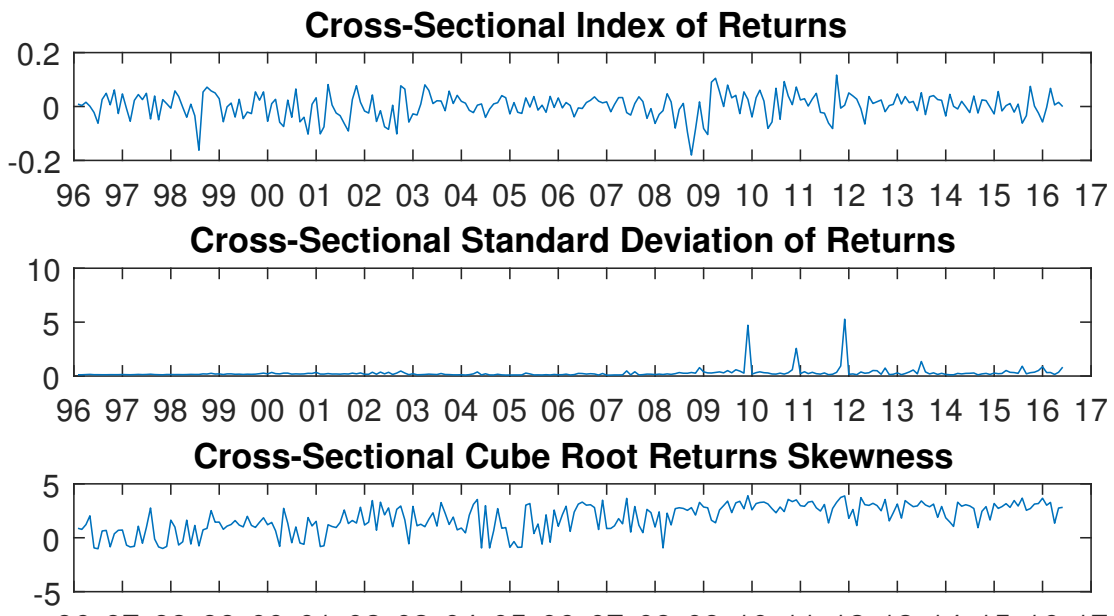

96979899000102030405060708091011121314151617

Cross-Sectional Fourth Root of Returns Kurtosis

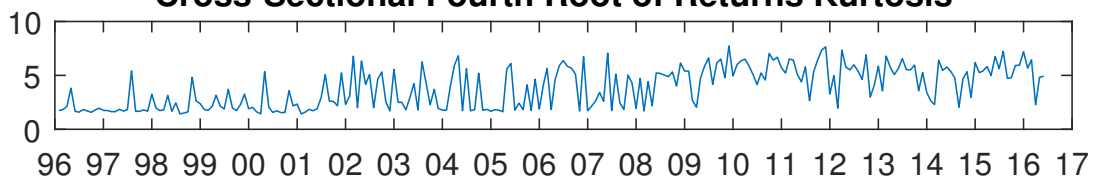

FiguRE 2.2: Cross-Sectional Equity Holdings Sample Moments for the United States 


\section{Chapter 3}

\section{Results and Interpretations}

\subsection{Results}

Regressions of $L G O$ and $G G O$ on one year ahead GDP and investment growth show that $\mathrm{P} / \mathrm{E}$ ratios yield significant and positive coefficient estimates, which confirms results found in BHLS07. GDP and investment data are from the World Economic Outlook (WEO) of the International Monetary Fund (IMF). GDP is denominated in international dollars, valued using purchasing power parity between the currencies of each region. Next, $S E G, L G O$, and $G G O$ are used in linear regression versus the random portfolio experiment metrics, which shows that $S E G, L G O$, and $G G O$ have shown significant relationships over the last 20 years, in a forward looking manner, for regions that exhibit lower excess correlation with existing portfolio holdings.

Figure 3.1 shows the time series of $S E G_{i, t}$ and $L G O_{i, t}$ for every region. A legend is withheld as interpreting individual country data from this perspective is impossible, but the figure is included to show the overall behavior of these two measures. Note that while $L G O$ has fallen for almost all regions with the progression of time, especially since the crisis of 2008, $S E G$ does not exhibit this behavior, and erratically rises for various countries over the entire time horizon. 

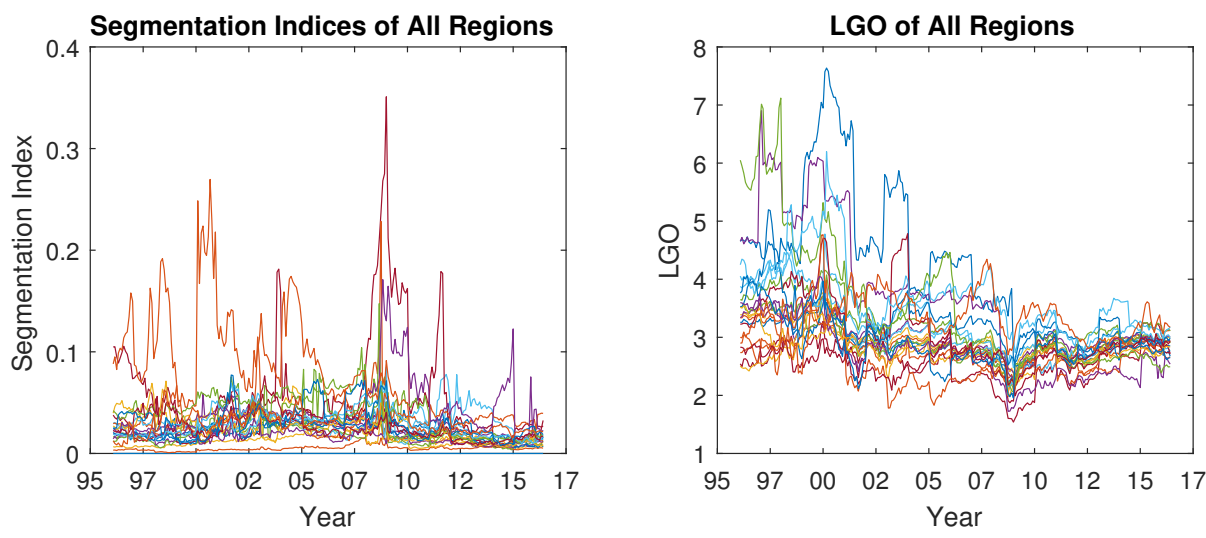

FIGURE 3.1: $S E G$ and $L G O$ over time. Note that $L G O$ has varied less as time progressed, especially since the crisis. $S E G$ shows more erratic behavior than $L G O$.

\begin{tabular}{c|c} 
& $\beta_{L G O}$ \\
\hline Coefficient & 1.48 \\
Std. Err. & 0.68 \\
t-stat & $2.17^{* *}$ \\
\hline$R^{2}$ & 0.46 \\
$N$ & 420
\end{tabular}

TABLE 3.1: Regressing GDP growth on LGO

\subsubsection{Macro Linkage Analysis}

$L G O$ and $G G O$ hold positive relationships with GDP and real investment growth in annual fixed effect regression analysis. Since these data are annual, GDP growth in year $t$ is compared in time with the observation of $L G O$ or $G G O$ from December of year $t-1$. Let $g d p_{i, t}$ denote the GDP growth in country $i$ in year $t$.

$$
g d p_{i, t}=\alpha_{i}+\beta L G O_{i, t}+\epsilon_{i, t}
$$

Table 3.1 presents the estimates from this regression, excluding the estimates for the $\alpha_{i}$ terms. The standard errors are calculated using Thompson (2011) two-way cluster estimation to account for dependencies within each country, as well as within each time period. ${ }^{*}$ and ${ }^{* *}$ represent significance at the $90 \%$ and $95 \%$ levels respectively. 


\begin{tabular}{c|c} 
& $\beta_{L G O}$ \\
\hline Coefficient & 3.99 \\
Std. Err. & 1.85 \\
t-stat & $2.16^{* *}$ \\
\hline$R^{2}$ & 0.17 \\
$N$ & 420
\end{tabular}

TABLE 3.2: Regressing Investment growth on LGO

\begin{tabular}{c|c} 
& $\beta_{G G O}$ \\
\hline Coefficient & 3.99 \\
Std. Err. & 1.67 \\
t-stat & $2.38^{* *}$ \\
\hline$R^{2}$ & 0.49 \\
$N$ & 420
\end{tabular}

TABLE 3.3: Regressing GDP growth on GGO

Similar regressions for investment growth insetad of GDP growth are presented in 3.2.

These same regressions are repeated for $G G O$ in tables 3.3 and 3.4.

As a final effort in replicating BHLS07, define local excess growth opportunities $L E G O_{i, t}=L G O_{i, t}-G G O_{i, t}$, which is meant to identify growth opportunities in segmented markets. The intuition behind this metric is to identify regions with $\mathrm{P} / \mathrm{E}$ ratios indicating growth opportunities in sectors that are not also signalling growth opportunities for integrated markets through the global $\mathrm{P} / \mathrm{E}$ ratios in $G G O$. LEGO is regressed on GDP growth in excess of average global GDP growth with results presented in Table 3.5.

\begin{tabular}{c|c} 
& $\beta_{G G O}$ \\
\hline Coefficient & 8.94 \\
Std. Err. & 5.15 \\
t-stat & $1.74^{*}$ \\
\hline$R^{2}$ & 0.16 \\
$N$ & 420
\end{tabular}

TABLE 3.4: Regressing Investment growth on GGO 


\begin{tabular}{c|c} 
& $\beta_{L E G O}$ \\
\hline Coefficient & 1.19 \\
Std. Err. & 0.47 \\
t-stat & $2.51^{* *}$ \\
\hline$R^{2}$ & 0.41 \\
$N$ & 400
\end{tabular}

TABLE 3.5: Regressing excess GDP growth on LEGO

Assuming that emerging markets exhibit the properties of segmented financial markets, Table 3.5 confirms the BHLS07 hypothesis that $L E G O_{i, t}$ can identify excess growth opportunities in emerging financial markets as defined by MSCI. While BHLSO7 test an additional term GEGO which they construct as an excess over global portfolio $\mathrm{P} / \mathrm{E}$ ratios and weights, the results in this analysis do not confirm explanatory power for GDP growth in developed markets, so regression results are not included.

Appendix C includes two dimensional plots of GDP growth and investment growth versus LGO for each region to visualize the relationship between LGO and GDP growth within a region in the context of global markets.

\subsubsection{Industry Contribution to SEG and LGO}

The contribution of individual industries to either segmentation or local growth opportunities can be shown by ranking the values of each industry in the $I W_{i, t}^{\prime} P E_{i, t}$ vector dot product. The natural logarithm can be ignored in this context, as it is a monotonic transformation. This ranking is presented in Table 3.6. A similar ranking of the values for each industry in the expression $I W_{i, t}^{\prime}\left|E P_{i, t}-E P_{w, t}\right|$ can be found in Table 3.7. These measures are for June 2016.

Table 3.8 shows the percentage of total regional market cap belonging to the top three industries in each region for June 2016, as defined by contributions to 


\begin{tabular}{|c|c|c|c|c|c|c|c|c|c|c|}
\hline & Energy & Materials & Industrials & Cons. Disc. & Cons. Staples & Healthcare & Financials & IT & Telecom & Utilities \\
\hline G7 & 7 & 8 & 6 & 4 & 3 & 2 & 5 & 1 & 10 & 9 \\
\hline USA & 7 & 9 & 6 & 3 & 5 & 2 & 4 & 1 & 10 & 8 \\
\hline Canada & 1 & 3 & 5 & 7 & 4 & 10 & 2 & 8 & 6 & 9 \\
\hline France & 5 & 10 & 1 & 3 & 2 & 4 & 6 & 8 & 9 & 7 \\
\hline Germany & 10 & 5 & 3 & 4 & 8 & 2 & 6 & 1 & 7 & 9 \\
\hline Italy & 6 & 9 & 4 & 1 & 8 & 7 & 3 & 10 & 5 & 2 \\
\hline Japan & 9 & 8 & 1 & 2 & 3 & 4 & 5 & 6 & 7 & 10 \\
\hline United Kingdom & 1 & 6 & 4 & 5 & 2 & 7 & 3 & 8 & 10 & 9 \\
\hline Australia/New Zealand & 5 & 2 & 4 & 6 & 7 & 3 & 1 & 10 & 9 & 8 \\
\hline Switzerland/Austria & - & 4 & 3 & 6 & 2 & 1 & 5 & 8 & 7 \\
\hline Dev. EU 1 & 9 & 4 & 3 & 5 & 1 & 2 & 6 & 7 & 8 & 9 \\
\hline Spain/Portugal & 4 & 10 & 5 & 1 & 9 & 7 & 3 & 8 & 6 & 10 \\
\hline Scandinavia & 9 & 8 & 1 & 3 & 4 & 6 & 2 & 7 & 5 \\
\hline Latin America & 5 & 2 & 4 & 6 & 1 & 10 & 3 & 9 & 8 & 10 \\
\hline South Korea & 8 & 5 & 7 & 4 & 2 & 3 & 6 & 1 & 9 & 7 \\
\hline EMRGAS & 8 & 7 & 3 & 5 & 1 & 6 & 2 & 10 & 4 \\
\hline EMRGEU & 2 & 6 & 9 & 5 & 8 & 7 & 1 & 10 & 3 & 9 \\
\hline MENA & 8 & 2 & 6 & 7 & 4 & 9 & 1 & 3 & 5 & 10 \\
\hline India/Sri Lanka & 8 & 2 & 7 & 5 & 1 & 6 & 3 & 4 & 9 & 10 \\
\hline South Africa & 7 & 4 & 8 & 1 & 3 & 6 & 2 & 9 & 5 & - \\
\hline China & 7 & 1 & 2 & 3 & 8 & 6 & 5 & 4 & 10 & 9 \\
\hline Taiwan & 8 & 2 & 7 & 5 & 6 & 9 & 3 & 1 & 4 & 9 \\
\hline
\end{tabular}

TABLE 3.6: Contribution to $L G O$ by Industry, June 2016 


\begin{tabular}{|c|c|c|c|c|c|c|c|c|c|c|}
\hline & Energy & Materials & Industrials & Cons. Disc. & Cons. Staples & Healthcare & Financials & IT & Telecom & Utilities \\
\hline G7 & 2 & 5 & 7 & 4 & 8 & 10 & 1 & 6 & 9 & 3 \\
\hline USA & 3 & 10 & 6 & 2 & 7 & 8 & 1 & 5 & 9 & 4 \\
\hline Canada & 1 & 4 & 10 & 6 & 7 & 9 & 2 & 8 & 3 & 5 \\
\hline France & 4 & 9 & 2 & 3 & 6 & 7 & 1 & 8 & 10 & 5 \\
\hline Germany & 10 & 6 & 2 & 1 & 8 & 7 & 3 & 4 & 5 & 9 \\
\hline Italy & 1 & 8 & 6 & 3 & 10 & 7 & 2 & 9 & 5 & 4 \\
\hline Japan & 9 & 3 & 2 & 1 & 10 & 8 & 6 & 4 & 7 & 5 \\
\hline United Kingdom & 1 & 7 & 6 & 3 & 8 & 2 & 10 & 9 & 4 & 5 \\
\hline Australia/New Zealand & 3 & 2 & 7 & 6 & 4 & 8 & 1 & 10 & 9 & 5 \\
\hline Switzerland/Austria & - & 3 & 2 & 7 & 5 & 1 & 4 & 6 & 8 & 9 \\
\hline Dev. EU 1 & 7 & 4 & 3 & 1 & 9 & 2 & 8 & 5 & 6 & 10 \\
\hline Spain/Portugal & 4 & 6 & 2 & 1 & 7 & 8 & 3 & 10 & 9 & 5 \\
\hline Scandinavia & 1 & 5 & 8 & 6 & 10 & 9 & 4 & 3 & 7 & 2 \\
\hline Latin America & 3 & 2 & 1 & 5 & 6 & 9 & 4 & 7 & 8 & 10 \\
\hline South Korea & 10 & 6 & 1 & 4 & 9 & 7 & 5 & 3 & 8 & 2 \\
\hline EMRGAS & 10 & 5 & 1 & 3 & 8 & 6 & 2 & 7 & 4 & 9 \\
\hline EMRGEU & 2 & 6 & 5 & 4 & 7 & 8 & 1 & 9 & 10 & 3 \\
\hline MENA & 5 & 1 & 2 & 6 & 7 & 9 & 4 & 3 & 8 & \multicolumn{2}{|c|}{10} \\
\hline India/Sri Lanka & 2 & 3 & 5 & 6 & 4 & 7 & 1 & 9 & 8 & 10 \\
\hline South Africa & 3 & 8 & 4 & 1 & 7 & 6 & 2 & 9 & 5 & - \\
\hline China & 6 & 3 & 2 & 4 & 8 & 7 & 1 & 5 & 9 & 10 \\
\hline Taiwan & 8 & 4 & 5 & 7 & 9 & 6 & 2 & 1 & 3 & 10 \\
\hline
\end{tabular}

TABLE 3.7: Contribution to $S E G$ by Industry, June 2016 

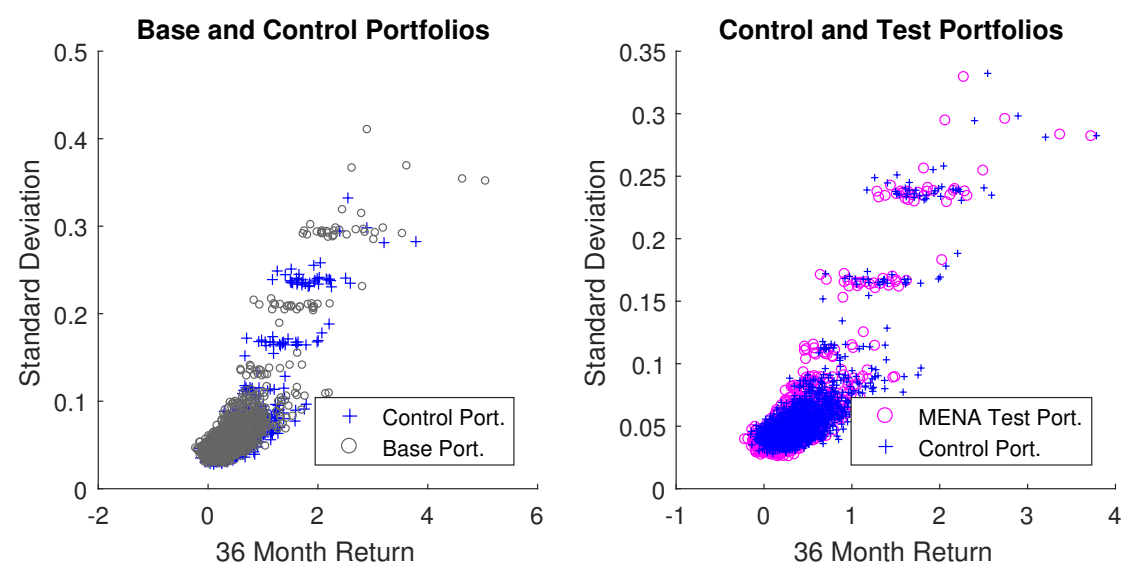

Figure 3.2: Left Panel: Base and Control Portfolios. Right Panel: Control and Test portfolios for diversification into the Middle East/North Africa region.

local growth opportunities. The three industries are also listed for each region.

\subsubsection{Visualizing the Random Portfolio Experiment Statistics}

The entire set of 2000 base and control portfolios are plotted in the risk-return plane in the left panel of Figure 3.2. The same set of 2000 control portfolios are shown in the right panel of Figure 3.2 along with the set of 2000 test portfolios from diversification into the Middle East/North Africa region. Each test and control portfolio pair represent different points in this plane, and the relative shifts in these and other measurement spaces define the central tendencies of regional market asset performance. It is easiest to see these shifts in the portfolio pairs with the highest returns, as there are not many and thus the graph is not very crowded.

\subsubsection{Random Portfolio Experiment Regressions}

Table 3.9 presents the results of regressing each performance measurement on the segmentation and local growth opportunity indices. Test results for each 


\begin{tabular}{|c|c|c|}
\hline & Market Cap Share & Top Industries \\
\hline Global & 0.3278 & Consumer Staples, Healthcare, IT \\
\hline G7 & 0.3679 & Consumer Staples, Healthcare, IT \\
\hline United States & 0.4686 & Consumer Discretionary, Healthcare, IT \\
\hline Canada & 0.6909 & Energy, Materials, Financials \\
\hline France & 0.5082 & Industrials, Consumer Discretionary, Consumer Staples \\
\hline Germany & 0.3932 & Industrials, Healthcare, IT \\
\hline Italy & 0.6142 & Consumer Discretionary, Financials, Utilities \\
\hline Japan & 0.4939 & Industrials, Consumer Discretionary, Consumer Staples \\
\hline United Kingdom & 0.4737 & Energy, Consumer Staples, Financials \\
\hline Australia and New Zealand & 0.6235 & Materials, Healthcare, Financials \\
\hline Switzerland/Austria & 0.6388 & Industrials, Consumer Staples, Healthcare \\
\hline Dev. EU 1 & 0.5760 & Industrials, Consumer Staples, Healthcare \\
\hline Spain/Portugal & 0.6438 & Consumer Discretionary, Financials, Utilities \\
\hline Scandinavia & 0.5626 & Industrials, Consumer Discretionary, Financials \\
\hline Latin America & 0.6017 & Materials, Consumer Staples, Financials \\
\hline Korea & 0.4222 & Consumer Staples, Healthcare, IT \\
\hline EMRGAS & 0.5940 & Industrials, Consumer Staples, Financials \\
\hline EMRGEU & 0.6326 & Energy, Financials, Telecom \\
\hline Middle East/North Africa & 0.7404 & Materials, Financials, IT \\
\hline India/Sri Lanka & 0.4035 & Materials, Consumer Staples, Financials \\
\hline South Africa & 0.6859 & Consumer Discretionary, Consumer Staples, Financials \\
\hline China & 0.4101 & Materials, Industrials, Consumer Discretionary \\
\hline Taiwan & 0.7340 & Materials, Financials, IT \\
\hline
\end{tabular}

TABLE 3.8: Market Cap Share of Top 3 Industries by Region 


\begin{tabular}{c|cccc} 
RPE Measure & $\beta_{S E G}(\mathrm{t}-\mathrm{stat})$ & $\beta_{L G O}$ (t-stat) & $\beta_{G G O}$ (t-stat) & $R^{2}$ \\
$T R_{T}$ & $0.79(1.25)$ & & & 0.08 \\
$T R_{T}$ & & $0.99(1.01)$ & & 0.05 \\
$T R_{T}$ & & & $2.54(1.06)$ & 0.05 \\
$T R_{T}$ & $0.87(1.39)^{*}$ & $0.39(0.27)$ & $3.53(1.13)$ & 0.09 \\
\hline $\operatorname{Corr}_{T}$ & $-0.11(-0.35)$ & & & 0.37 \\
$\operatorname{Corr}_{T}$ & & $-7.00(-7.70)^{* * *}$ & & 0.49 \\
$\operatorname{Corr}_{T}$ & & & $-19.18(-5.97)^{* * *}$ & 0.52 \\
$\operatorname{Corr}_{T}$ & $-0.47(-2.82)^{* * *}$ & $-3.28(-3.01)^{* * *}$ & $-15.02(-4.48)^{* * *}$ & 0.54 \\
\hline$C V a R_{T}$ & $0.0004(0.03)$ & & & 0.18 \\
$C V a R_{T}$ & & $0.12(1.10)$ & & 0.20 \\
$C V a R_{T}$ & & & $0.46(2.35)^{* * *}$ & 0.22 \\
$C V a R_{T}$ & $0.01(0.88)$ & $0.01(0.04)$ & $0.47(2.28)^{* *}$ & 0.22
\end{tabular}

TABle 3.9: Coefficient Values from Regressions with Robust Standard Error Estimation. ${ }^{* * *},{ }^{* *}$, and ${ }^{*}$ represent significance at $0.01,0.05$, and 0.10 significance, respectively.

performance metric are presented in four lines - one line for a simple linear regression versus $S E G$, one line for a simple linear regression with $L G O$, one line for a simple linear regression with $G G O$, and a multiple regression containing $S E G, L G O$, and $G G O$ all together as explanatory variables. $L G O$ and $G G O$ do not exhibit enough correlation in each region to worry about issues involving multi-collinearity. Years in which the differential between control and test portfolios is not statistically nonzero, as tested using a Wilcoxon signed rank test $^{1}$, are excluded from the regression. All regressions include a fixed effect estimator (dummy variable) for each region, which is not reported.

Neither $S E G, L G O$, or $G G O$ provide statistically significant foresight over 36 months of future return premiums from diversifying into a particular region. These three indicators do show negative coefficient estimates for excess correlation carried in test region portfolios. The significance of each estimator is consistent across regressions of the entire set of regions, as well as only on those countries defined as developed markets or emerging markets by MSCI

\footnotetext{
${ }^{1}$ Wilcoxon signed rank tests, from Wilcoxon (1945), are nonparametric tests designed to outperform t-tests when the underlying data is not normally distributed.
} 
index membership, thus not included to avoid redundancy. The same regressions are run with lower granularity at the annual frequency, also producing similar estimates. Plots of all of these metrics are presented for each region in Appendix D.

\subsection{Interpretations}

The test portfolio premiums in this experiment identify average portfolio performance differences between regional diversification options. This is different from efficient frontier analysis, which examines whether targeted diversification into an international market can increase the optimal return and risk profile available in the base market (here, the United States). This analysis instead focuses the movement of the core of the set of assets in various regions as identified by the random samples of portfolios with 50 holdings each. The results can be considered akin to index-based analysis with an enhancement of distributional properties.

It is interesting to note that $S E G$ does not carry a significant relationship with correlation differentials in the simple bivariate regression, but gains explanatory power once $L G O$ and $G G O$ are included in the regression. This means that $S E G$ accounts for variation in correlation only after the effect of $G G O$ and $L G O$, at a much smaller scale. Also, increases in $G G O$ lead to portfolios with greater values of CVaR. This means regions with industry compositions tilted towards those industries with the highest $\mathrm{P} / \mathrm{E}$ ratios in the US generally exacerbate the worst negative returns in an individual month.

While the greatest diversification premiums based on market segmentation are probably gone due to the advancement of globalization, recent populist political waves could lead to trade barriers and nationalistic economic policy 
by various sovereigns which have long been considered centers of the globally integrated financial markets.

\subsection{Directions for Future Work}

The analysis conducted here can be extended along many dimensions. First and foremost, varying the length of time portfolios are held from a fixed three years would give more insight how forward looking $\mathrm{P} / \mathrm{E}$ ratios are in conveying information about growth opportunities and portfolio diversification benefits. The random selection process could also be augmented to include a pseudo-random portfolio selection, targeting particular equity attributes that may be of interest to any particular investor. Diversification strategy rules can determine the portfolio selection process and compared to random results as well. Using a randomized experiment as the framework for any strategy-based decision process allows for the grading of strategies within a distribution, versus simply comparing the results of various aggregated indices.

Secondly, many more measures of portfolio performance measurement other than those included in this study can further the output from the randomized portfolio experiment. No measure of the risk-free rate of return was included in this study, as the base of each portfolio comprised the same holdings, which all would in theory face the same risk-free rate. Also, measures of currency risk are excluded, which are a central component to any analysis regarding investment management decision making. Finally, the base portfolio could be selected pseudo-randomly to reflect a more specific set of investor preferences as the starting point of performance analysis.

Finally, the measures of integration may be explored beyond the work of BHLS. SEG and $L G O$ are defined based on data only from the current time 
period. The evolution of the industrial mix within a country can indicate which particular industries provide the most stable growth over their lifetimes. Also, other measures of integration, such as that presented in Carrieri, Errunza, and Hogan (2007), could potentially support to these findings. The data set used in this study did not include information on ADR's and country funds, which would provide more insight into the options available to investors at any given time.

\subsection{Conclusion}

Price to earnings $(\mathrm{P} / \mathrm{E})$ ratios contain forward-looking information for investors based in the United States about regional financial markets with assets that are on average have less correlation than other holdings available in US financial markets, and more generally can serve to indicate growth opportunities and regional financial markets segmented from globally integrated markets. Randomized portfolio experiment results find the existence and significance of regional diversification premiums in portfolios held for three years. Cumulative returns, a measure of within-portfolio correlation, Conditional Value at Risk, and an additional metric combining total returns and three-year volatility are used to define portfolio performance in the experiment, conducted on a rolling 36-month window using 20 years of monthly data starting in February of 1996. This result is found using linear regressions with coefficient standard error estimation robust to clustered dependence over time and within regions. 


\section{Appendix A}

\section{A Valuation Model of P/E Ratios}

The rationale for using these three measures is based in a valuation model outlined in both Bekaert et al. (2007) and Bekaert et al. (2011). Their model assumes that real log earnings growth can be defined as the sum of a persistent world growth opportunity and an idiosyncratic growth disturbance for each region and industry, or

$$
\Delta \ln \left(\operatorname{Earn}_{i, j, t}\right)=G O_{w, j, t-1}+\epsilon_{i, j, t}
$$

where $\epsilon_{i, j, t} \sim N\left(0, \sigma_{i, j}^{2}\right)$. World growth opportunity is modelled with persistence, where

$$
G O_{w, j, t}=\mu_{j}+\phi_{j} G O_{w, j, t-1}+\epsilon_{w, j, t}
$$

and $\epsilon_{w, j, t} \sim N\left(0, \sigma_{w, j}^{2}\right)$.

Each industry within each region has a discount rate $\delta_{i, j, t}$, which is a function of the world discount rate $\delta_{w, t}$. The relationship is defined

$$
\delta_{i, j, t}=r_{f}\left(1-\beta_{i, j}\right)+\beta_{i, j} \delta_{w, t}
$$

A fundamental assumption by the authors is that for integrated markets,

$$
\beta_{i, j}=\beta_{j}
$$

implying that the local industry discount rates within integrated markets are identical. Weakening this assumption would imply that $L E G O$ could be powerful in explaining growth opportunities in integrated as well as segmented markets.

The world market discount rate is modelled as

$$
\delta_{w, t}=d_{w}+\phi_{w} \delta_{w, t-1}+\eta_{w, t}
$$

where $\eta_{w, t} \sim N\left(0, s_{w}^{2}\right)$.

All of these assumptions can be put together into a valuation of any given industry under the assumption that all industries pay out all of their economic earnings in dividends, where industry valuation $V_{i, j, t}$ is defined as

$$
V_{i, j, t}=\mathbb{E}\left[\sum_{k=1}^{\infty} \exp \left(-\sum_{l=0}^{k-1} \delta_{i, j, t+l}\right) \operatorname{Earn}_{i, j, t+k}\right]
$$


To make this valuation stationary, dividing by current earnings gives:

$$
\frac{V_{i, j, t}}{\operatorname{Earn}_{i, j, t}}=\mathbb{E}\left[\sum_{k=1}^{\infty} \exp \left(\sum_{l=0}^{k-1}-\delta_{i, j, t+l}+\Delta \ln \left(\operatorname{Earn}_{i, j, t+1+l}\right)\right)\right]=\sum_{k=1}^{\infty} Q_{i, j, k, t}
$$

The authors go on to derive a recursive representation of the $Q_{i, j, k, t}$ terms, which implies that $\mathrm{P} / \mathrm{E}$ ratio for any industry can be represented as a log linear function of coefficients

$$
\log \left(P E_{i, j, t}\right)=\bar{a}_{i, j, k}+\bar{b}_{j, k} \delta_{w, t}+\bar{c}_{j, k} G O_{w, j, t}
$$

Which implies that increased growth opportunities can be observed in an increasing industry aggregate $\mathrm{P} / \mathrm{E}$ ratio. Based on this rationale, the deviation of an individual region's industry $\mathrm{P} / \mathrm{E}$ ratios from a global industry $\mathrm{P} / \mathrm{E}$ ratio should also provide an indicator for the level of segmentation between a market and the global economy.

Full exposition of the derivation of the recursive representation can be found in Bekaert et al. (2007) and Bekaert et al. (2011). 


\section{Appendix B}

\section{Return Indices and Higher Cross-Sectional Moments}

This appendix includes four panels per region, showing the index return, as well as the standard deviation, cube root of skewness, and fourth root of kurtosis for returns in each time period. 


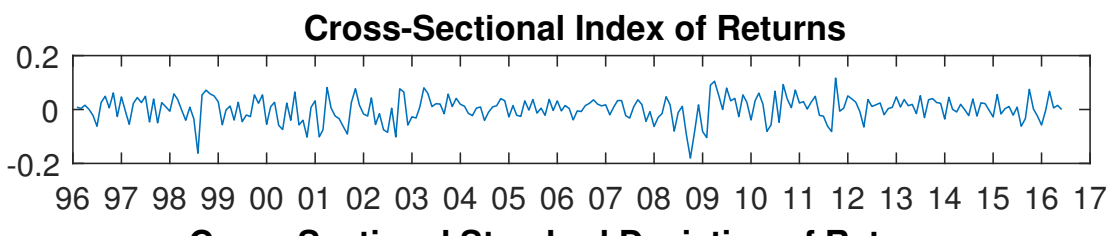

Cross-Sectional Standard Deviation of Returns

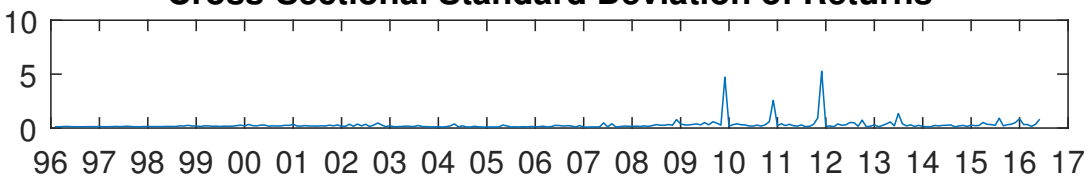

Cross-Sectional Cube Root Returns Skewness

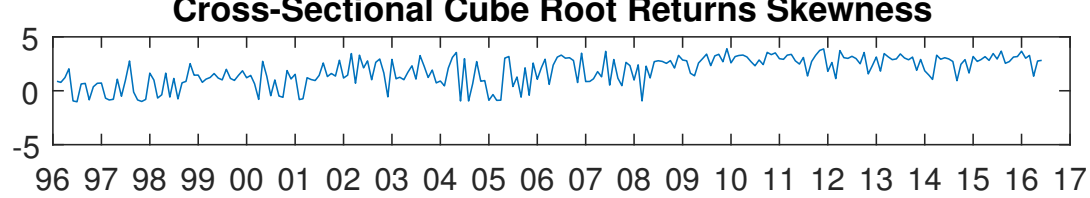

Cross-Sectional Fourth Root of Returns Kurtosis

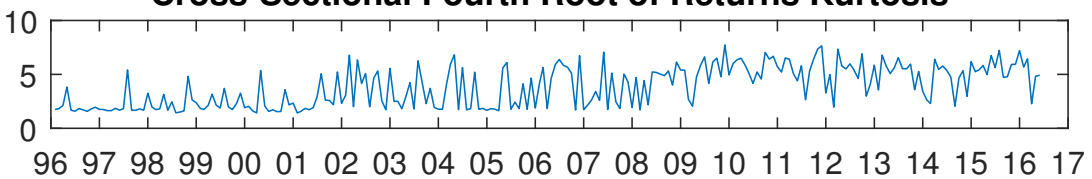

FIGURE B.1: Cross-Sectional Equity Holdings Sample Moments for the United States

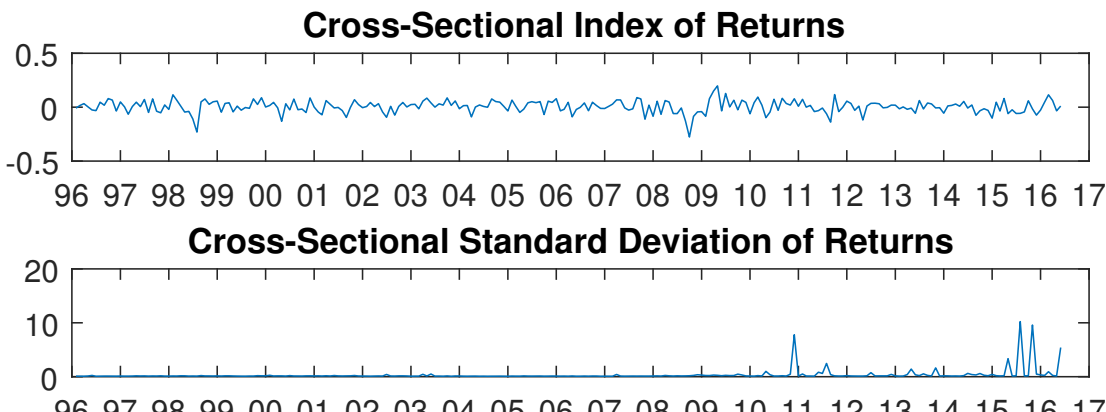

96979899000102030405060708091011121314151617

Cross-Sectional Cube Root Returns Skewness

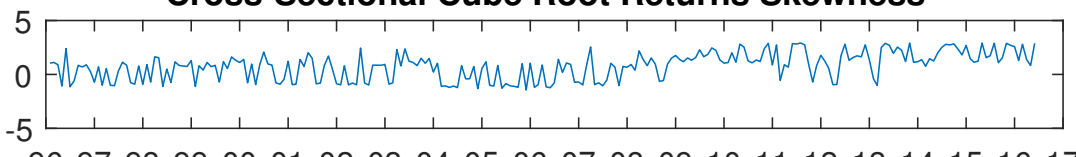

96979899000102030405060708091011121314151617

Cross-Sectional Fourth Root of Returns Kurtosis

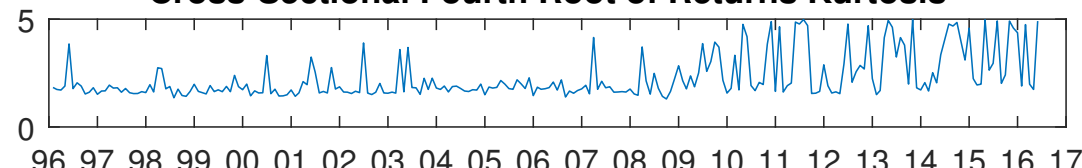

FIGURE B.2: Cross-Sectional Equity Holdings Sample Moments for Canada 


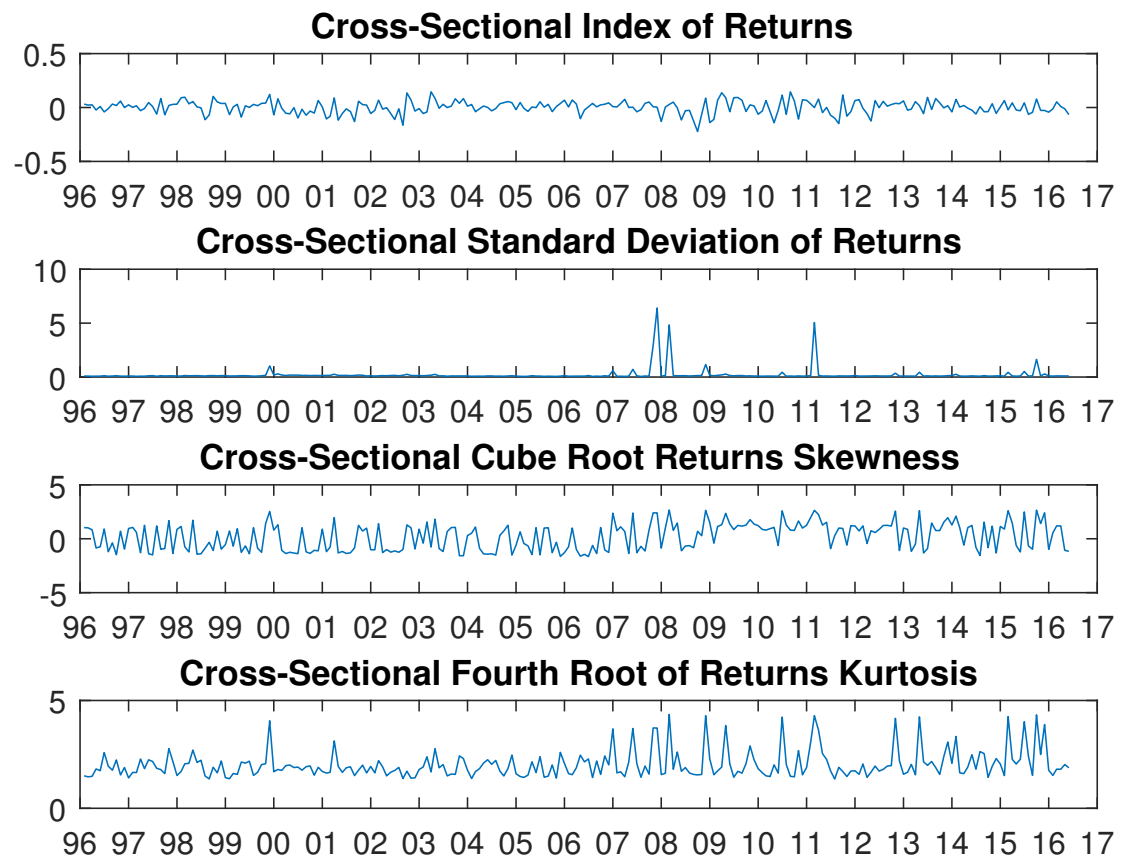

FIGURE B.3: Cross-Sectional Equity Holdings Sample Moments for France
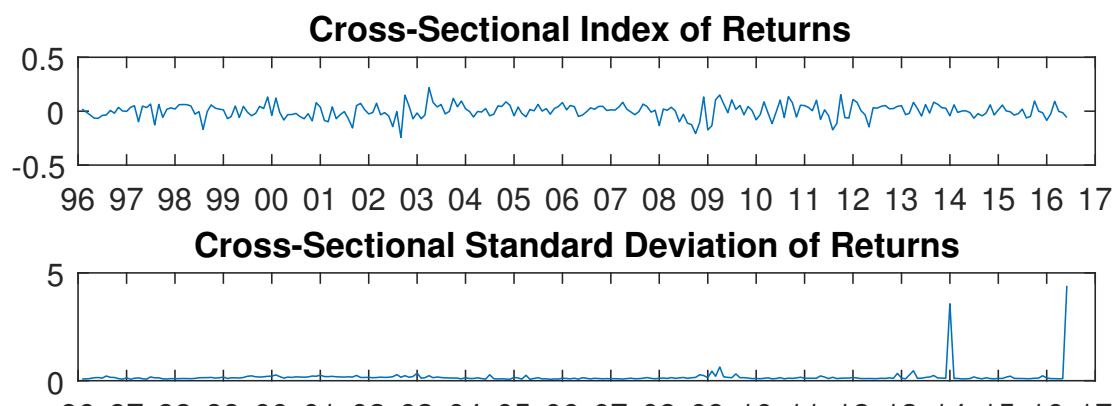

96979899000102030405060708091011121314151617

Cross-Sectional Cube Root Returns Skewness

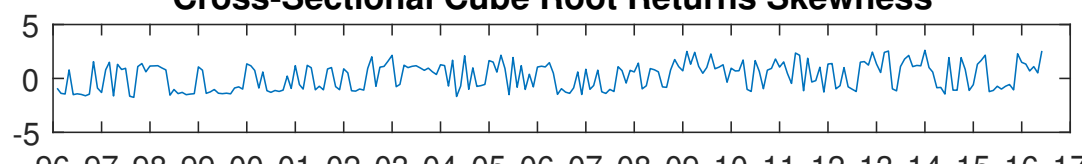

96979899000102030405060708091011121314151617 Cross-Sectional Fourth Root of Returns Kurtosis

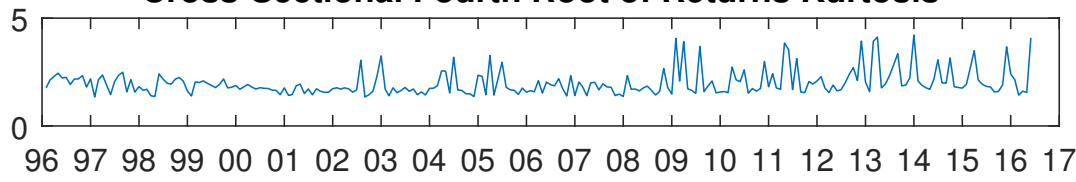

FIGURE B.4: Cross-Sectional Equity Holdings Sample Moments for Germany 


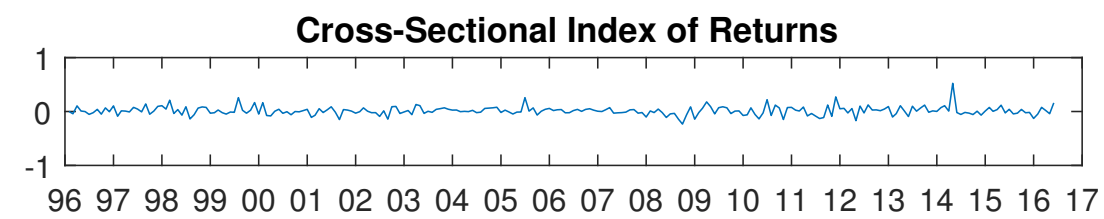

Cross-Sectional Standard Deviation of Returns

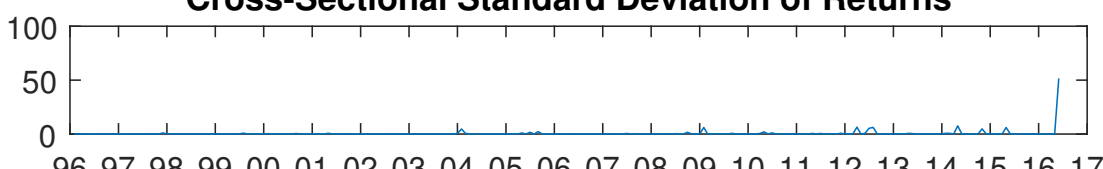

Cross-Sectional Cube Root Returns Skewness

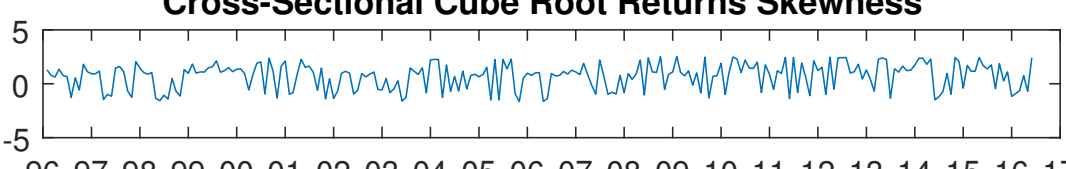

96979899000102030405060708091011121314151617

Cross-Sectional Fourth Root of Returns Kurtosis

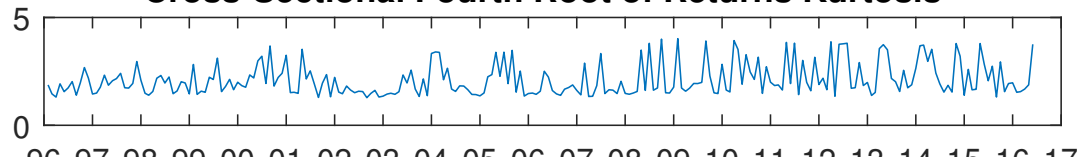

96979899000102030405060708091011121314151617

FIGURE B.5: Cross-Sectional Equity Holdings Sample Moments for Italy

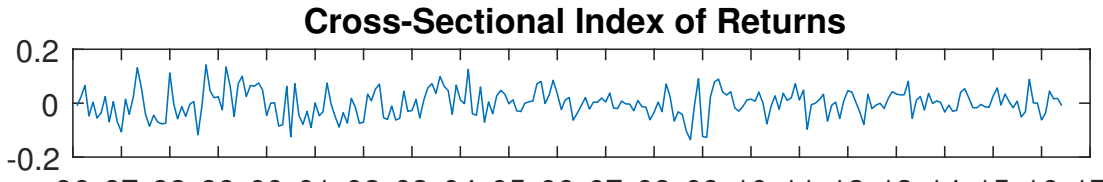

$9697989900010203040506070809101112131415 \quad 16 \quad 17$

Cross-Sectional Standard Deviation of Returns

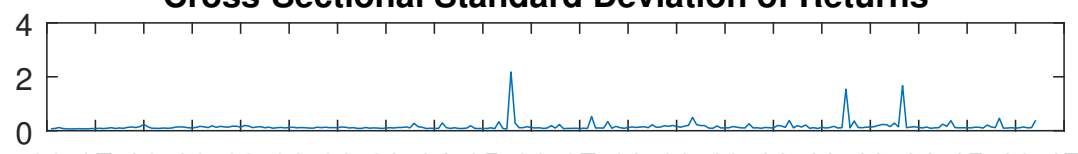

96979899000102030405060708091011121314151617

Cross-Sectional Cube Root Returns Skewness

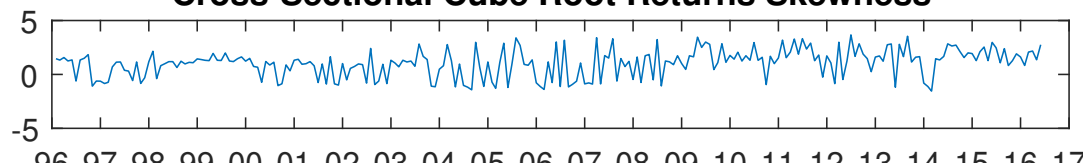

96979899000102030405060708091011121314151617

Cross-Sectional Fourth Root of Returns Kurtosis

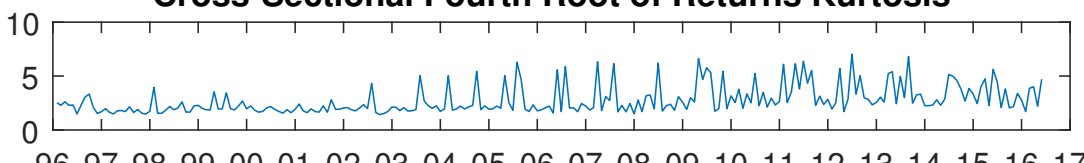

96979899000102030405060708091011121314151617

FIGURE B.6: Cross-Sectional Equity Holdings Sample Moments for Japan 


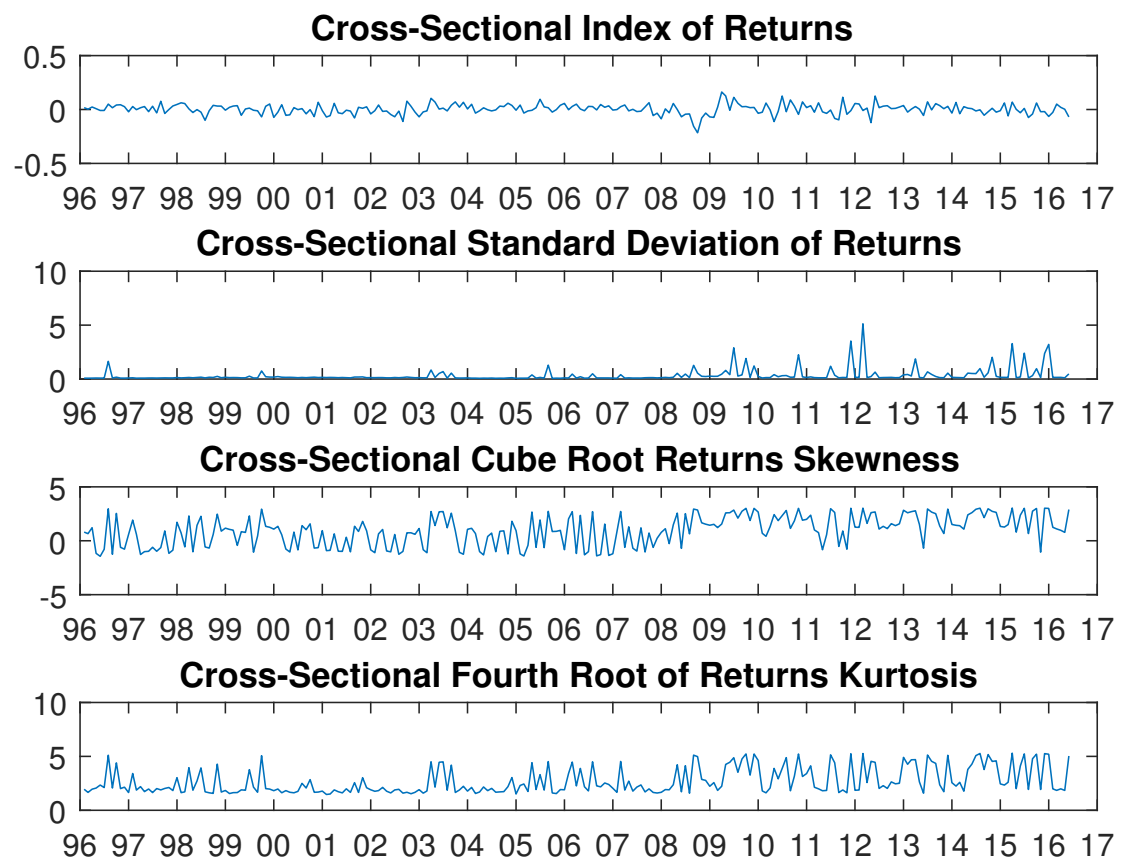

FIGURE B.7: Cross-Sectional Equity Holdings Sample Moments for the United Kingdom

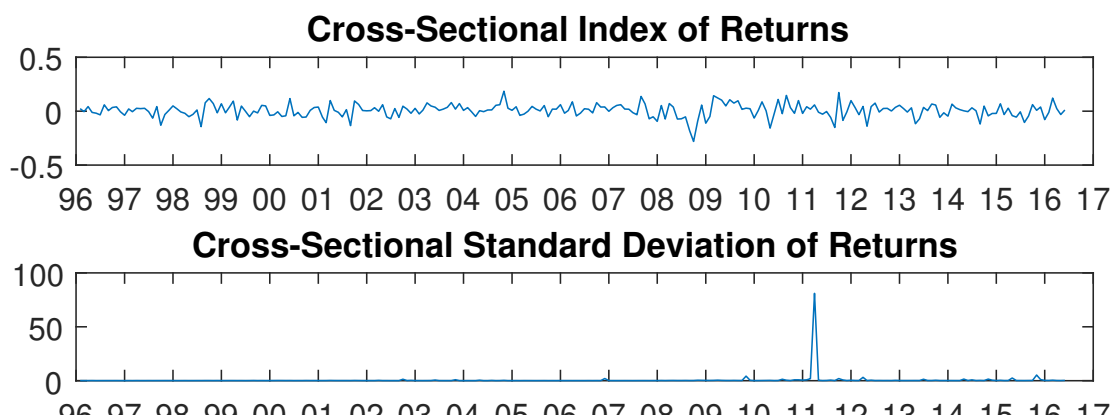

Cross-Sectional Cube Root Returns Skewness

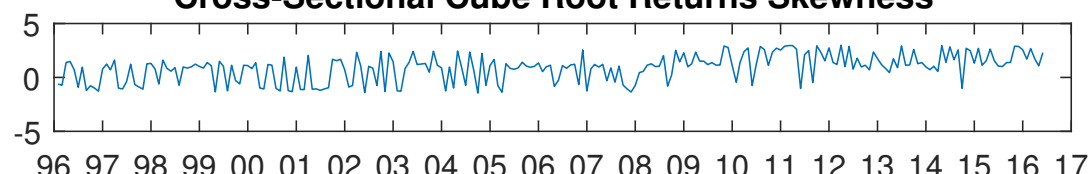

Cross-Sectional Fourth Root of Returns Kurtosis

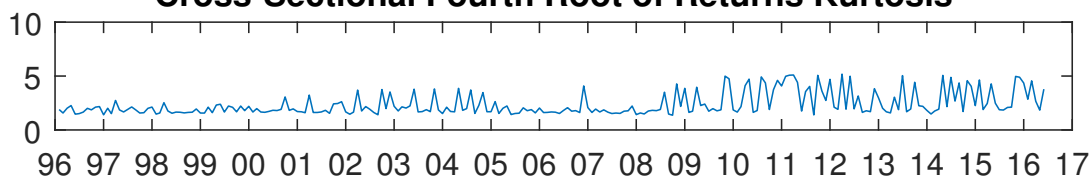

FIGURE B.8: Cross-Sectional Equity Holdings Sample Moments for the Australia/New Zealand 


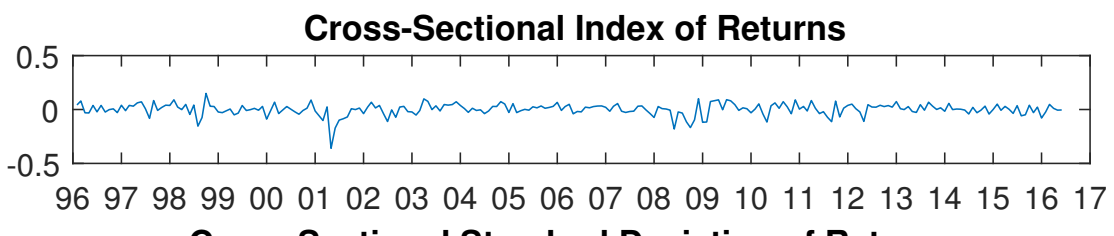

Cross-Sectional Standard Deviation of Returns

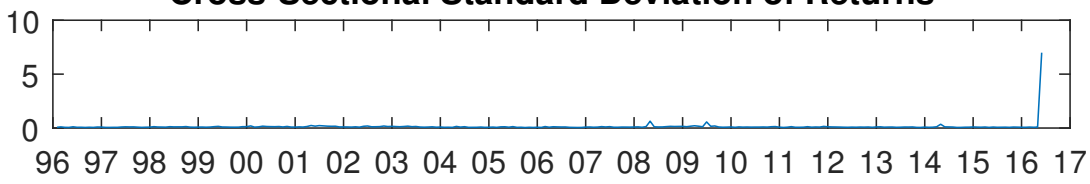

Cross-Sectional Cube Root Returns Skewness

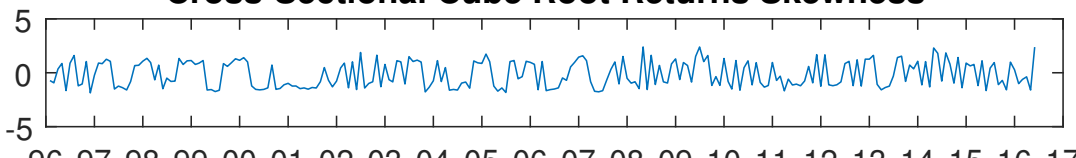

96979899000102030405060708091011121314151617

Cross-Sectional Fourth Root of Returns Kurtosis

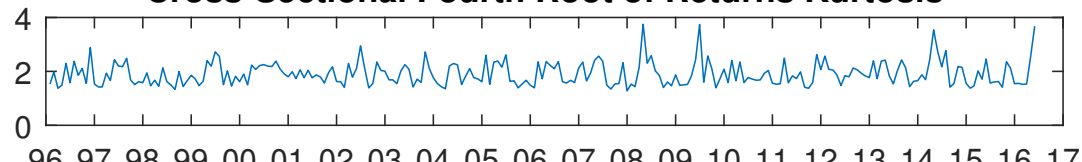

FIGURE B.9: Cross-Sectional Equity Holdings Sample Moments for the Switzerland/Austria

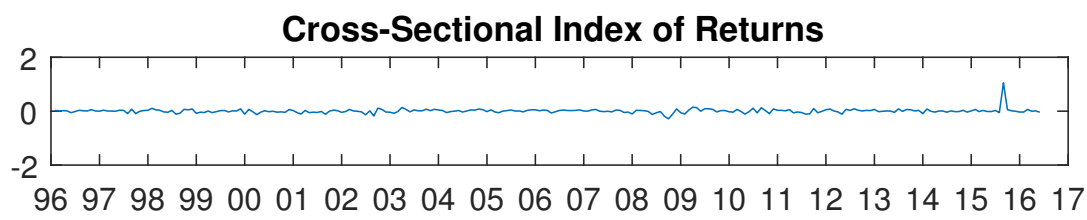

Cross-Sectional Standard Deviation of Returns

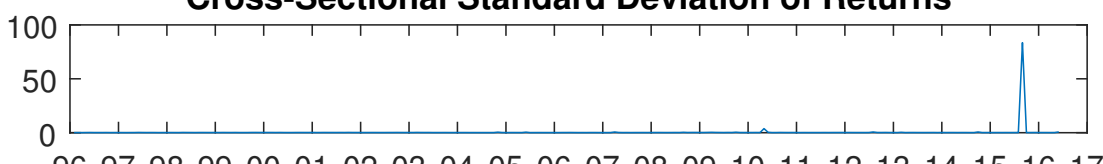

96979899000102030405060708091011121314151617

Cross-Sectional Cube Root Returns Skewness

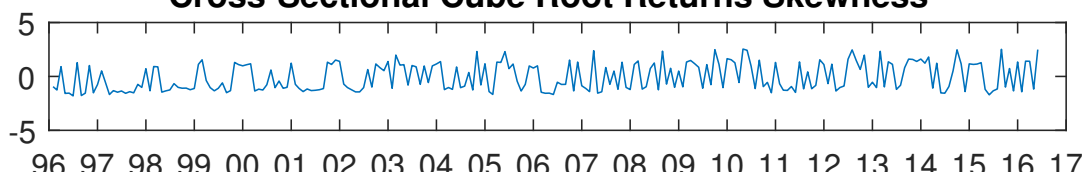

Cross-Sectional Fourth Root of Returns Kurtosis

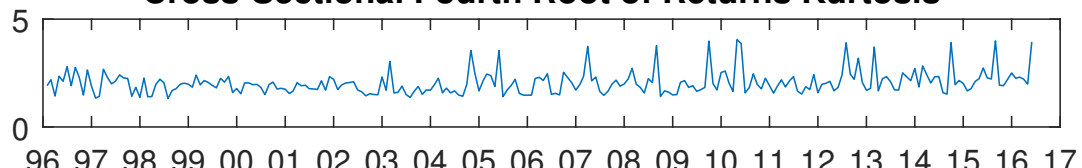

Figure B.10: Cross-Sectional Equity Holdings Sample Moments for the Developed EU 


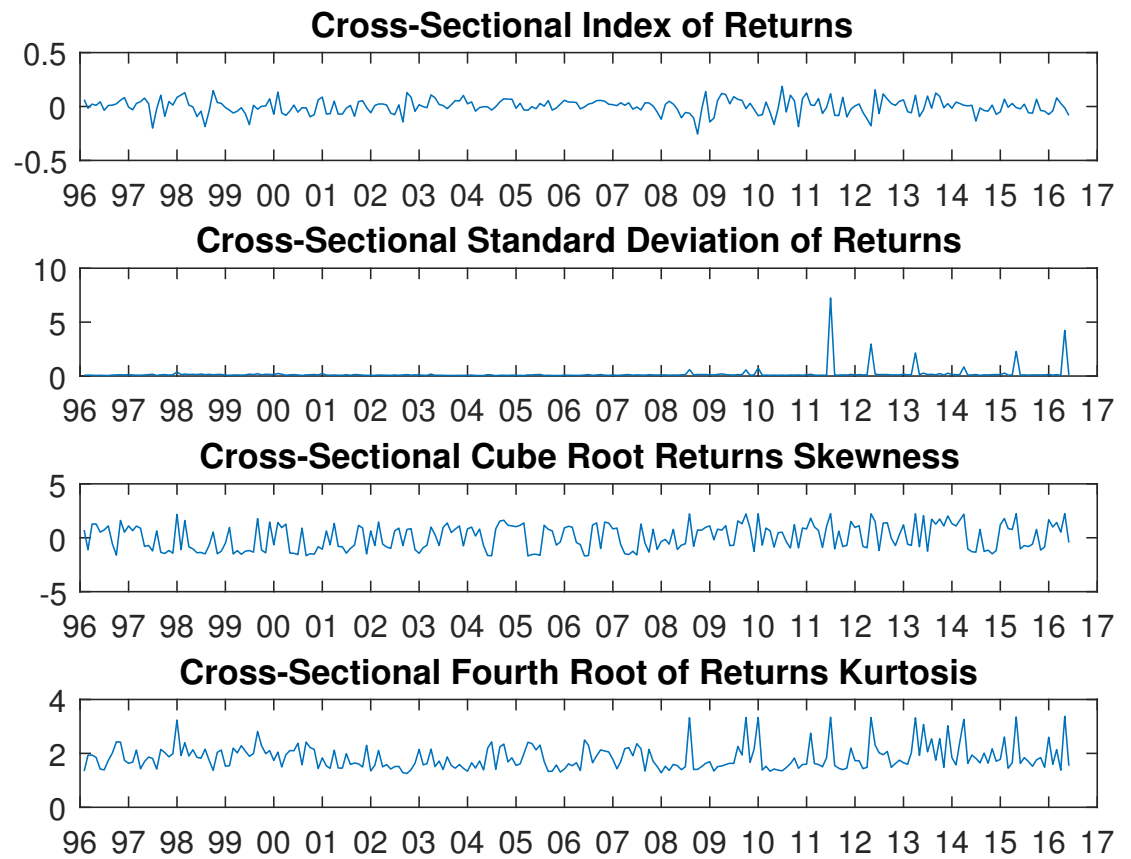

Figure B.11: Cross-Sectional Equity Holdings Sample Moments for Spain/Portugal

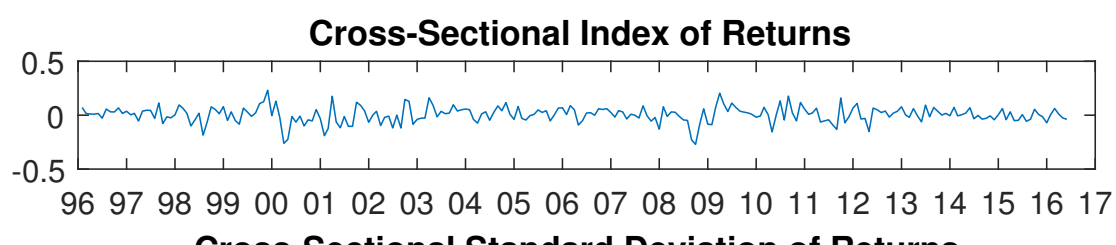

Cross-Sectional Standard Deviation of Returns

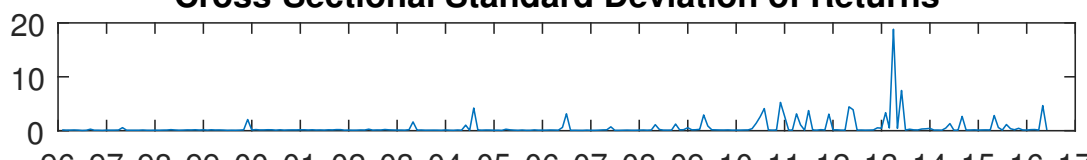

96979899000102030405060708091011121314151617

Cross-Sectional Cube Root Returns Skewness

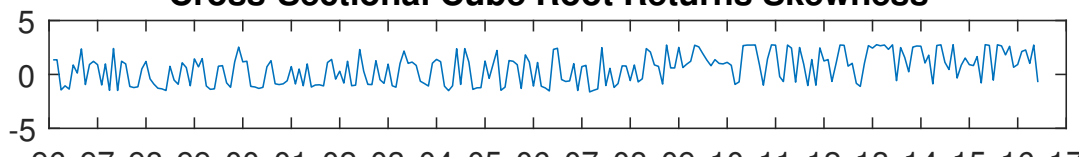

96979899000102030405060708091011121314151617

Cross-Sectional Fourth Root of Returns Kurtosis

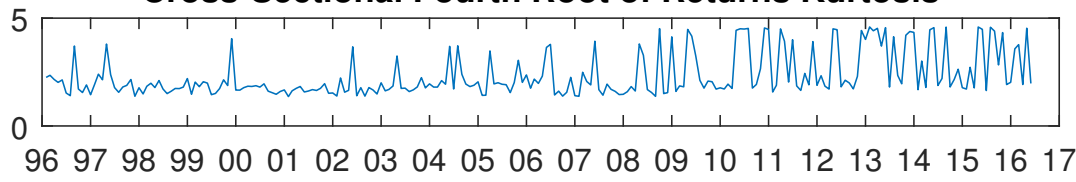

FIGURE B.12: Cross-Sectional Equity Holdings Sample Moments for Scandinavia 

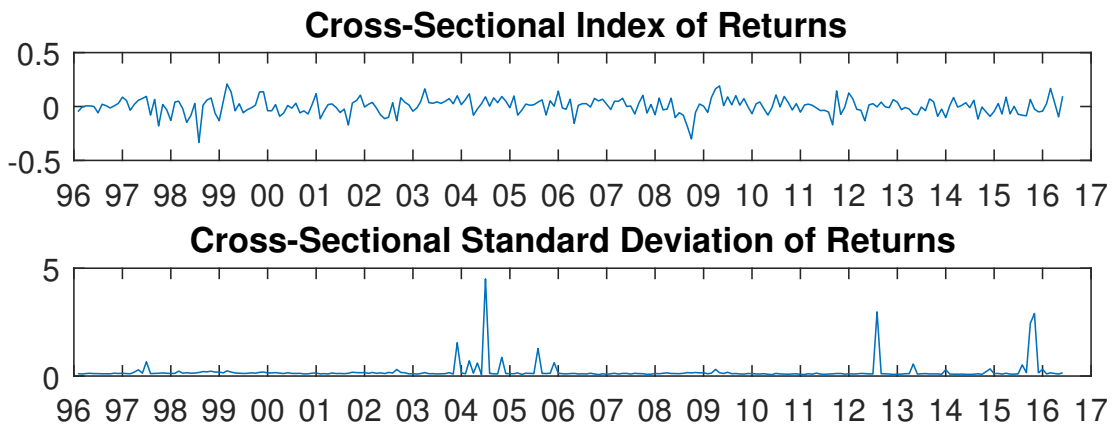

Cross-Sectional Cube Root Returns Skewness

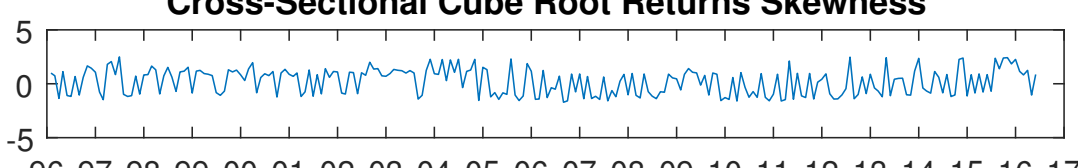

96979899000102030405060708091011121314151617

Cross-Sectional Fourth Root of Returns Kurtosis

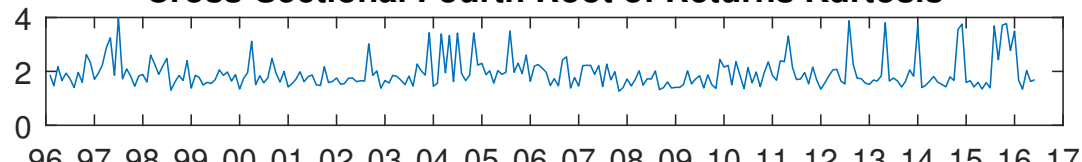

FIGURE B.13: Cross-Sectional Equity Holdings Sample Moments for Latin America

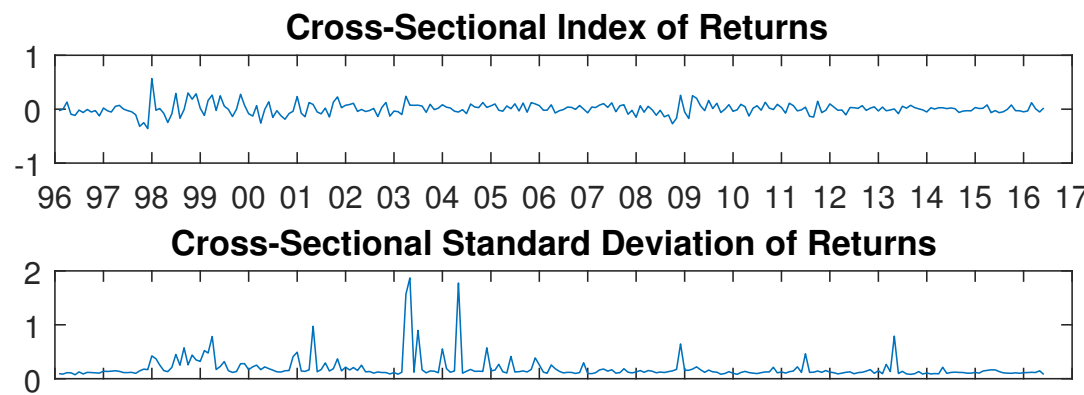

96979899000102030405060708091011121314151617

Cross-Sectional Cube Root Returns Skewness

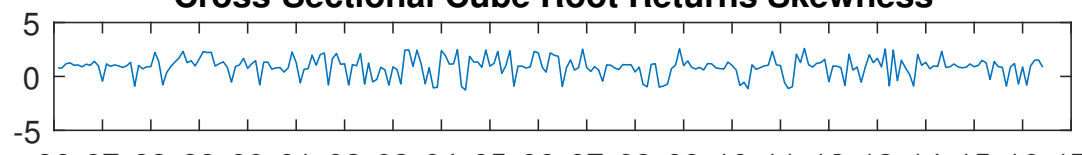

96979899000102030405060708091011121314151617

Cross-Sectional Fourth Root of Returns Kurtosis

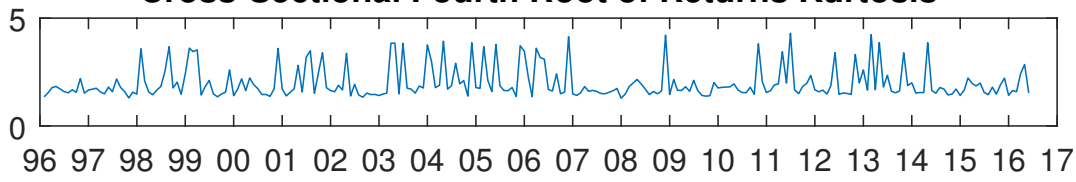

FIgURE B.14: Cross-Sectional Equity Holdings Sample Moments for Korea 


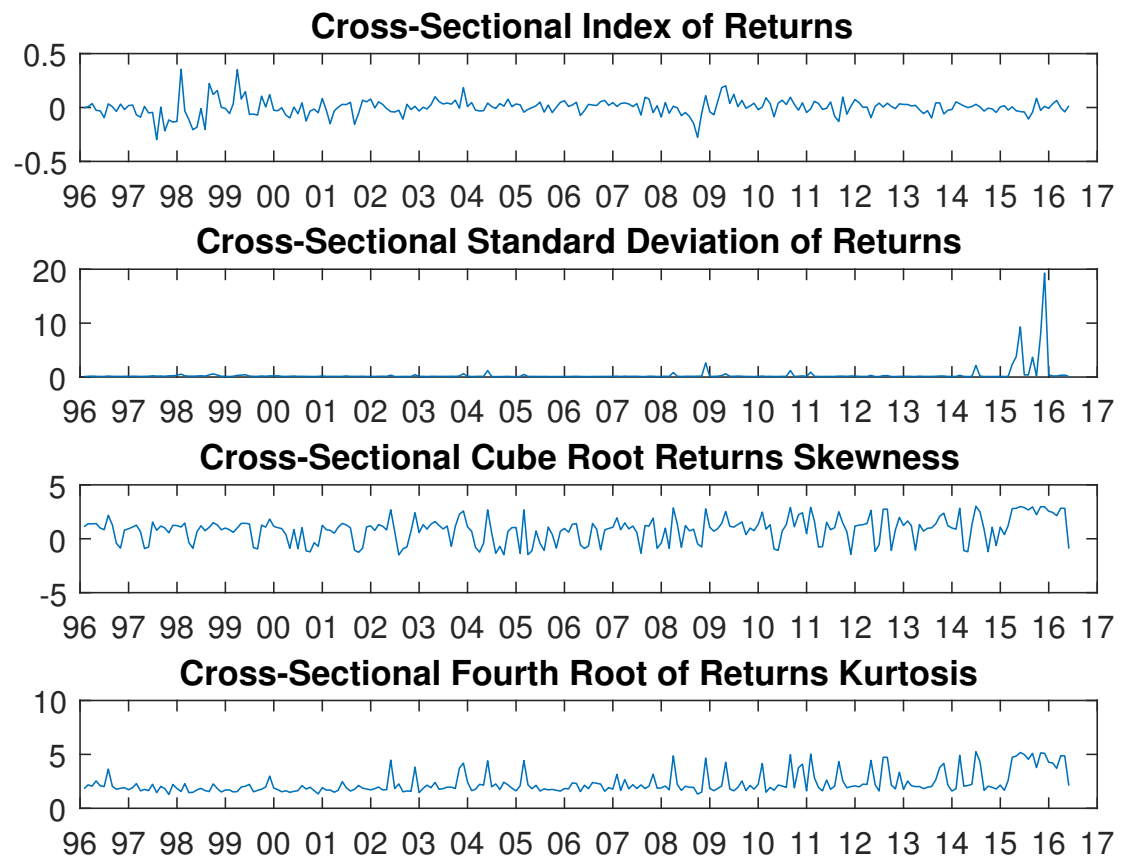

FIGURE B.15: Cross-Sectional Equity Holdings Sample Moments for emerging Asia

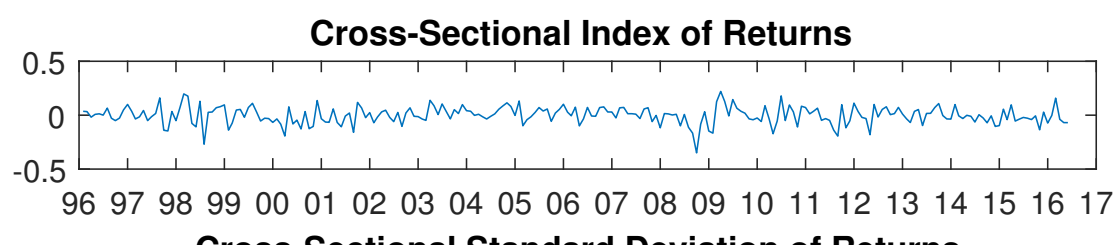

Cross-Sectional Standard Deviation of Returns

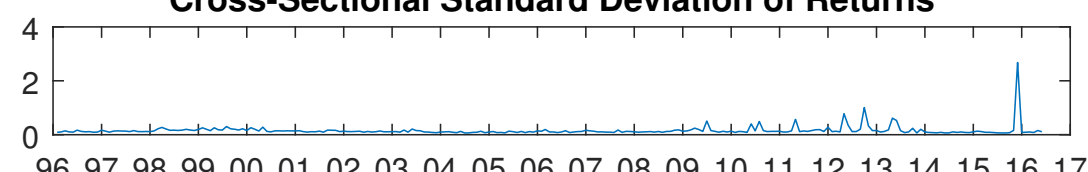

Cross-Sectional Cube Root Returns Skewness

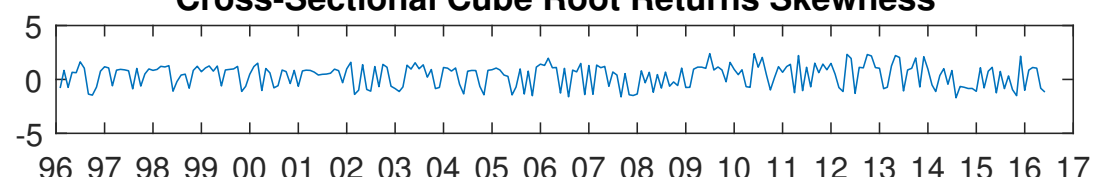

Cross-Sectional Fourth Root of Returns Kurtosis

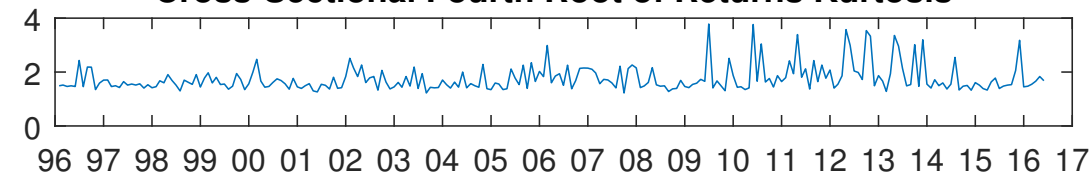

FIgURE B.16: Cross-Sectional Equity Holdings Sample Moments for emerging EU 


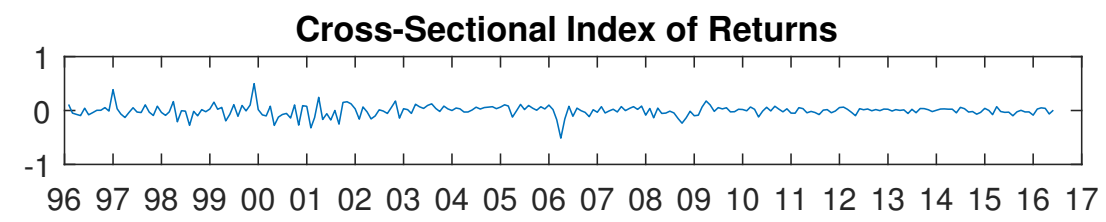

Cross-Sectional Standard Deviation of Returns

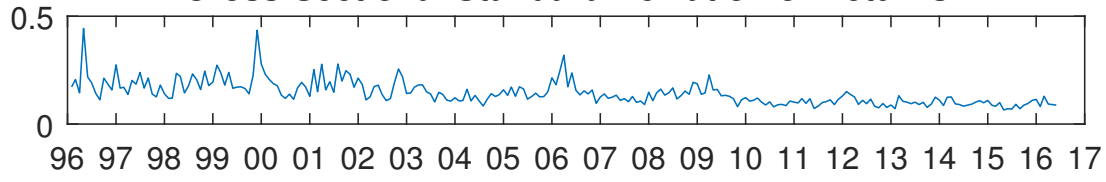

Cross-Sectional Cube Root Returns Skewness

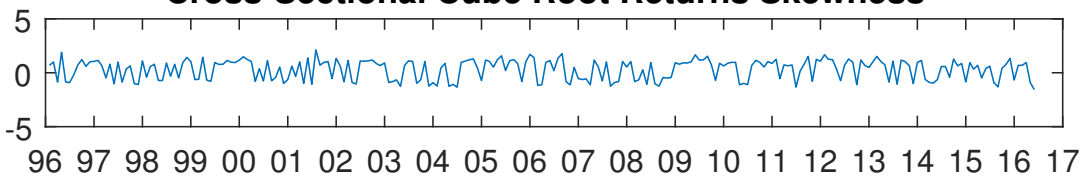

Cross-Sectional Fourth Root of Returns Kurtosis

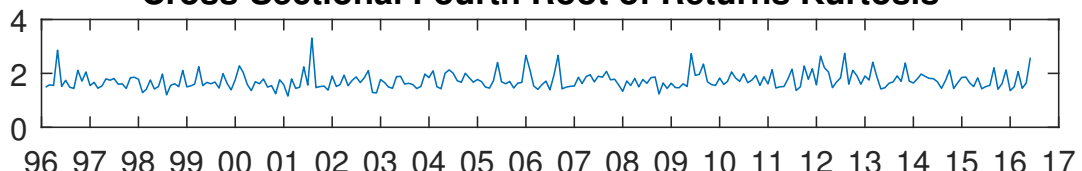

FIGURE B.17: Cross-Sectional Equity Holdings Sample Moments for Middle East/North Africa

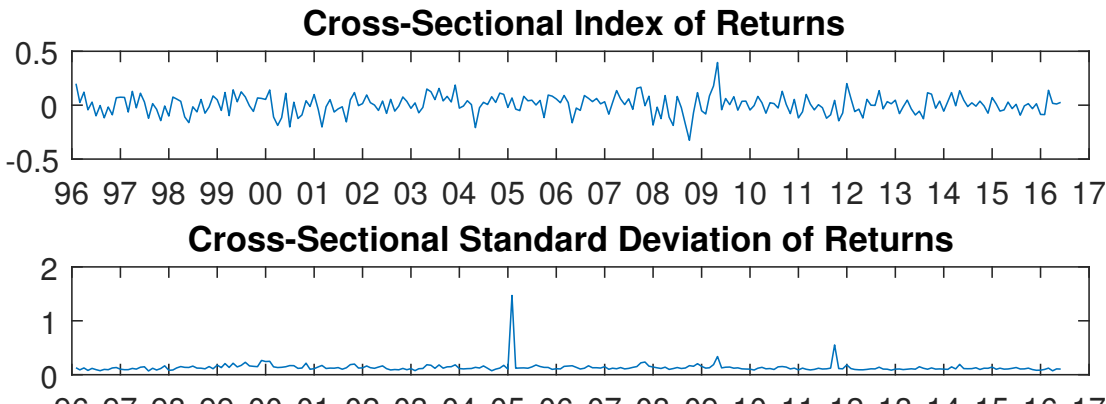

96979899000102030405060708091011121314151617

Cross-Sectional Cube Root Returns Skewness

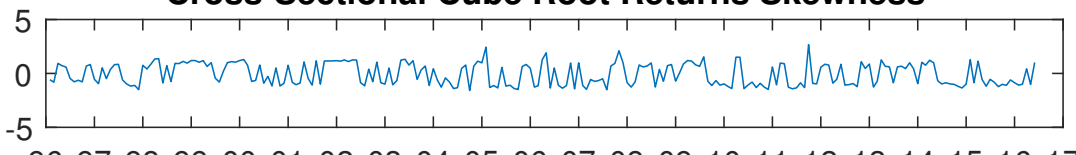

96979899000102030405060708091011121314151617

Cross-Sectional Fourth Root of Returns Kurtosis

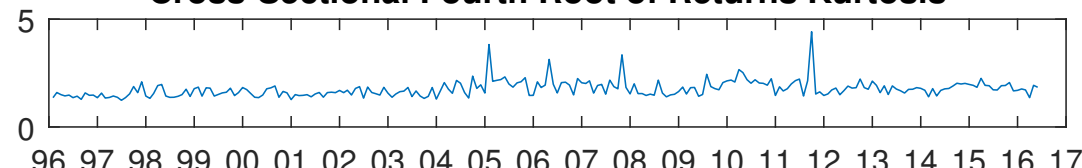

FIGURE B.18: Cross-Sectional Equity Holdings Sample Moments for India/Sri Lanka 


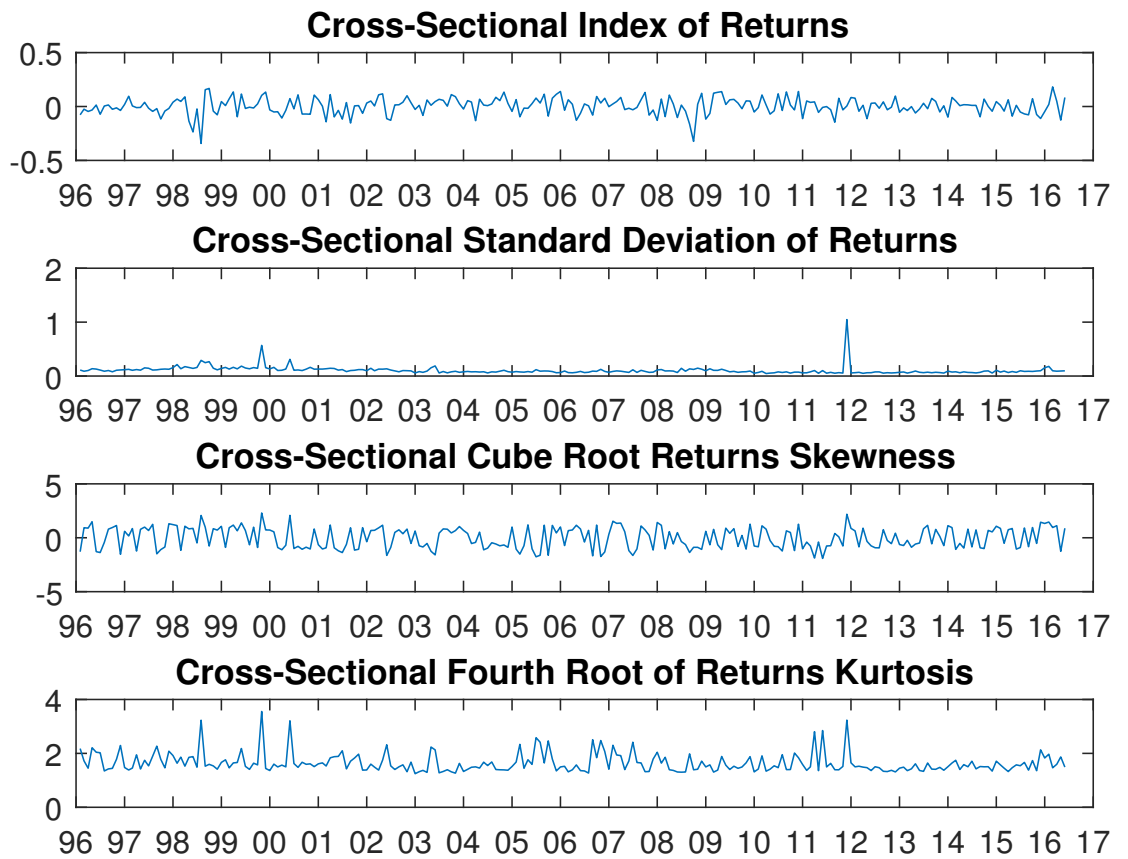

FIGURE B.19: Cross-Sectional Equity Holdings Sample Moments for South Africa

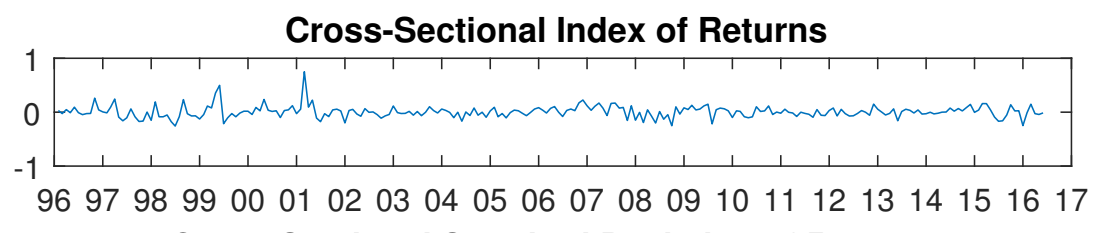

Cross-Sectional Standard Deviation of Returns

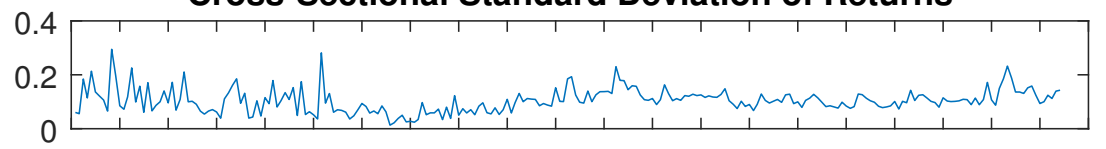

96979899000102030405060708091011121314151617

Cross-Sectional Cube Root Returns Skewness

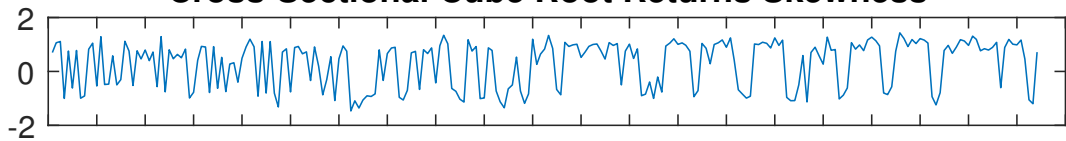

96979899000102030405060708091011121314151617

Cross-Sectional Fourth Root of Returns Kurtosis

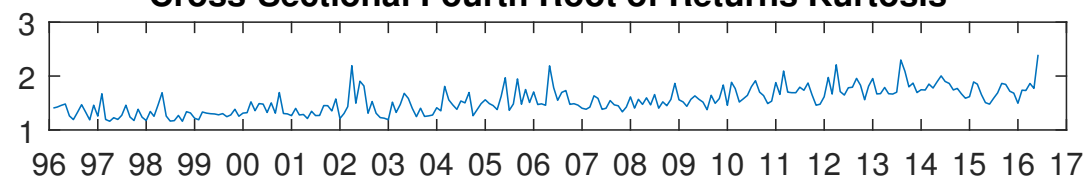

FIgURE B.20: Cross-Sectional Equity Holdings Sample Moments for China 

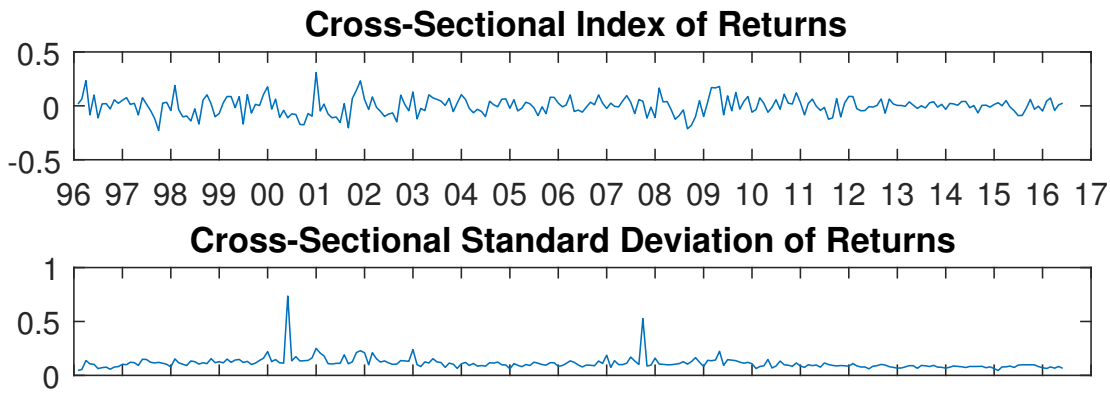

96979899000102030405060708091011121314151617

Cross-Sectional Cube Root Returns Skewness

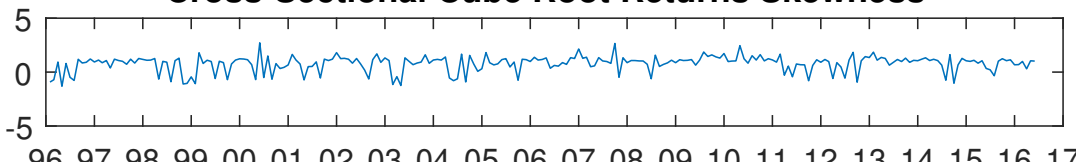

Cross-Sectional Fourth Root of Returns Kurtosis

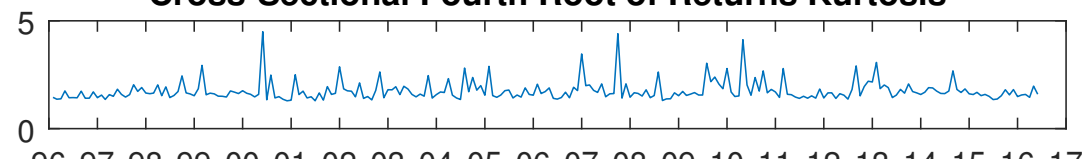

$9697989900010203040506 \quad 0708 \quad 09101112 \quad 1314 \quad 151617$

FIGURE B.21: Cross-Sectional Equity Holdings Sample Moments for Taiwan 
Appendix C

\section{GDP and Investment Growth vs. LGO}

This appendix includes two panels per region, showing GDP growth and investment growth against $L G O$. 

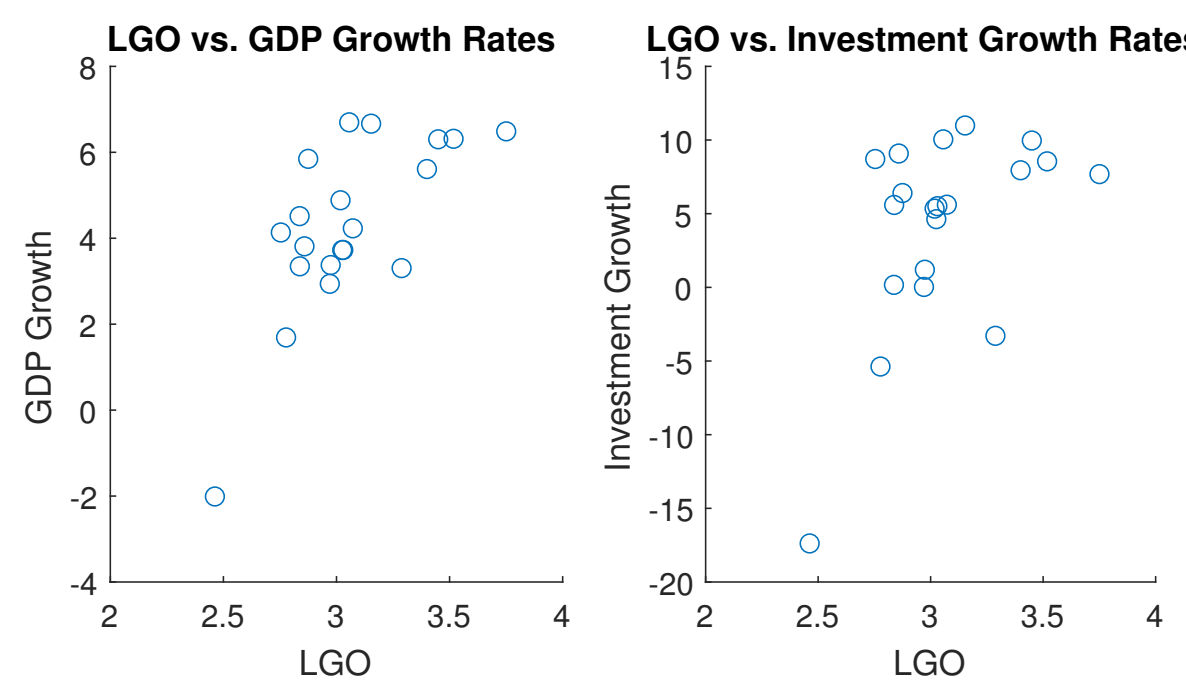

FIGURE C.1: GDP and Investment Growth versus LGO for the United States
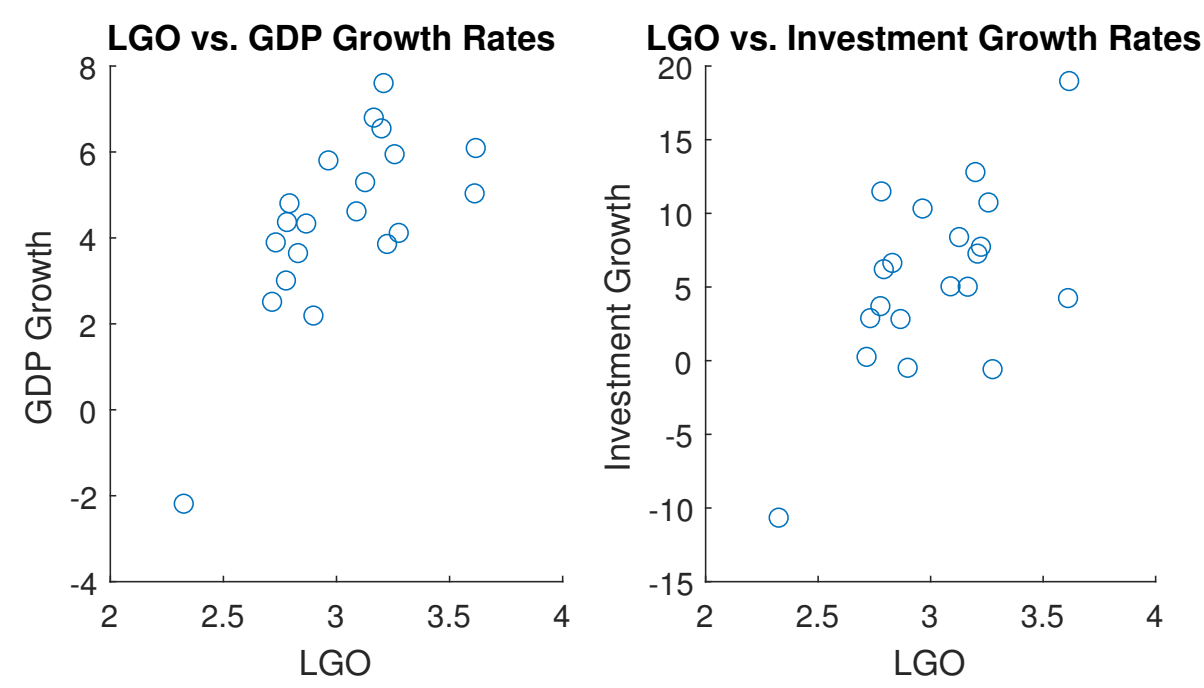

FIGURE C.2: GDP and Investment Growth versus LGO for Canada 

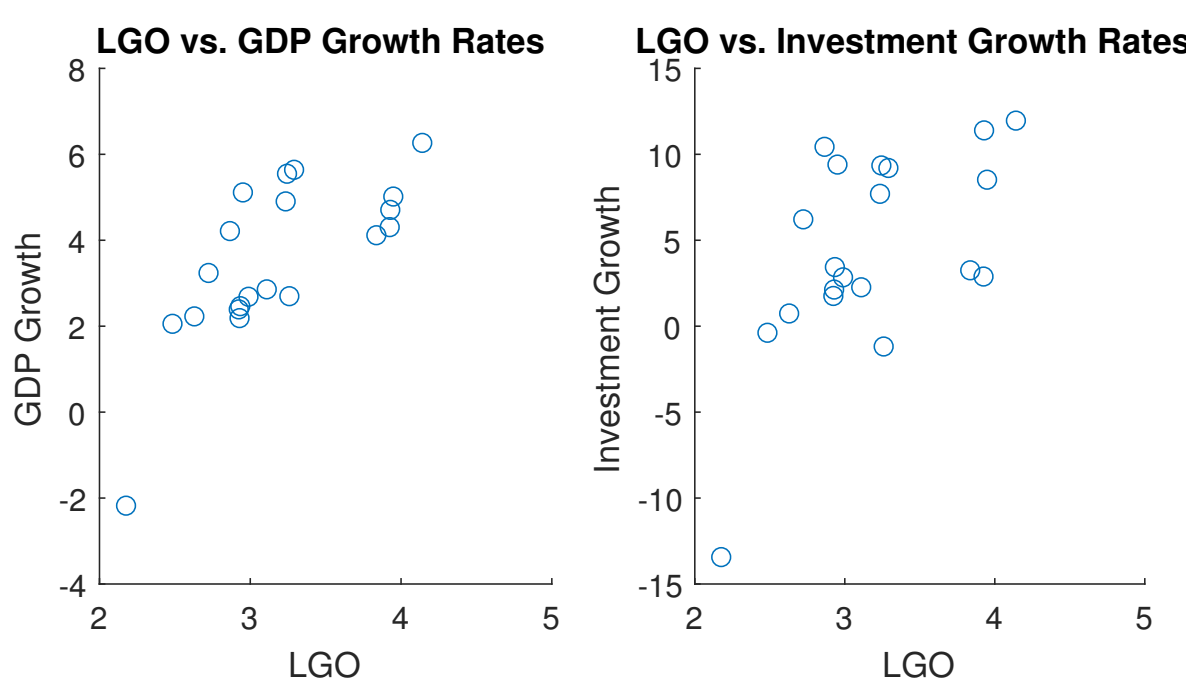

FIGURE C.3: GDP and Investment Growth versus LGO for France
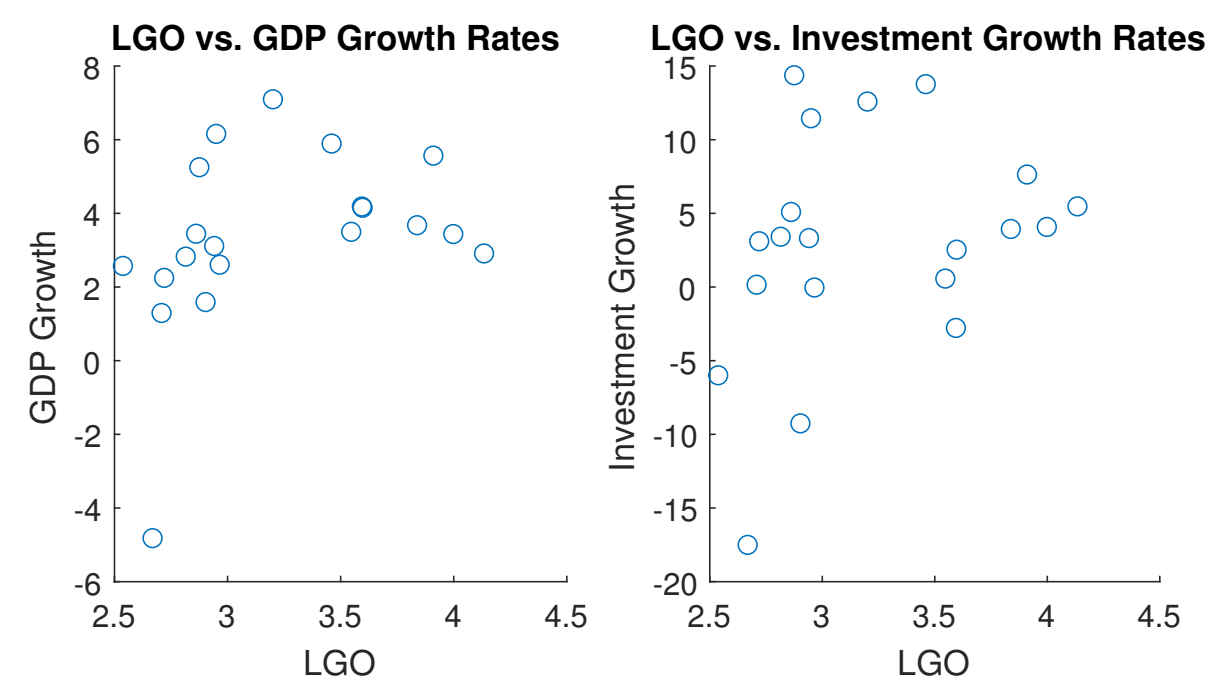

FIGURE C.4: GDP and Investment Growth versus LGO for Germany 

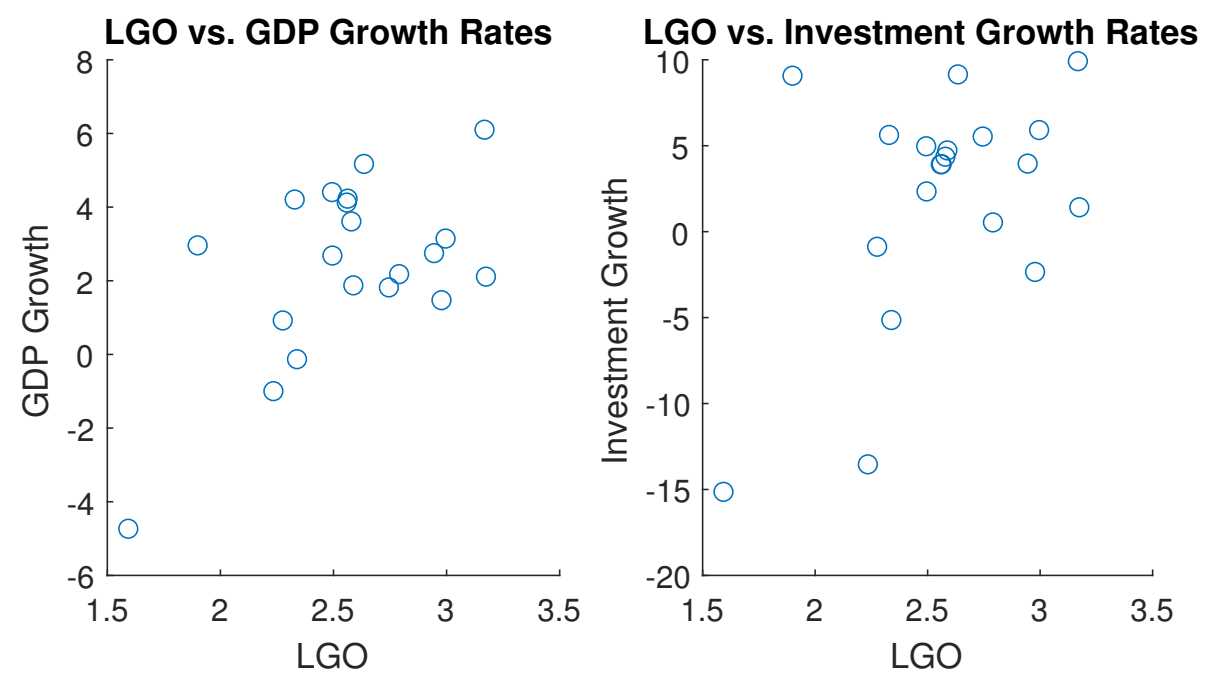

FIGURE C.5: GDP and Investment Growth versus LGO for Italy
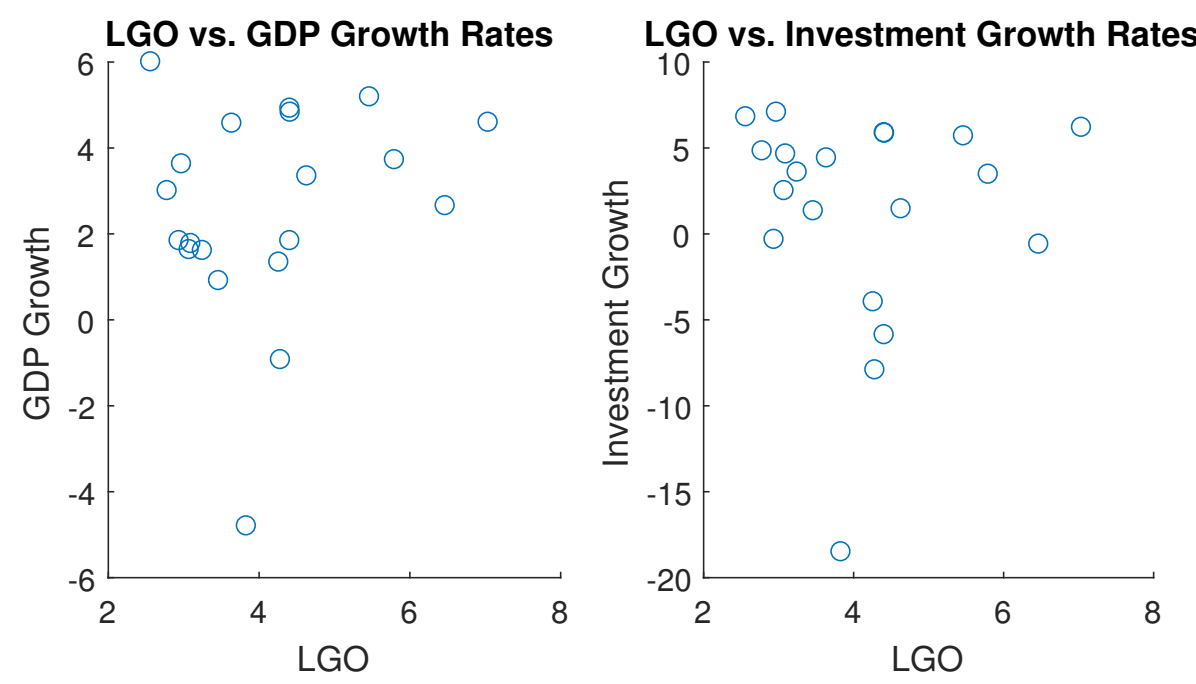

FIGURE C.6: GDP and Investment Growth versus LGO for Japan 

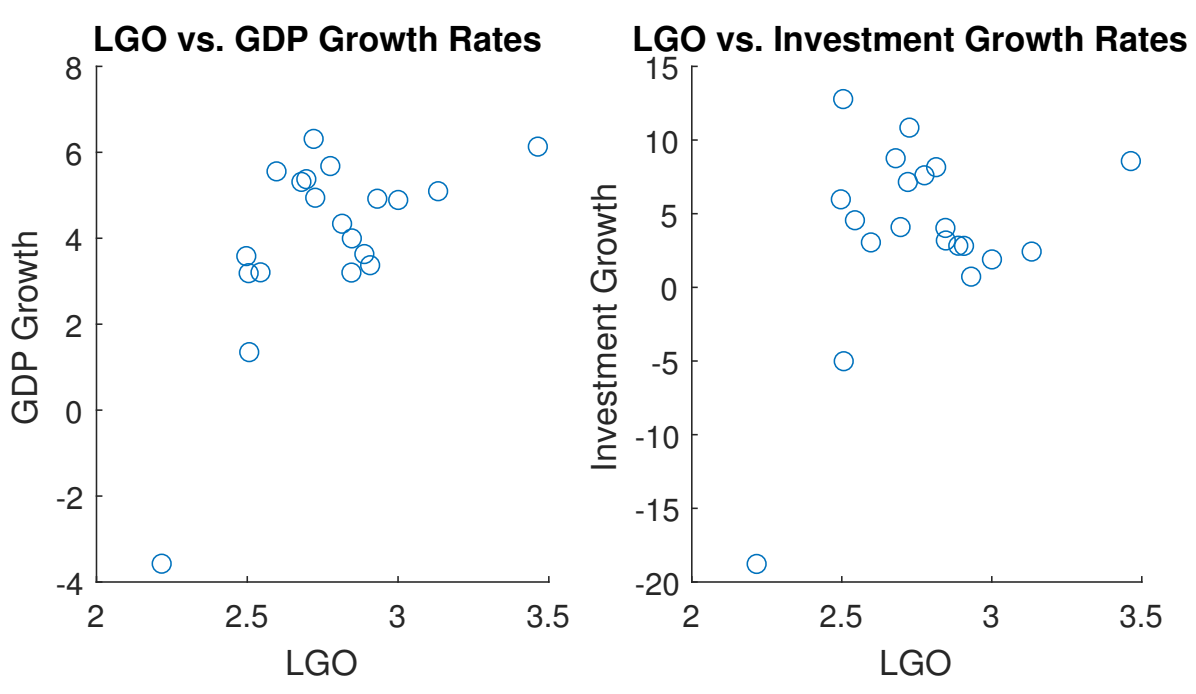

FIGURE C.7: GDP and Investment Growth versus LGO for the United Kingdom
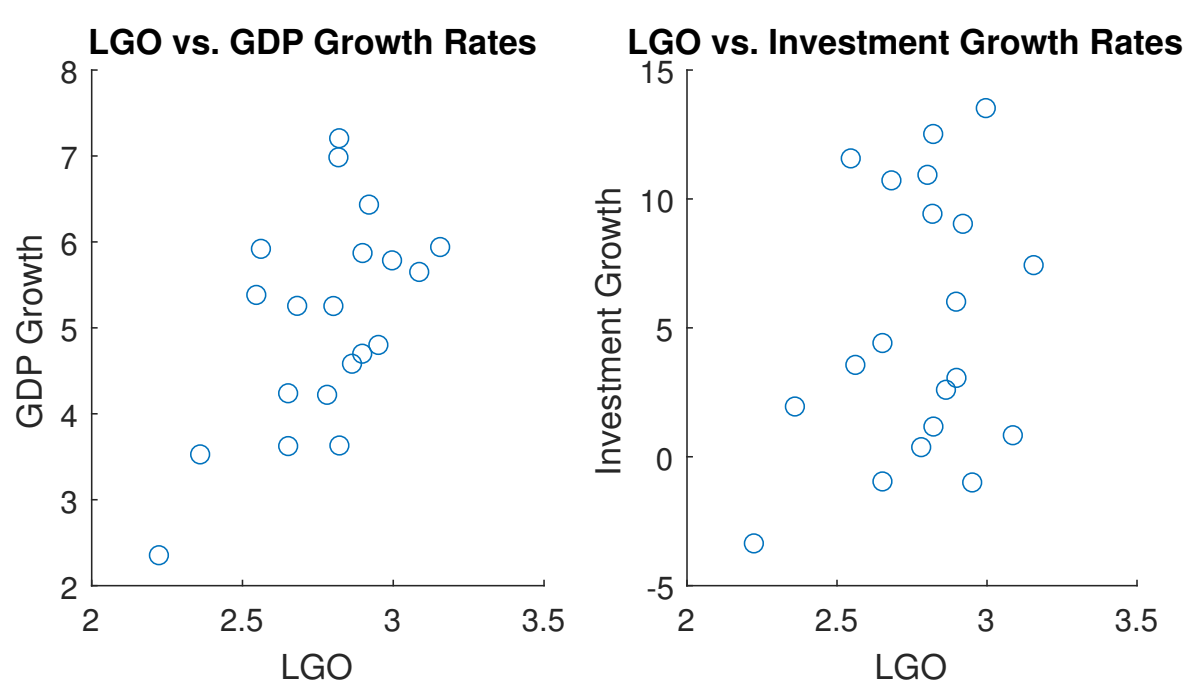

FIGURE C.8: GDP and Investment Growth versus LGO for the Australia/New Zealand 

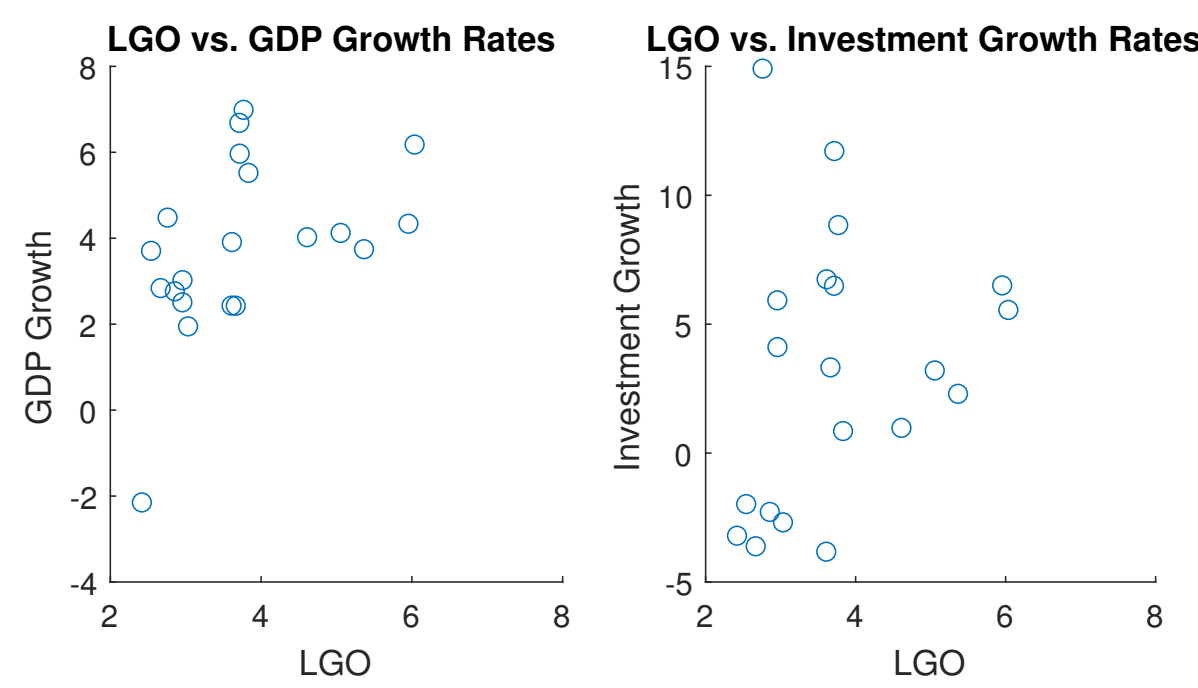

FIGURE C.9: GDP and Investment Growth versus LGO for the Switzerland/Austria
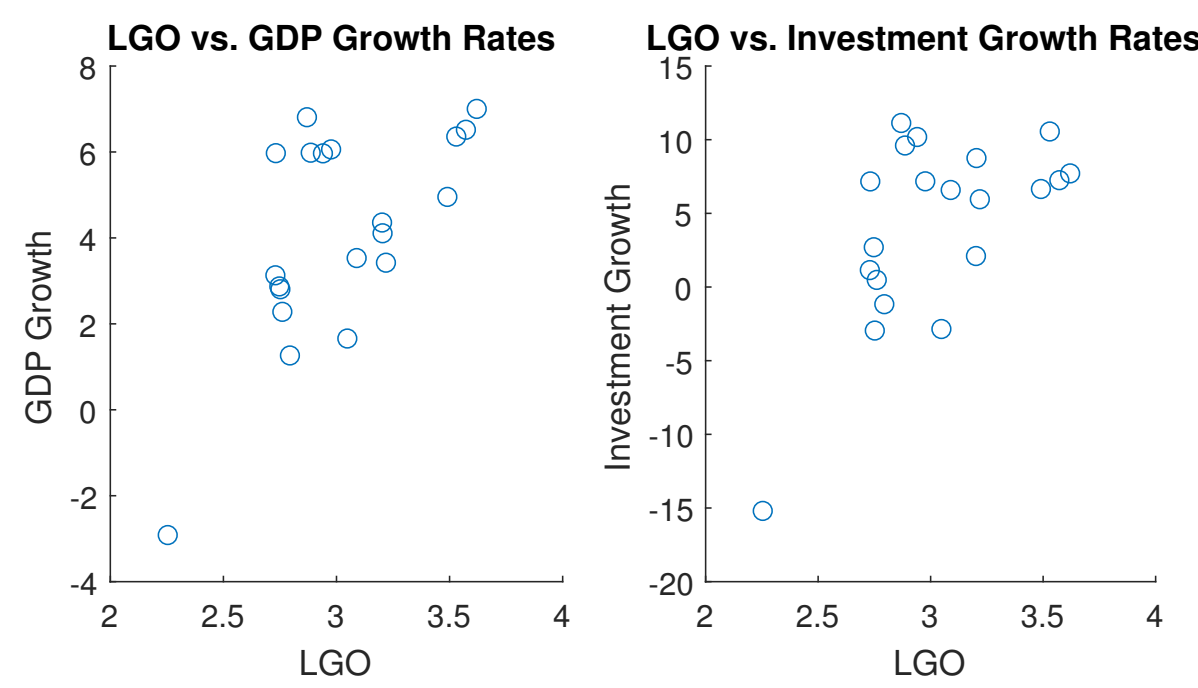

FIGURE C.10: GDP and Investment Growth versus LGO for the Developed EU 

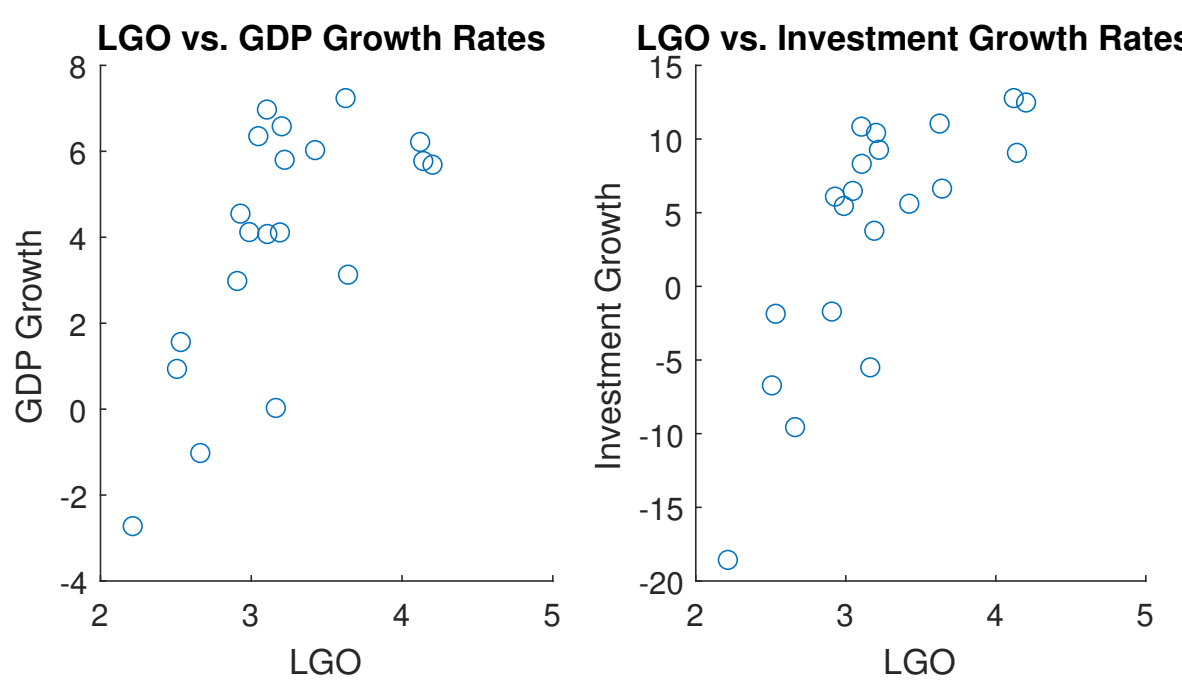

FIGURE C.11: GDP and Investment Growth versus LGO for Spain/Portugal
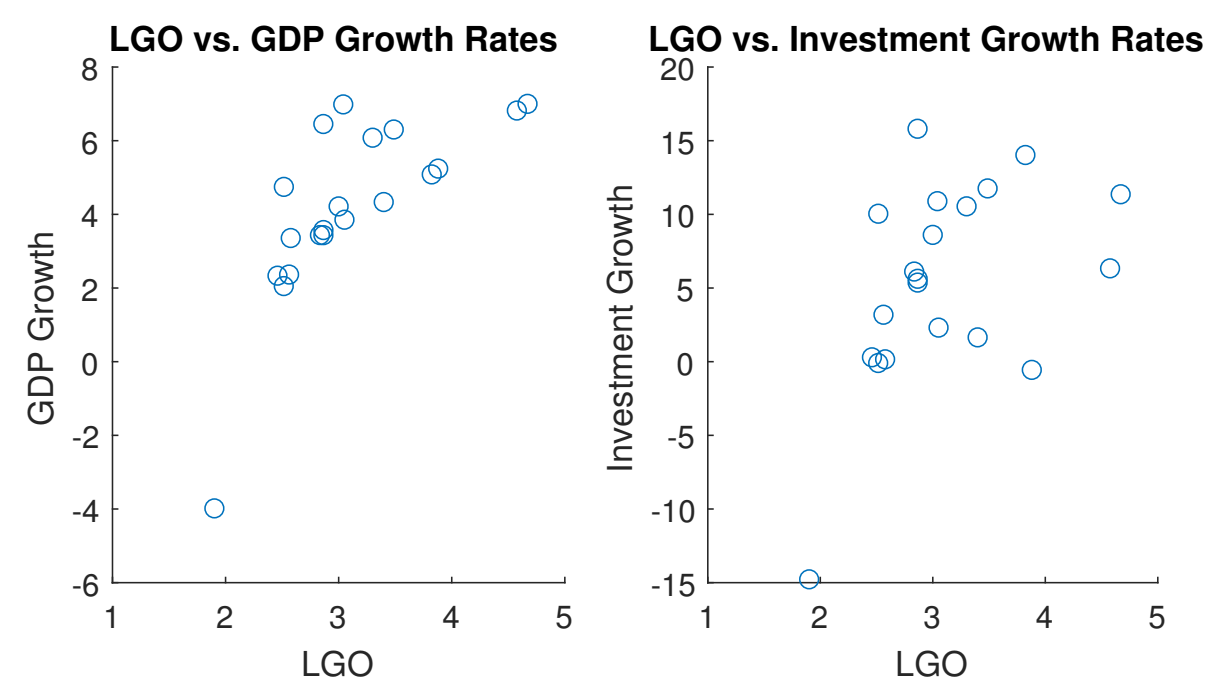

FIGURE C.12: GDP and Investment Growth versus LGO for Scandinavia 

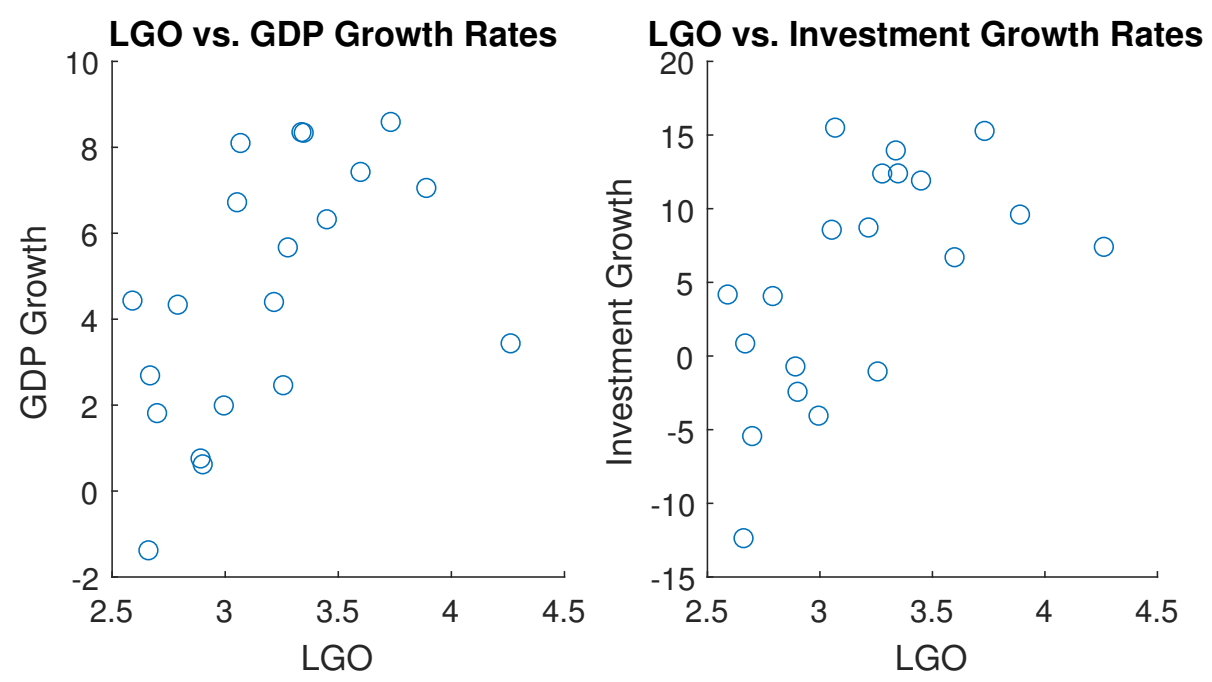

FIGURE C.13: GDP and Investment Growth versus LGO for Latin America
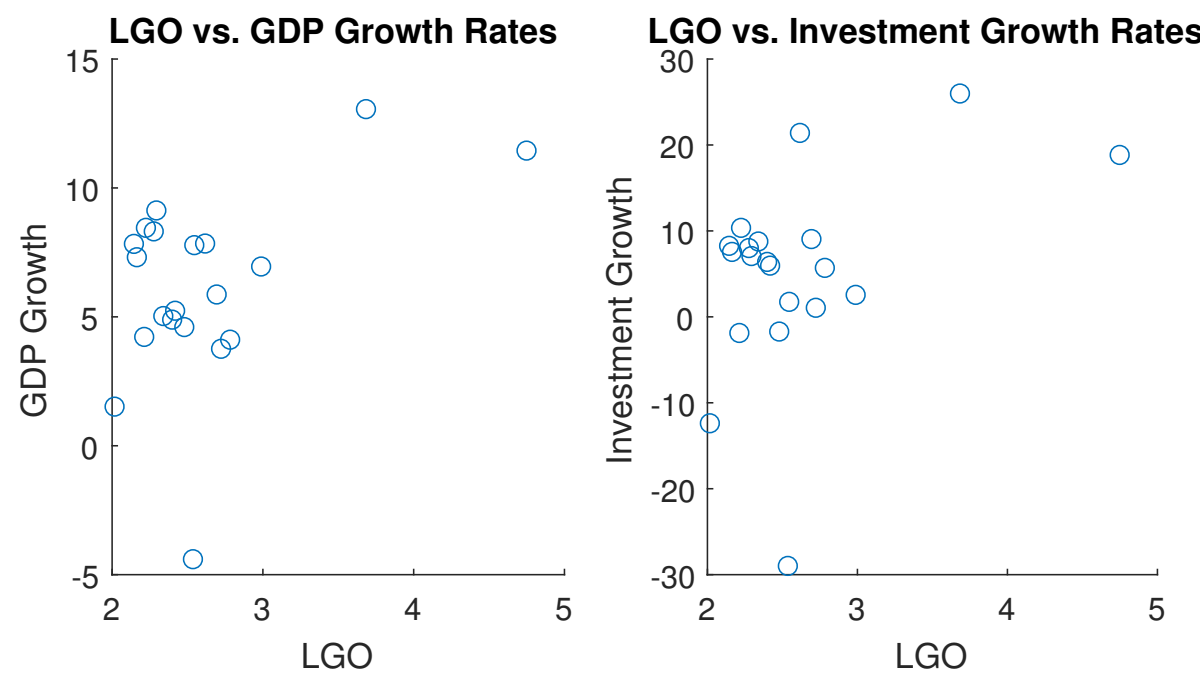

FIGURE C.14: GDP and Investment Growth versus LGO for Korea 

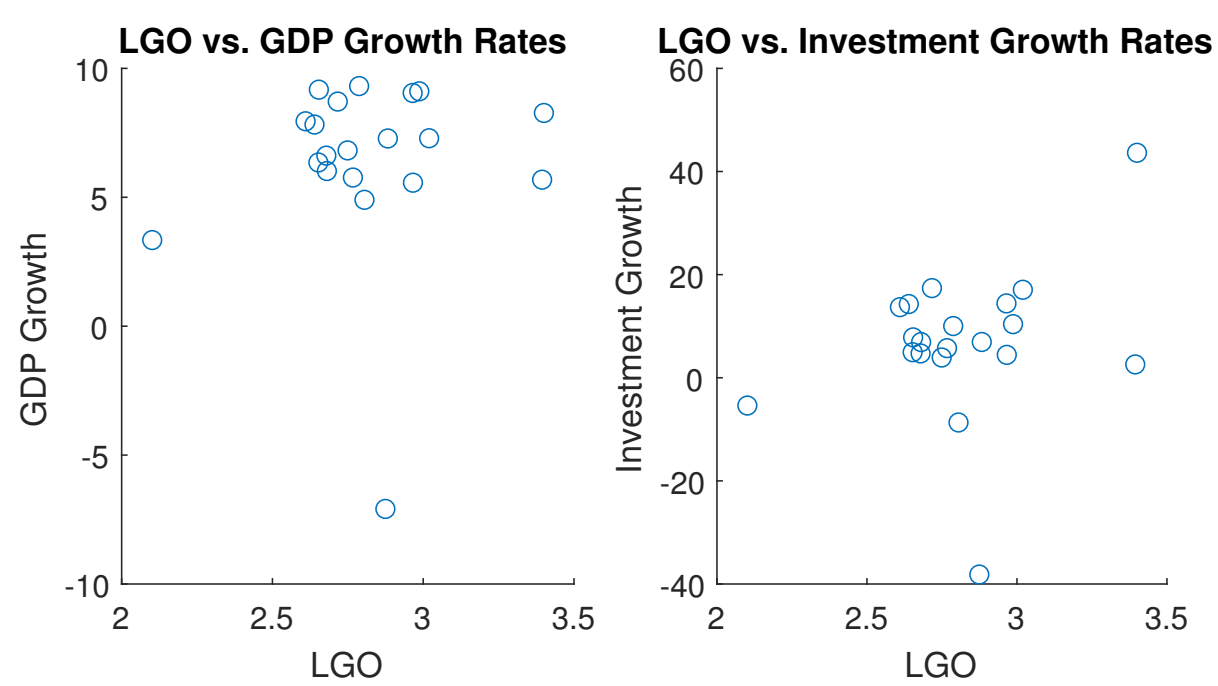

FIGURE C.15: GDP and Investment Growth versus LGO for emerging Asia
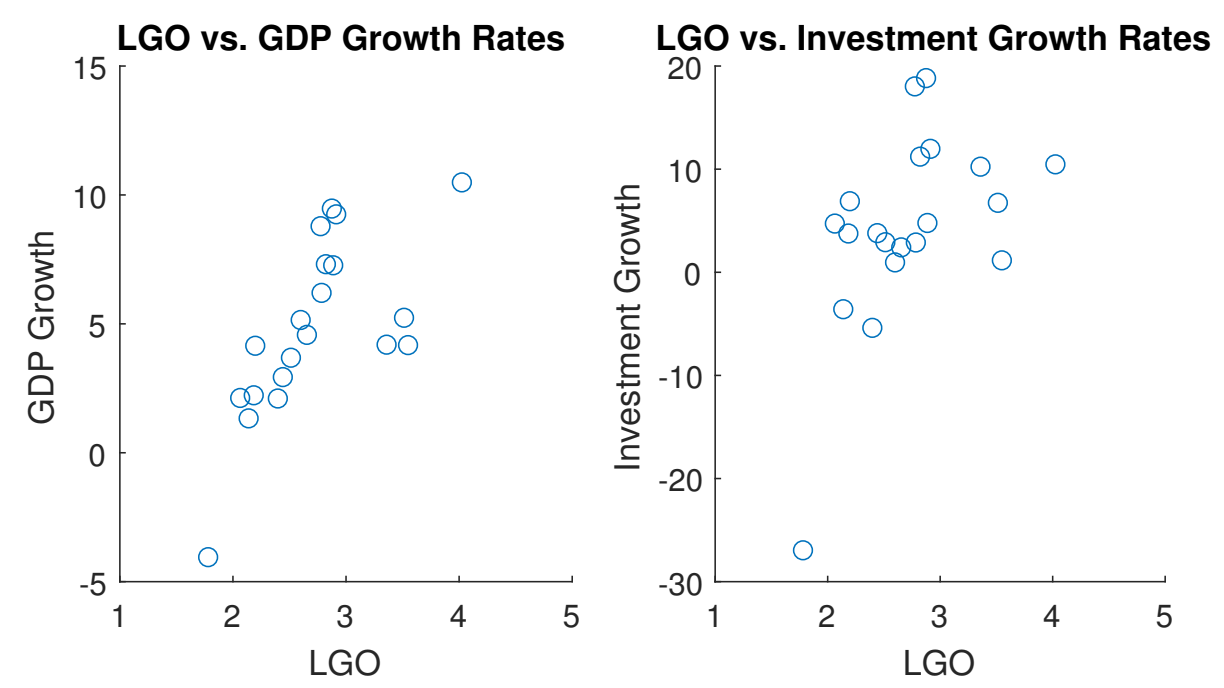

FIGURE C.16: GDP and Investment Growth versus LGO for emerging EU 

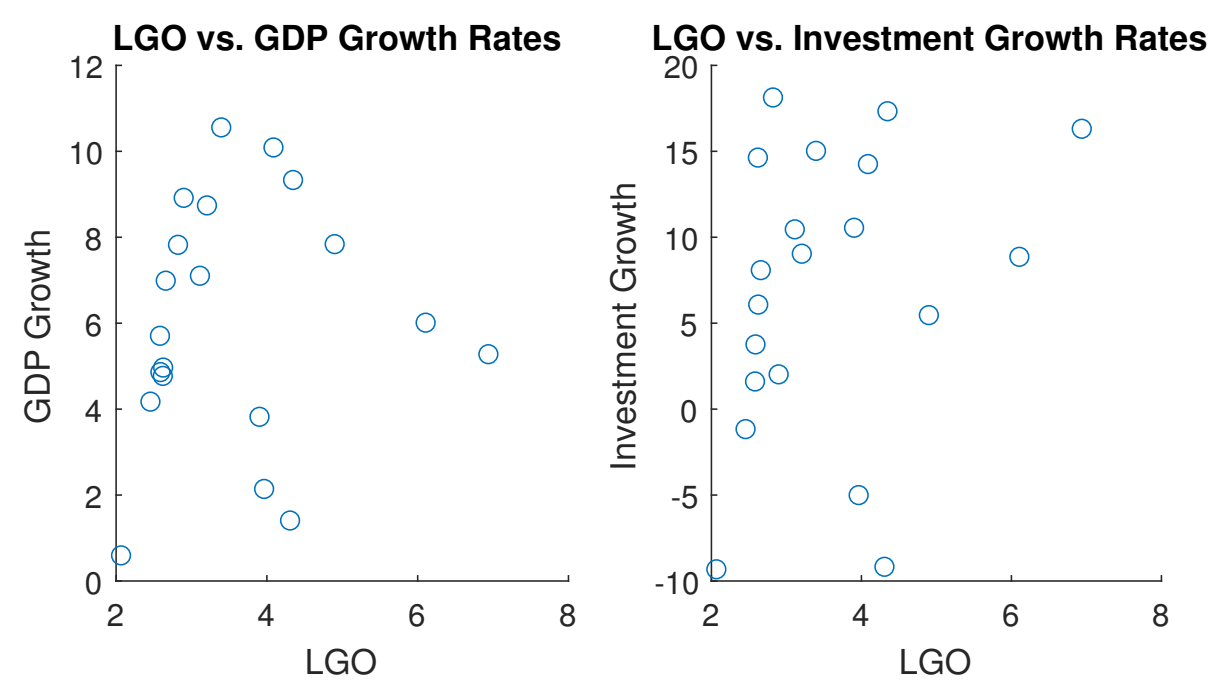

FIGURE C.17: GDP and Investment Growth versus LGO for Middle East/North Africa
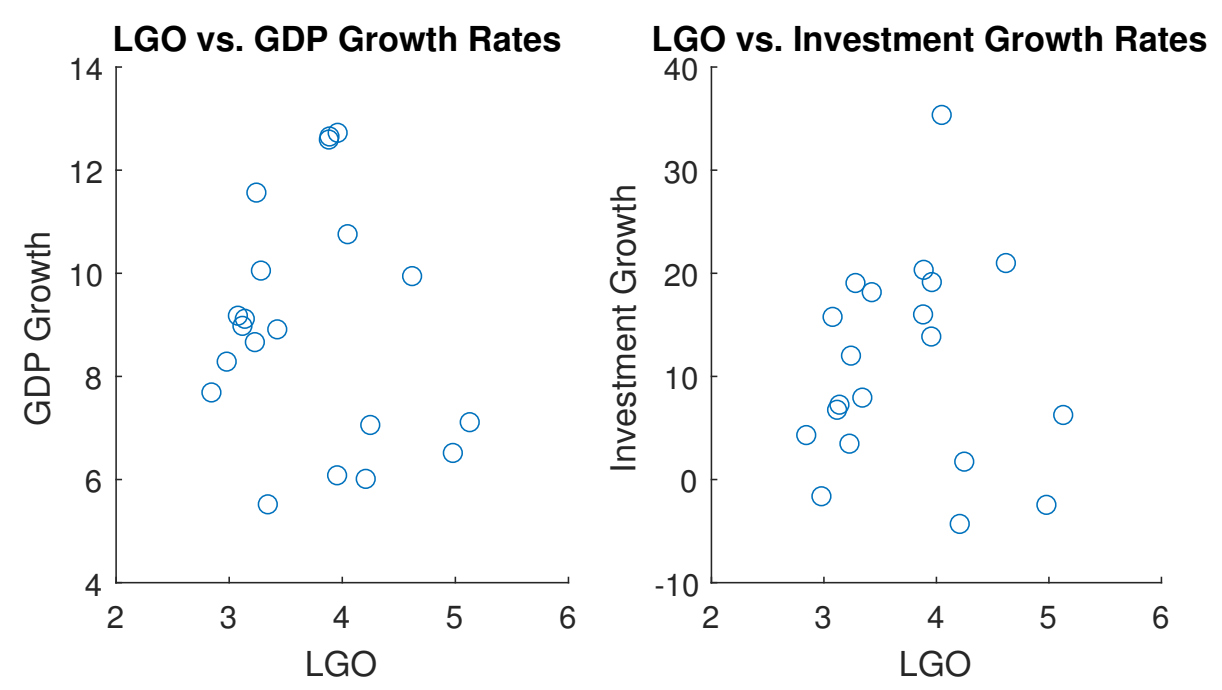

FIGURE C.18: GDP and Investment Growth versus LGO for India/Sri Lanka 

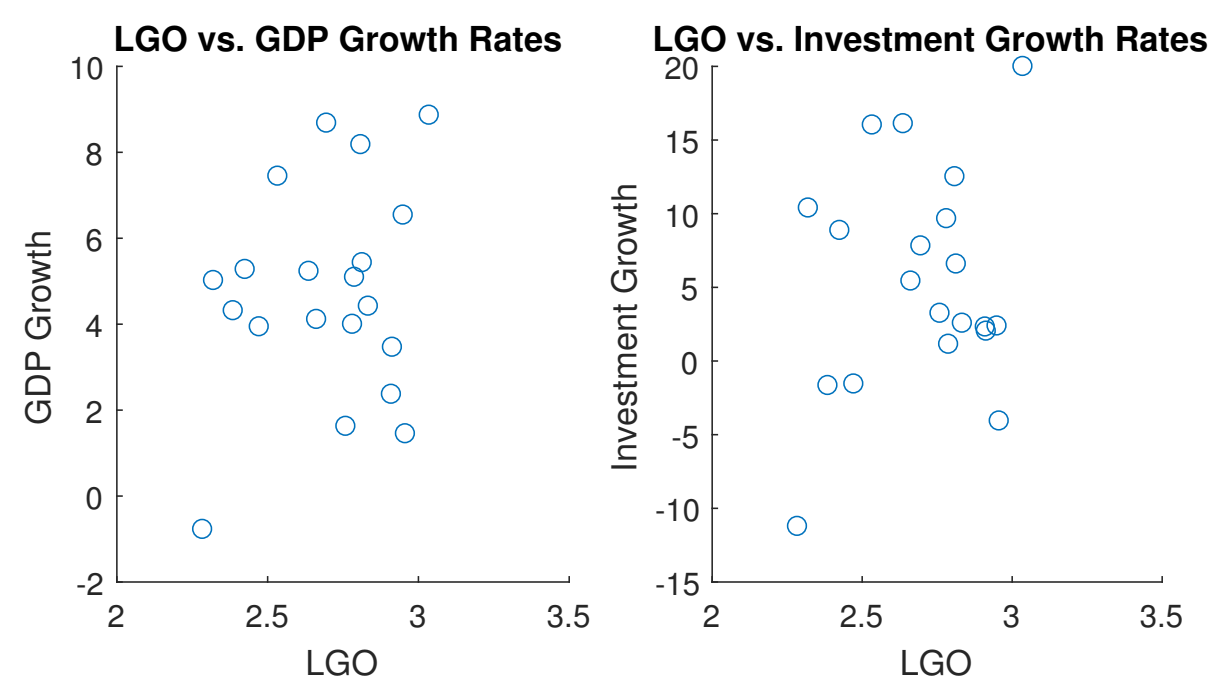

FIGURE C.19: GDP and Investment Growth versus LGO for South Africa
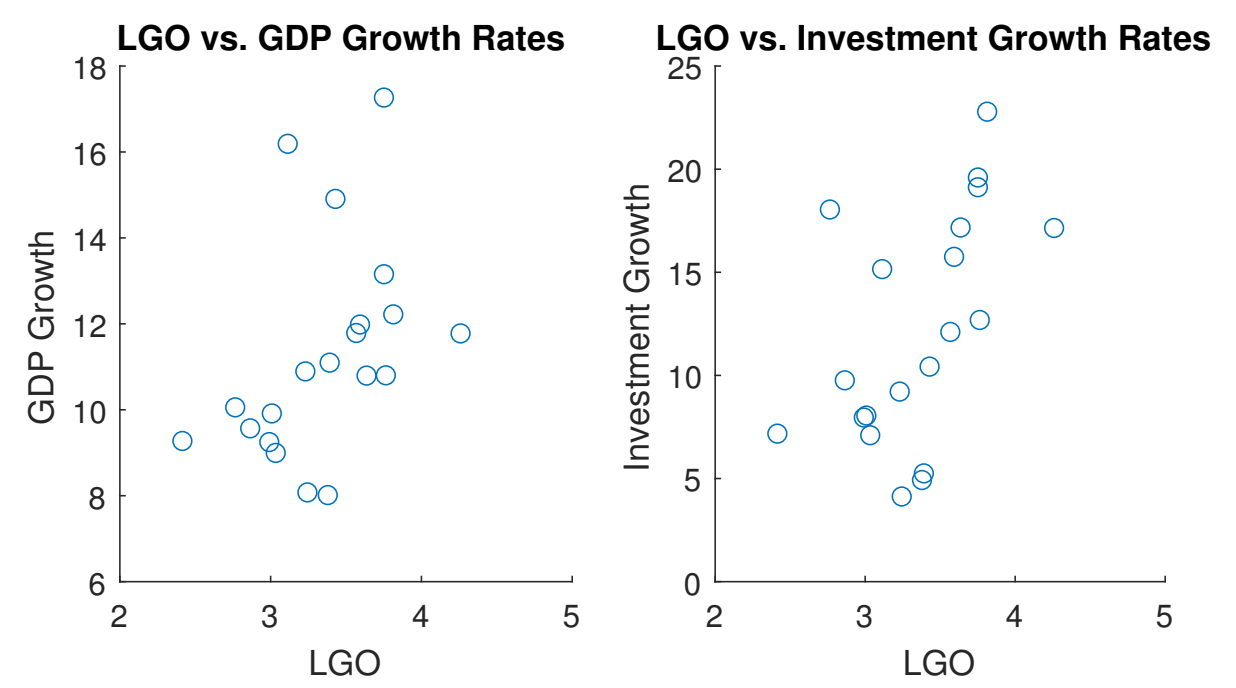

FIGURE C.20: GDP and Investment Growth versus LGO for China 

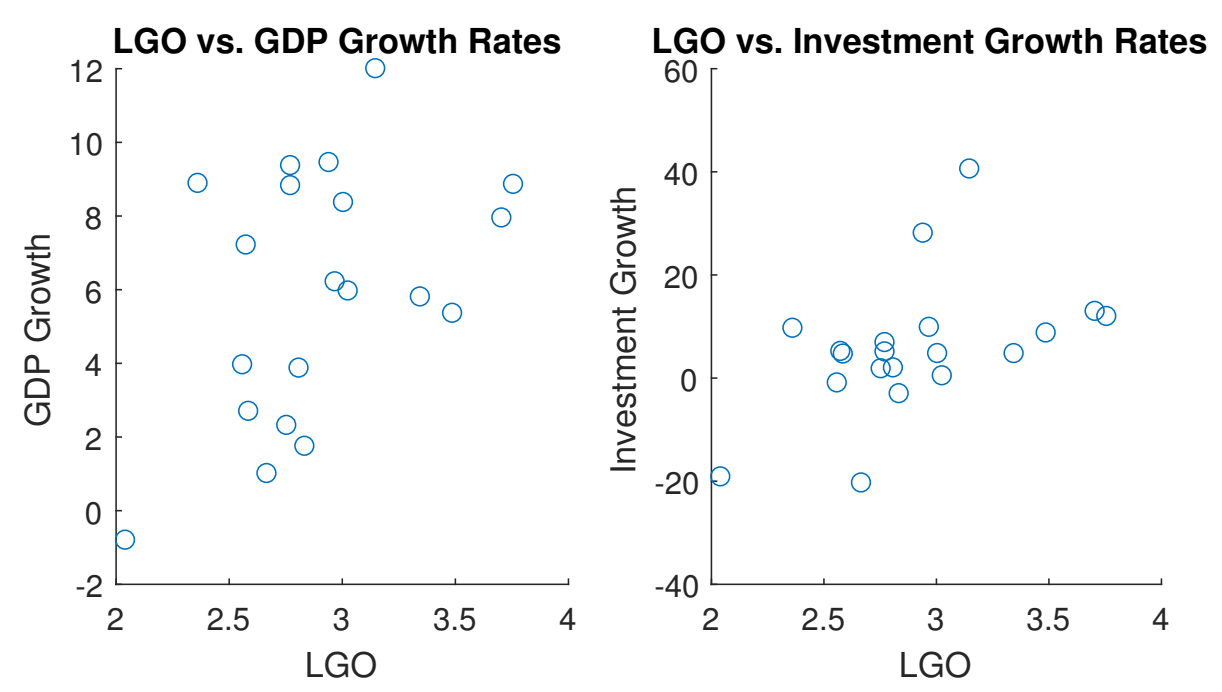

FIGURE C.21: GDP and Investment Growth versus LGO for Taiwan 


\section{Appendix D}

\section{Random Portfolio Experiment Results}

This appendix six panels per region. The first panel shows the median excess returns of the test portfolios, versus the excess return of holding an aggregate index of the test and control regions in similar proportions. The second panel shows excess correlation to existing holdings for test portfolios. The third panel shows excess CVaR. The fourth panel shows the net number of test portfolios which are strictly preferred to control portfolios. Finally, the fifth and sixth panels show $S E G, L G O$, and $G G O$ over time. 


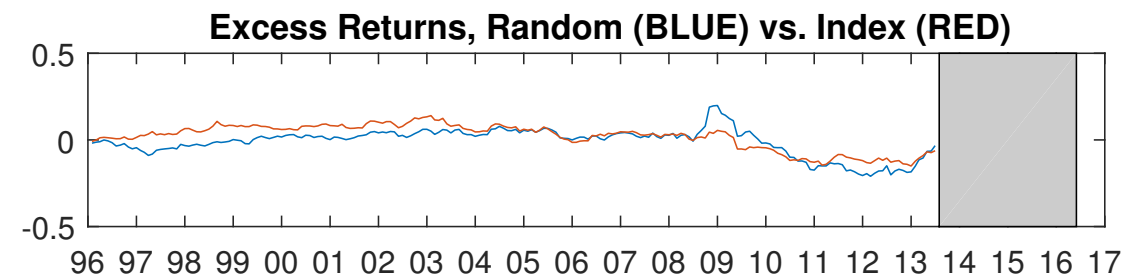

Excess Correlation of Test Portfolios

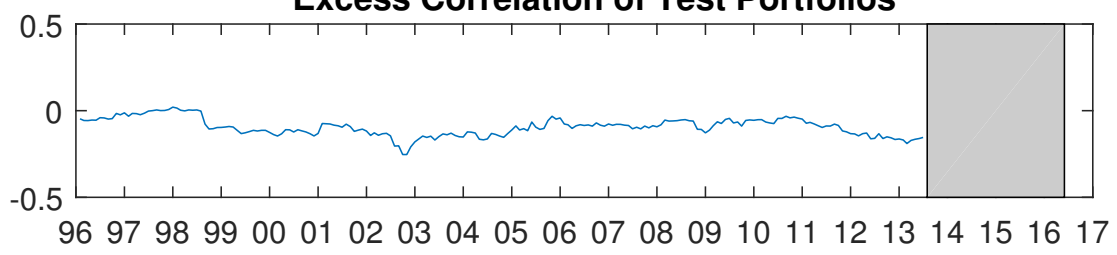

Excess CVaR of Test Portfolios

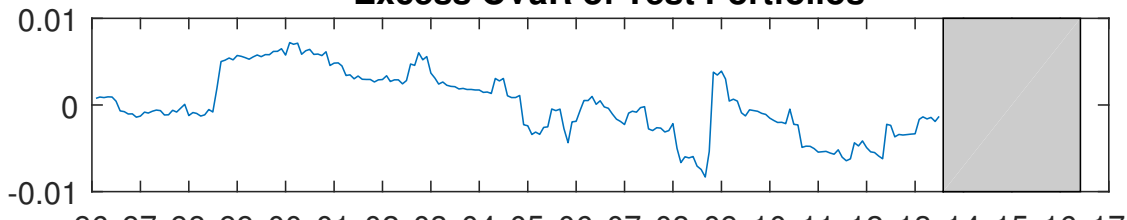

96979899000102030405060708091011121314151617 Net Count of Strictly Preferred Test Portfolios

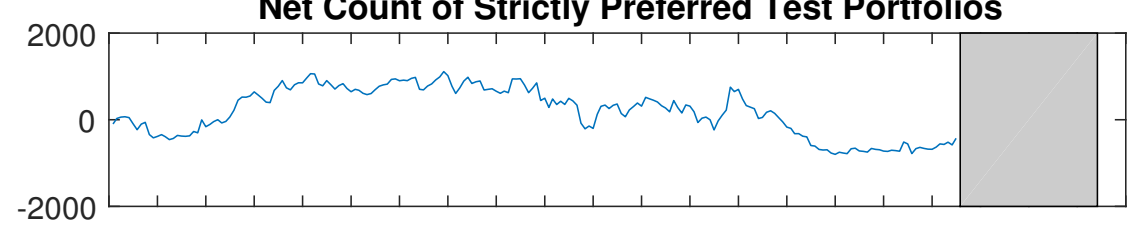

$969798990001020304050607080910111213141516 \quad 17$ SEG

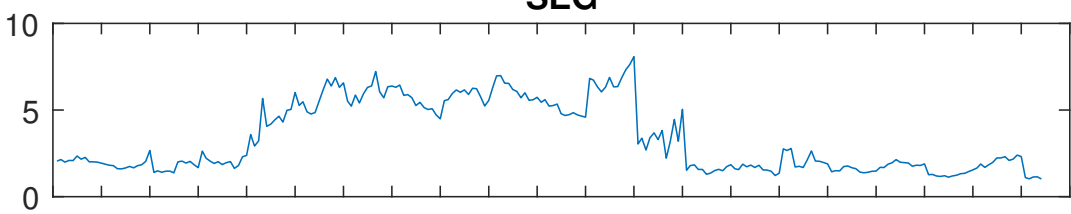

96979899000102030405060708091011121314151617

LGO (BLUE) and GGO (RED)

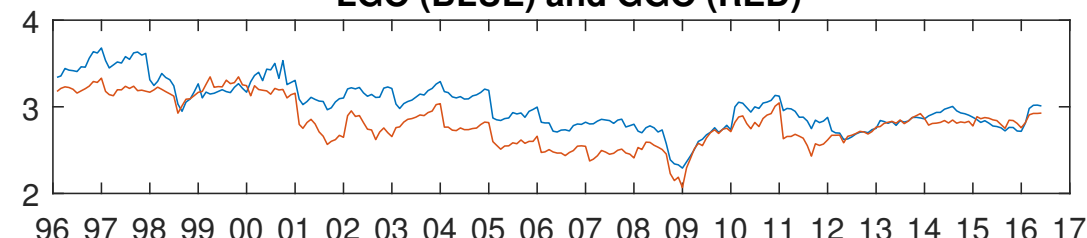

FIGURE D.1: Random Portfolio Experiment Results for Canada 


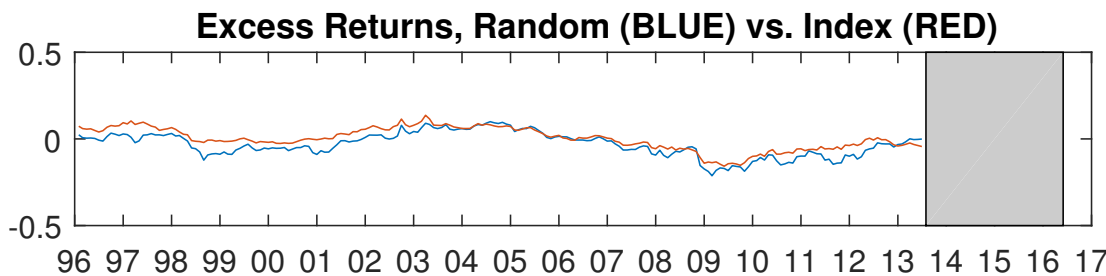

Excess Correlation of Test Portfolios

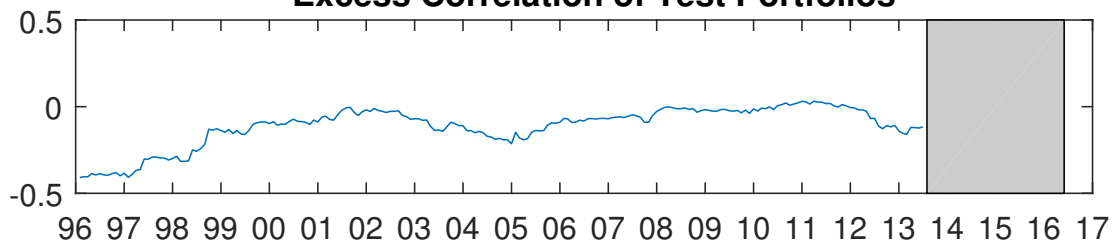

Excess CVaR of Test Portfolios

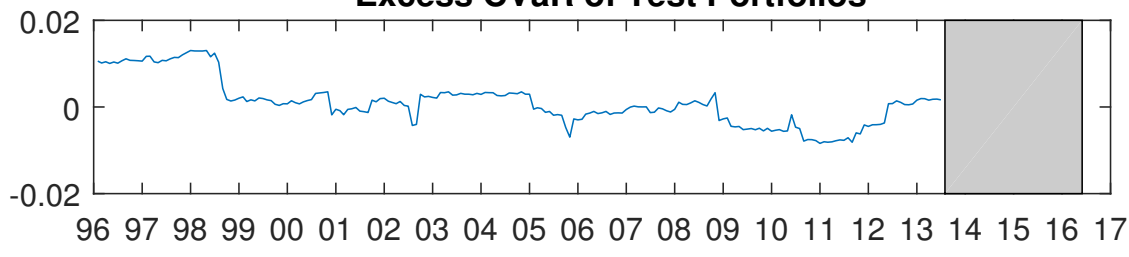

Net Count of Strictly Preferred Test Portfolios

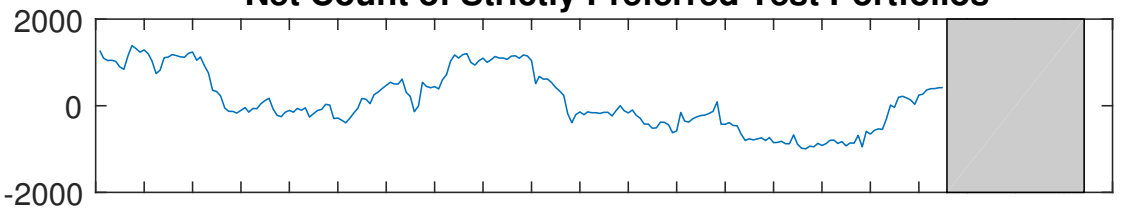

96979899000102030405060708091011121314151617

SEG

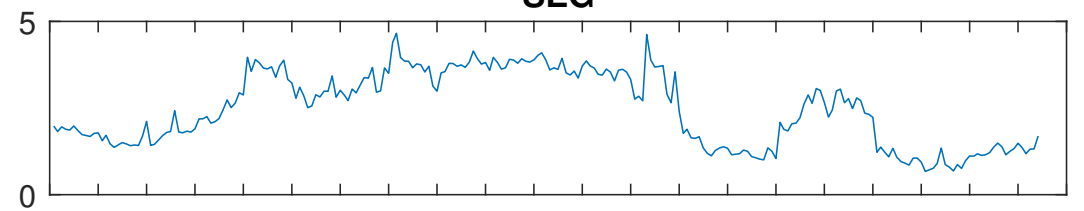

96979899000102030405060708091011121314151617 LGO (BLUE) and GGO (RED)

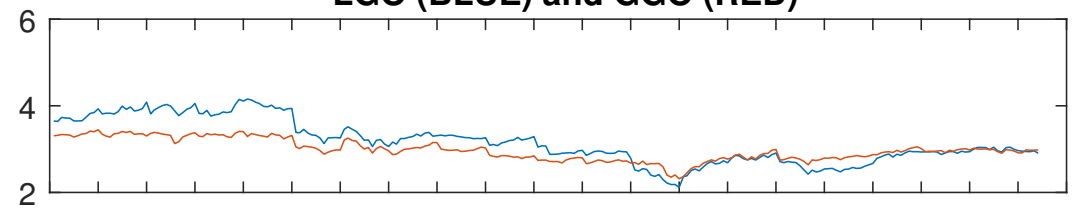

$969798990001020304050607080910111213141516 \quad 17$

FIgURE D.2: Random Portfolio Experiment Results for France 


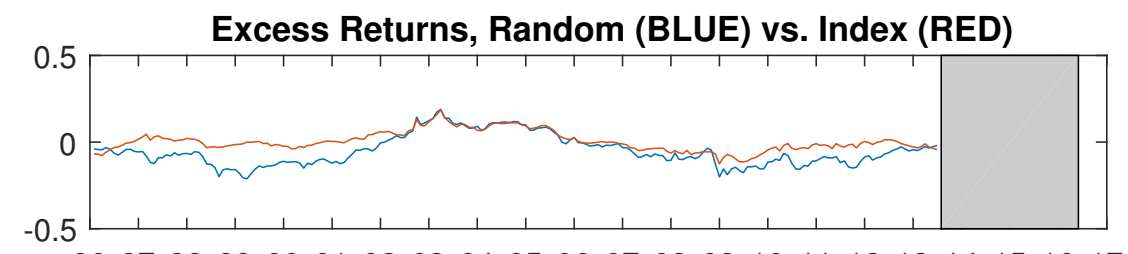

96979899000102030405060708091011121314151617

Excess Correlation of Test Portfolios

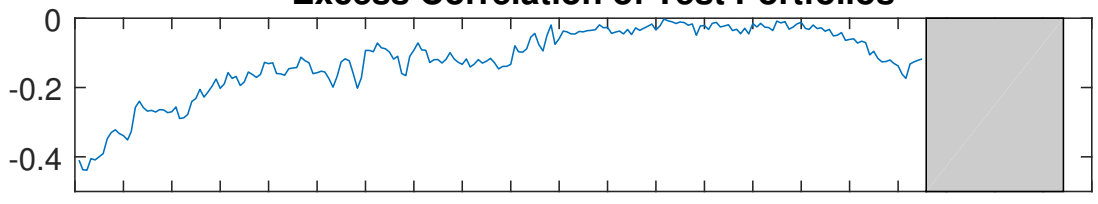

96979899000102030405060708091011121314151617

Excess CVaR of Test Portfolios

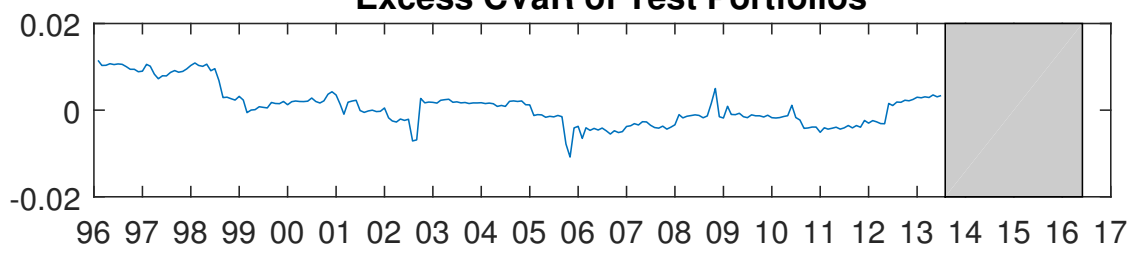

Net Count of Strictly Preferred Test Portfolios

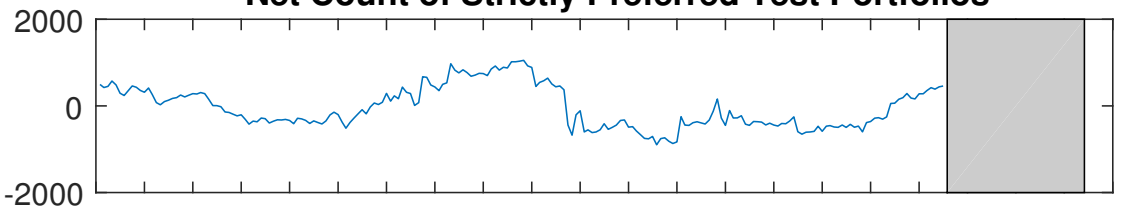

96979899000102030405060708091011121314151617

SEG

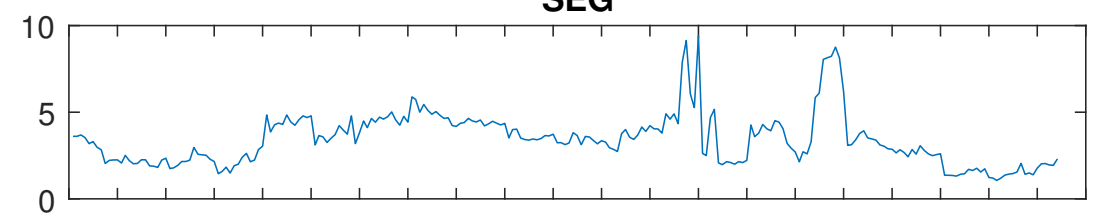

96979899000102030405060708091011121314151617

LGO (BLUE) and GGO (RED)

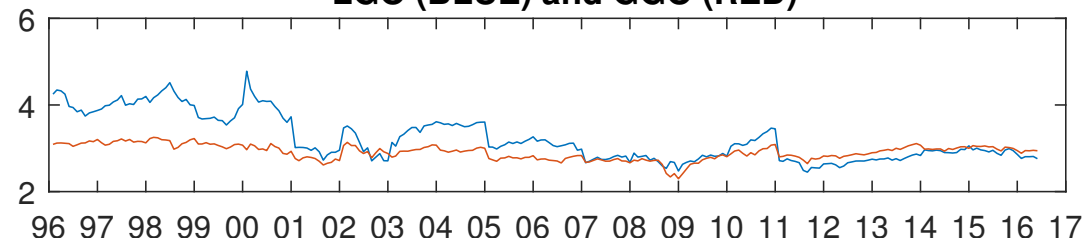

FIgURE D.3: Random Portfolio Experiment Results for Germany 


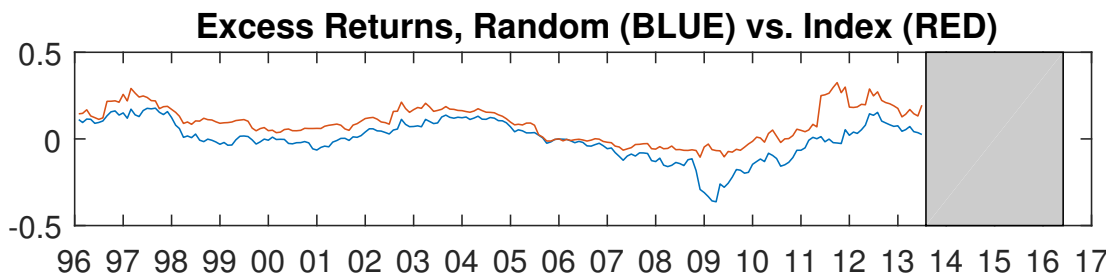

Excess Correlation of Test Portfolios

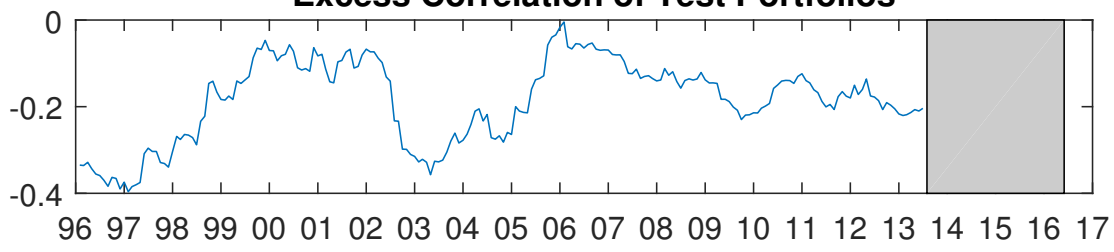

Excess CVaR of Test Portfolios

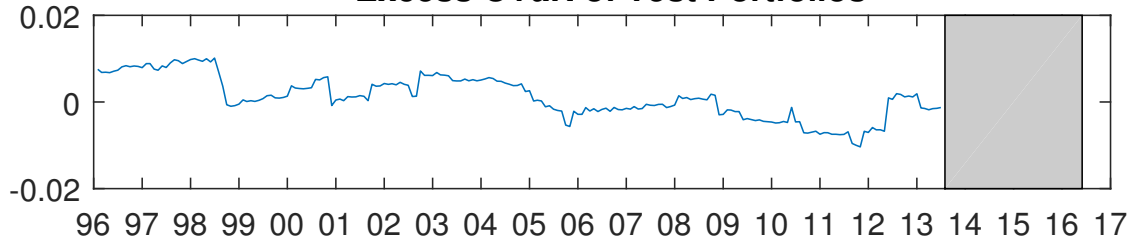

Net Count of Strictly Preferred Test Portfolios

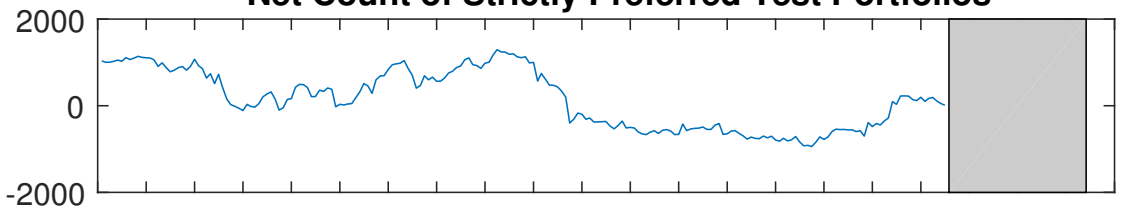

$969798990001020304050607080910111213141516 \quad 17$

SEG

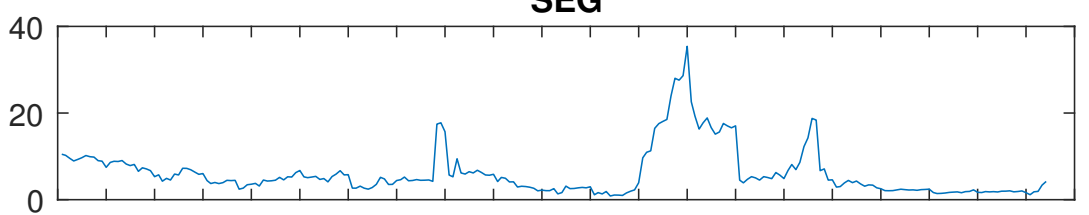

96979899000102030405060708091011121314151617 LGO (BLUE) and GGO (RED)

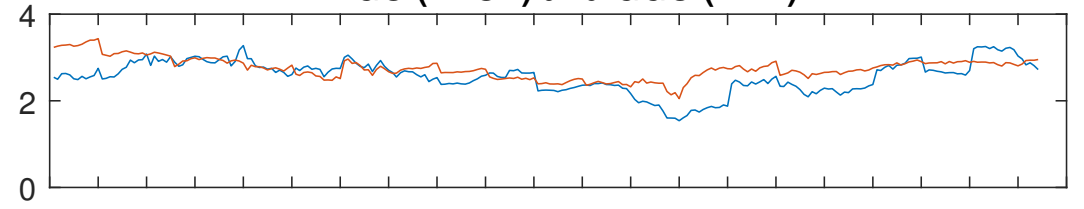

$969798990001020304050607080910111213141516 \quad 17$

FIGURE D.4: Random Portfolio Experiment Results for Italy 


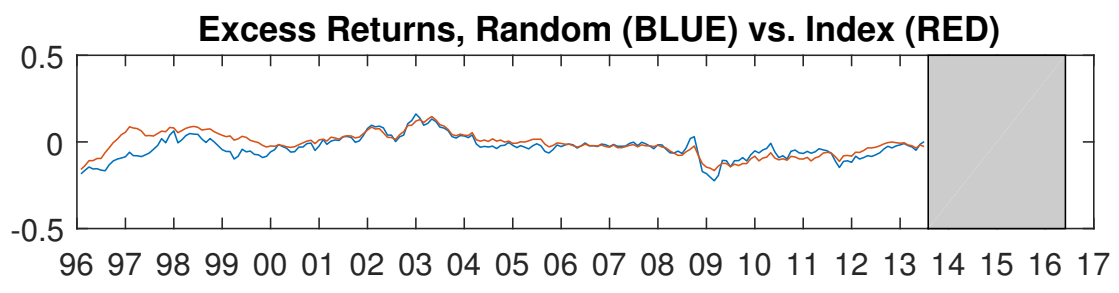

Excess Correlation of Test Portfolios

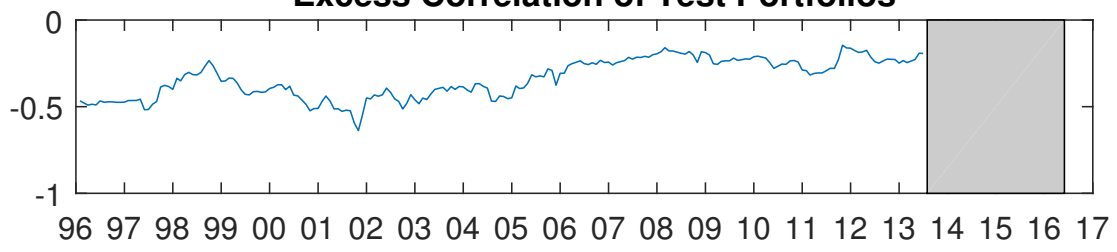

Excess CVaR of Test Portfolios

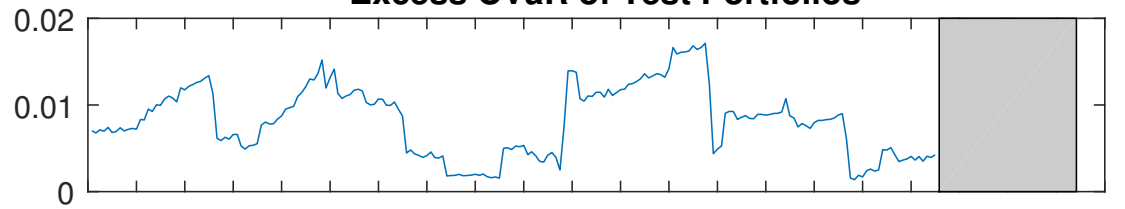

96979899000102030405060708091011121314151617

Net Count of Strictly Preferred Test Portfolios

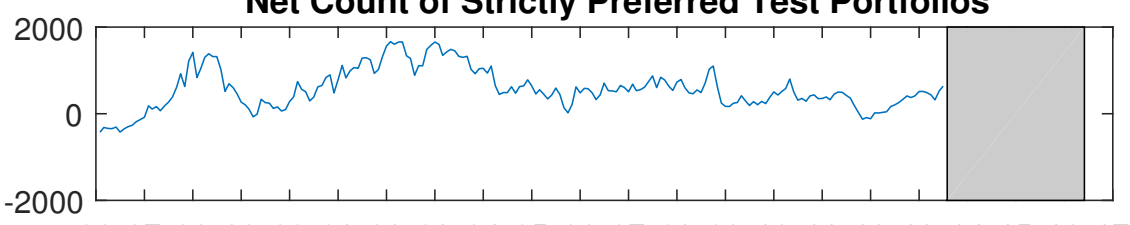

$969798990001020304050607080910111213141516 \quad 17$

SEG

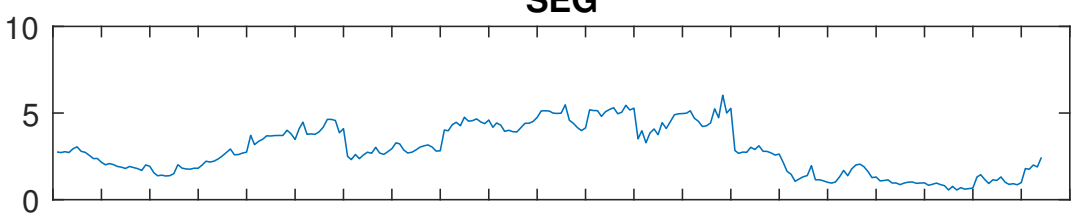

96979899000102030405060708091011121314151617

LGO (BLUE) and GGO (RED)

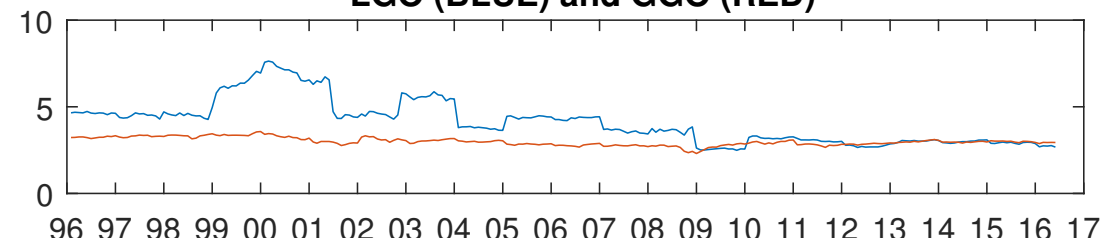

FIGURE D.5: Random Portfolio Experiment Results for Japan 


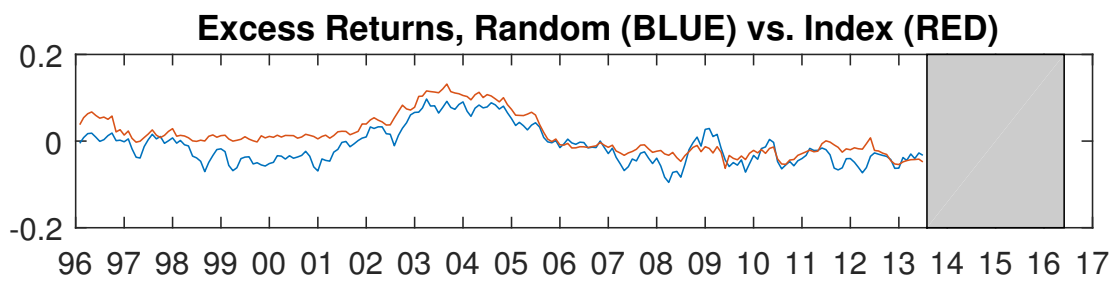

Excess Correlation of Test Portfolios

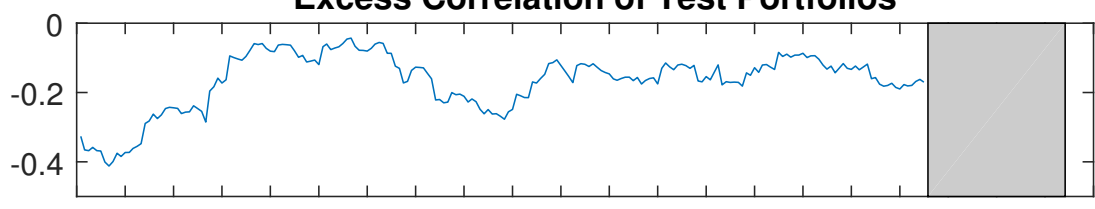

96979899000102030405060708091011121314151617

Excess CVaR of Test Portfolios

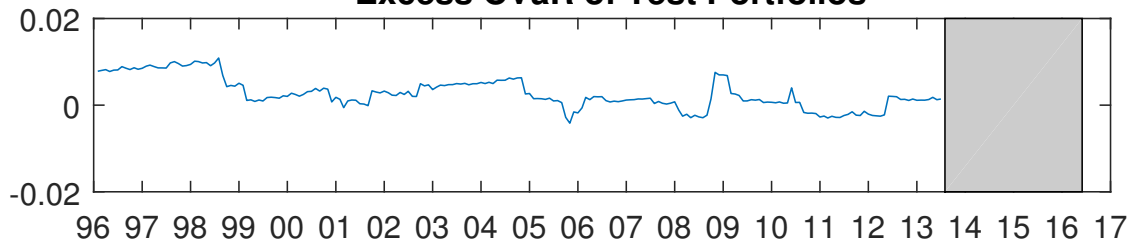

Net Count of Strictly Preferred Test Portfolios

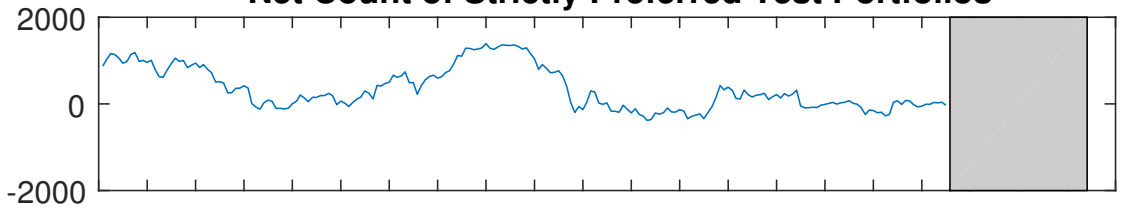

$969798990001020304050607080910111213141516 \quad 17$

SEG

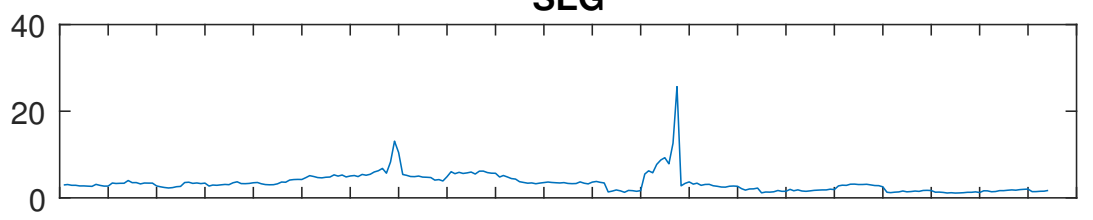

96979899000102030405060708091011121314151617

LGO (BLUE) and GGO (RED)

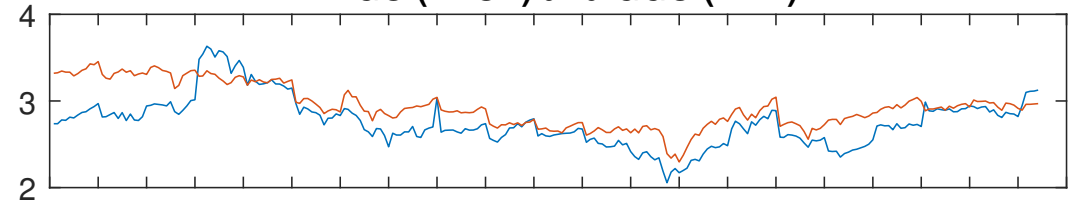

$969798990001020304050607080910111213141516 \quad 17$

FiguRE D.6: Random Portfolio Experiment Results for the United Kingdom 


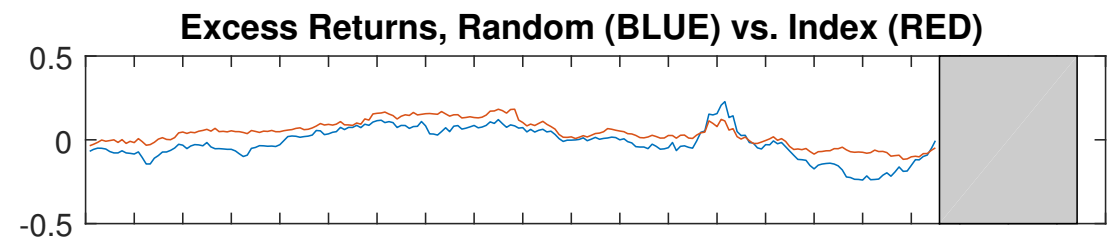

96979899000102030405060708091011121314151617

Excess Correlation of Test Portfolios

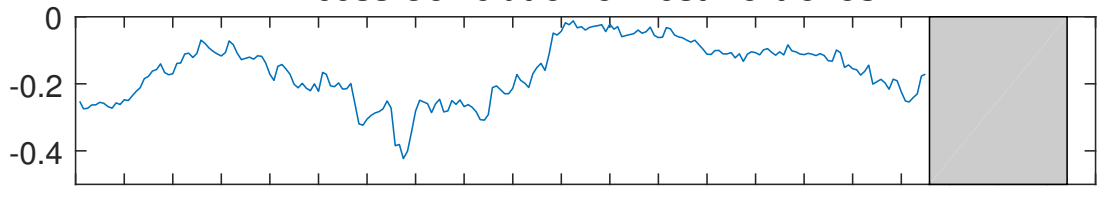

$96979899000102030405060708091011 \quad 121314151617$

Excess CVaR of Test Portfolios

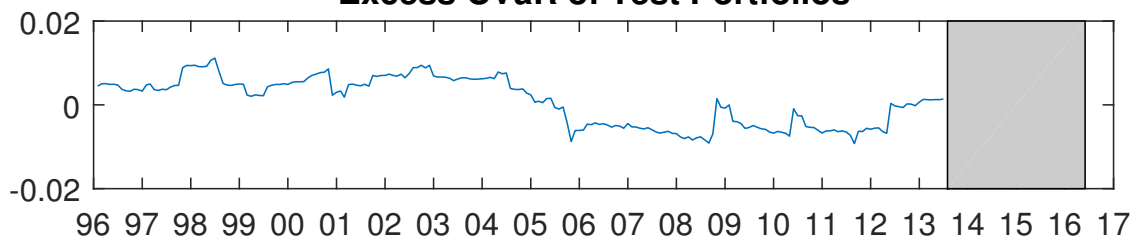

Net Count of Strictly Preferred Test Portfolios

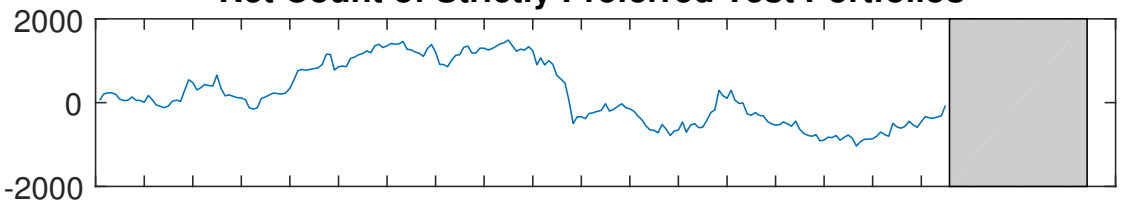

96979899000102030405060708091011121314151617

SEG

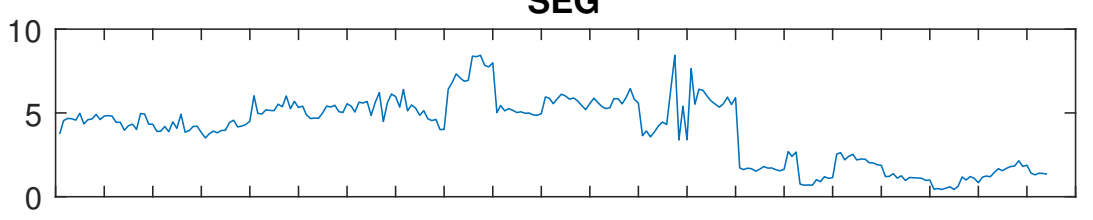

96979899000102030405060708091011121314151617

LGO (BLUE) and GGO (RED)

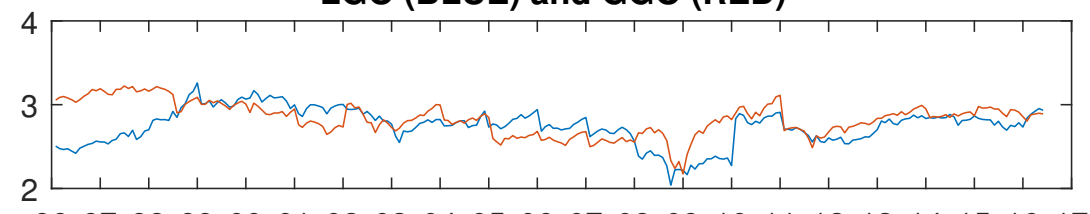

$969798990001020304050607080910111213141516 \quad 17$

FIGURE D.7: Random Portfolio Experiment Results for the Australia/New Zealand 


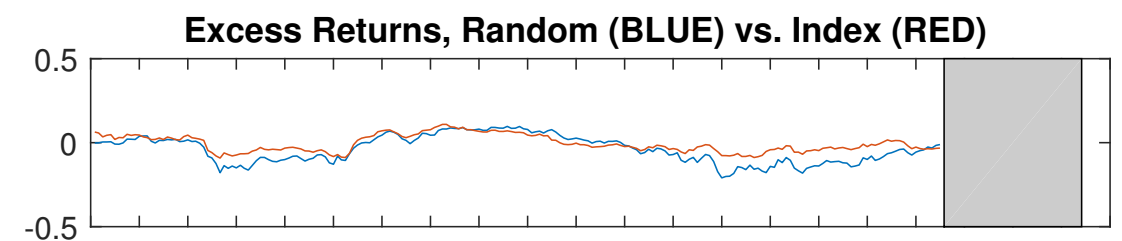

96979899000102030405060708091011121314151617

Excess Correlation of Test Portfolios

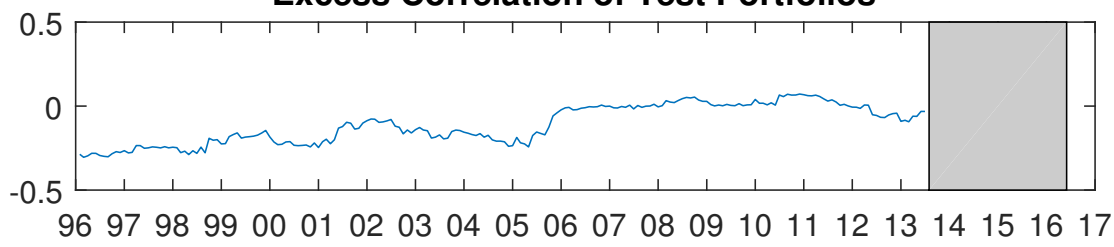

Excess CVaR of Test Portfolios

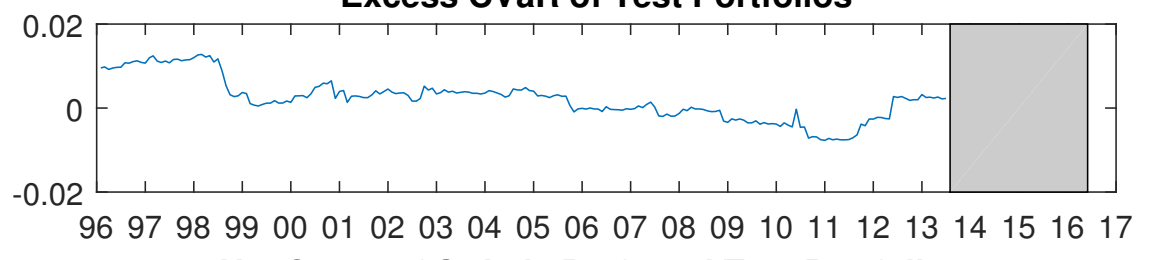

Net Count of Strictly Preferred Test Portfolios

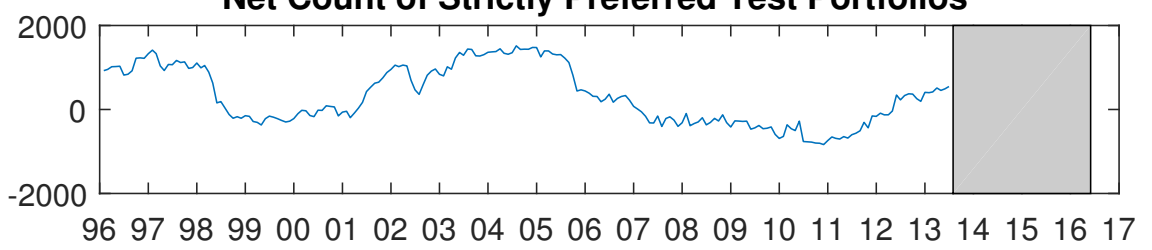

SEG

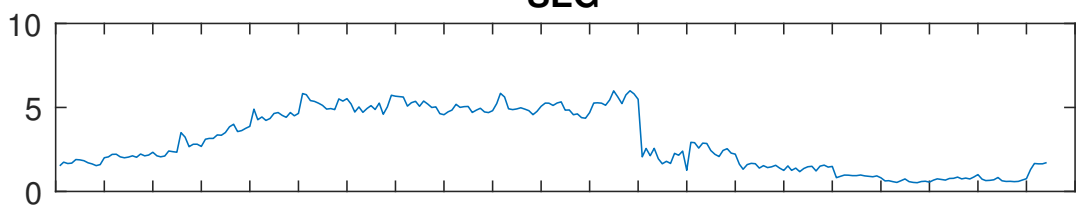

96979899000102030405060708091011121314151617

LGO (BLUE) and GGO (RED)

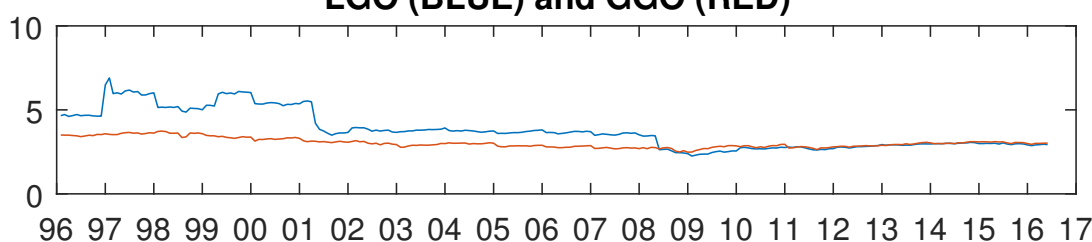

FiguRE D.8: Random Portfolio Experiment Results for the Switzerland/Austria 


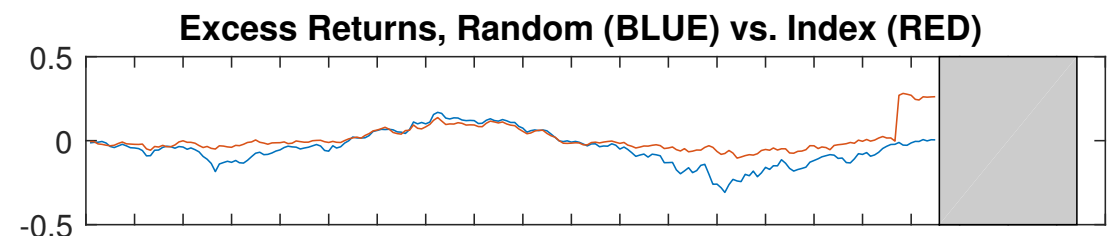

96979899000102030405060708091011121314151617

Excess Correlation of Test Portfolios

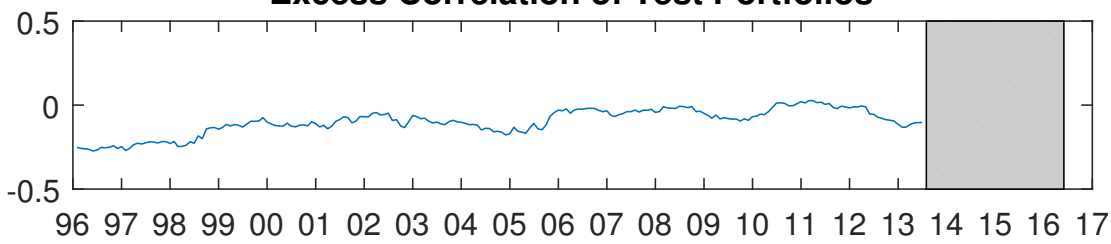

Excess CVaR of Test Portfolios

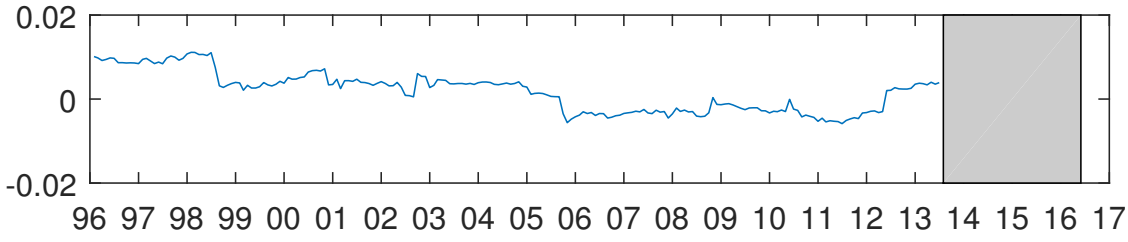

Net Count of Strictly Preferred Test Portfolios

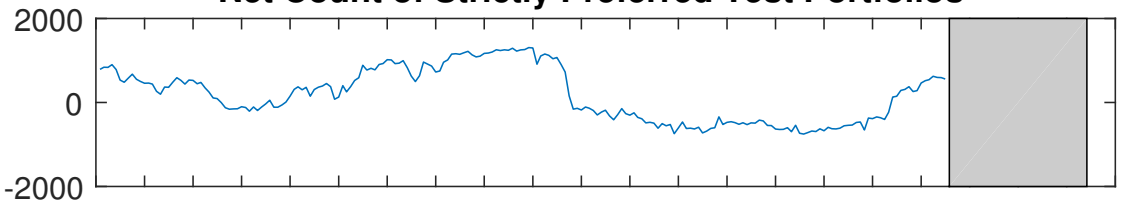

96979899000102030405060708091011121314151617

SEG

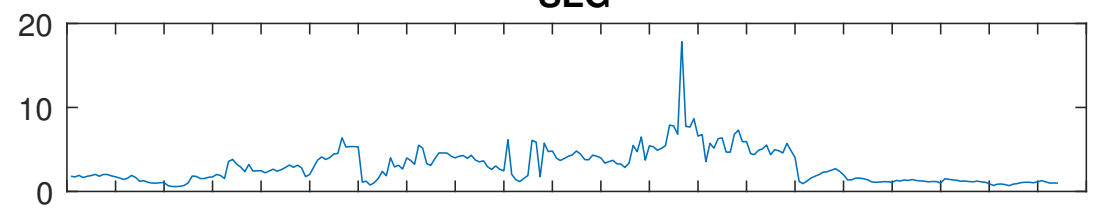

96979899000102030405060708091011121314151617

LGO (BLUE) and GGO (RED)

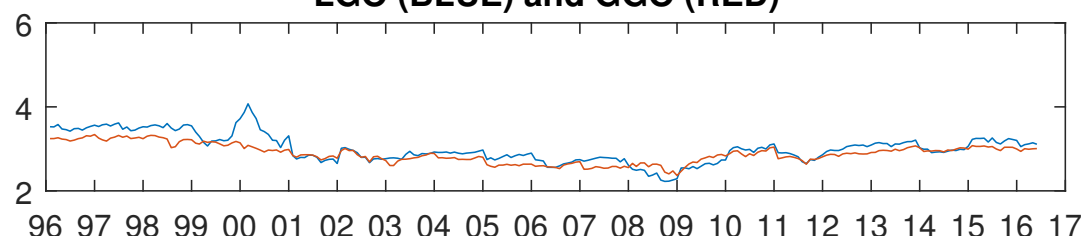

FIGURE D.9: Random Portfolio Experiment Results for the Developed EU 


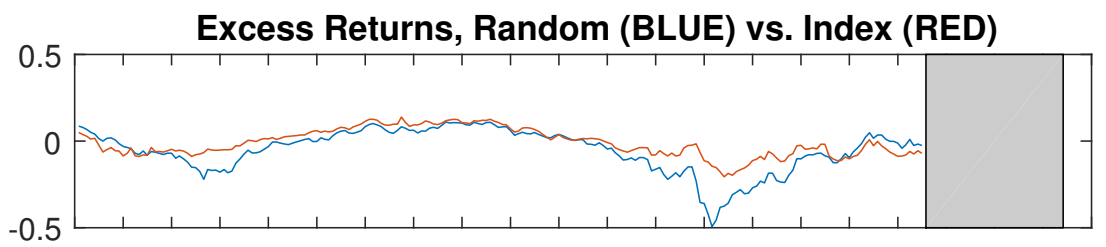

96979899000102030405060708091011121314151617

Excess Correlation of Test Portfolios

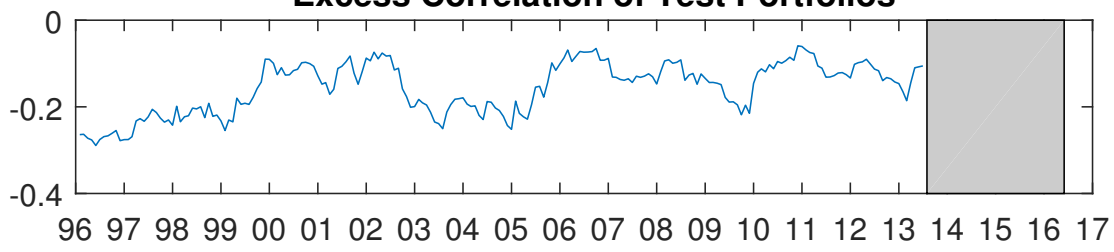

Excess CVaR of Test Portfolios

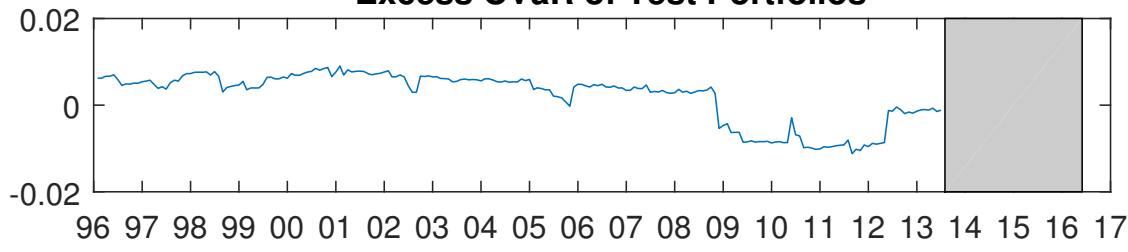

Net Count of Strictly Preferred Test Portfolios

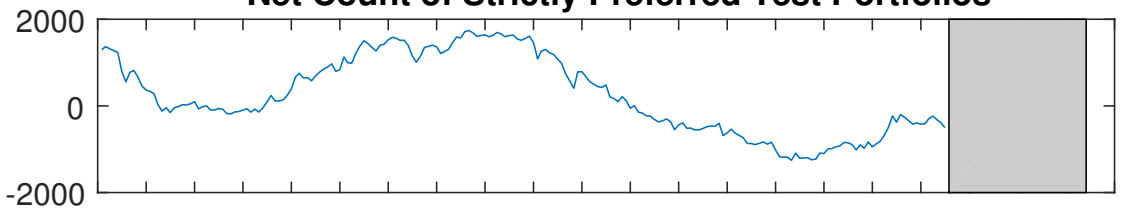

96979899000102030405060708091011121314151617

SEG
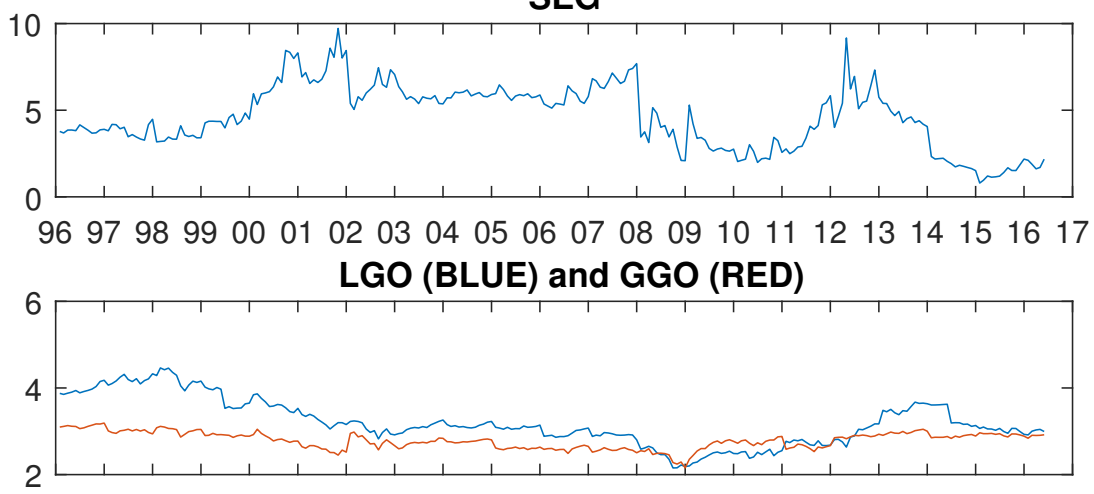

96979899000102030405060708091011121314151617

FIgURE D.10: Random Portfolio Experiment Results for Spain/Portugal 


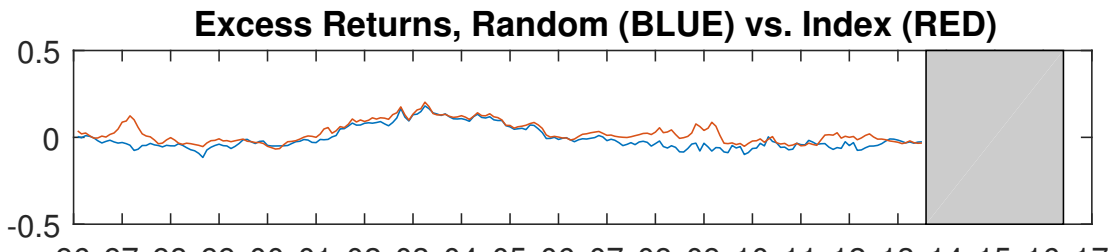

$96979899000102030405060708091011 \quad 121314151617$

Excess Correlation of Test Portfolios

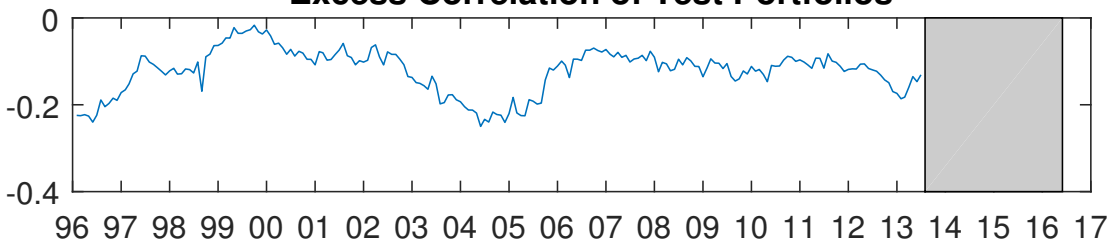

Excess CVaR of Test Portfolios

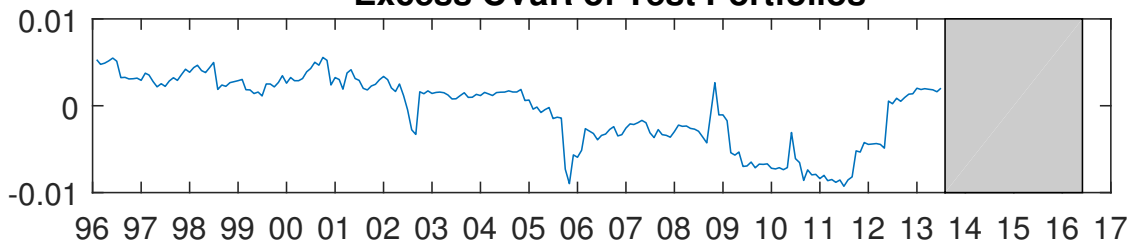

Net Count of Strictly Preferred Test Portfolios

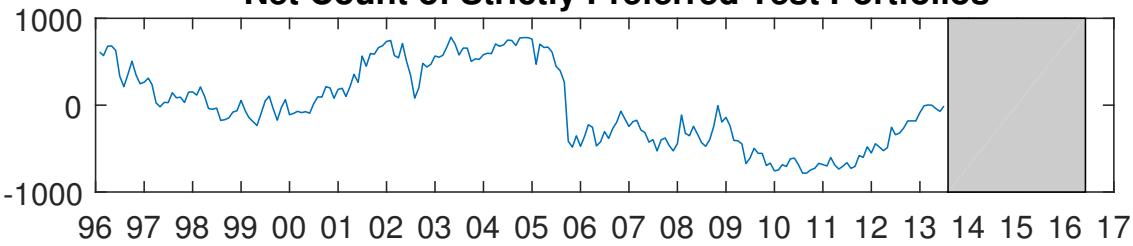

SEG

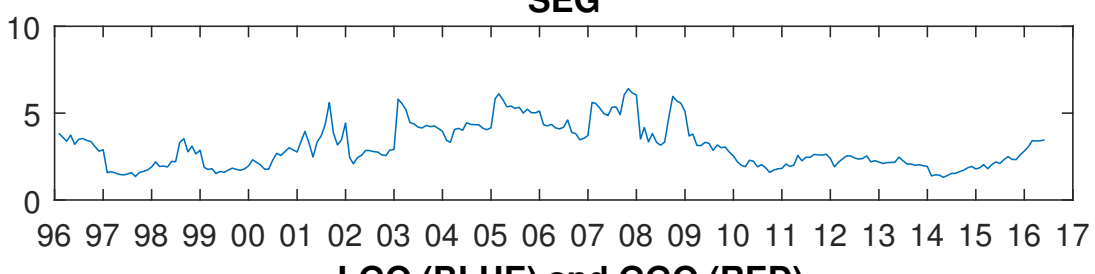

LGO (BLUE) and GGO (RED)

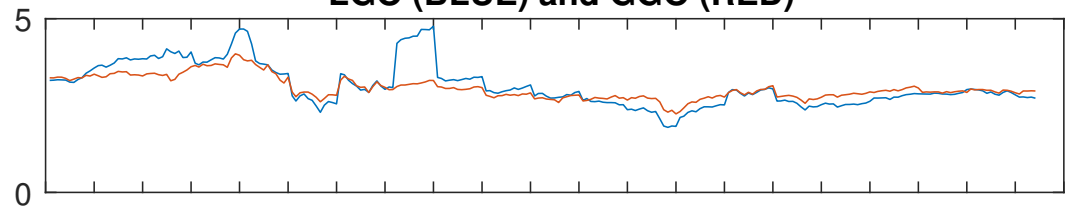

$969798990001020304050607080910111213141516 \quad 17$

FIGURE D.11: Random Portfolio Experiment Results for Scandinavia 


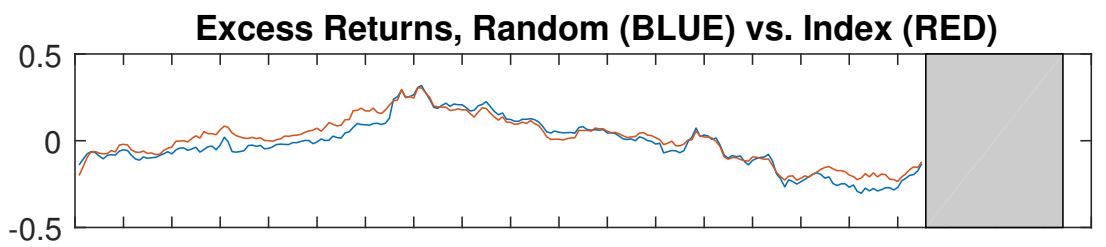

96979899000102030405060708091011121314151617

Excess Correlation of Test Portfolios

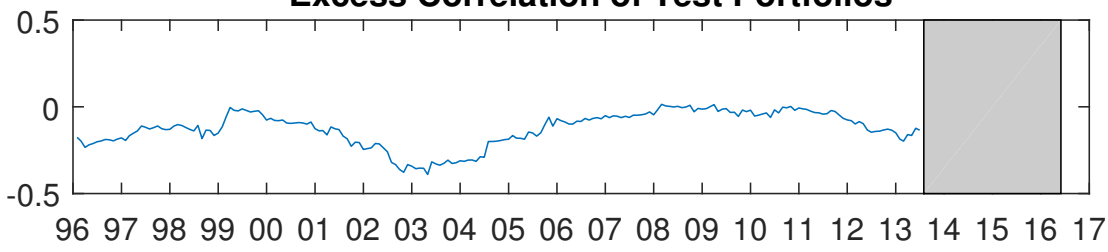

Excess CVaR of Test Portfolios

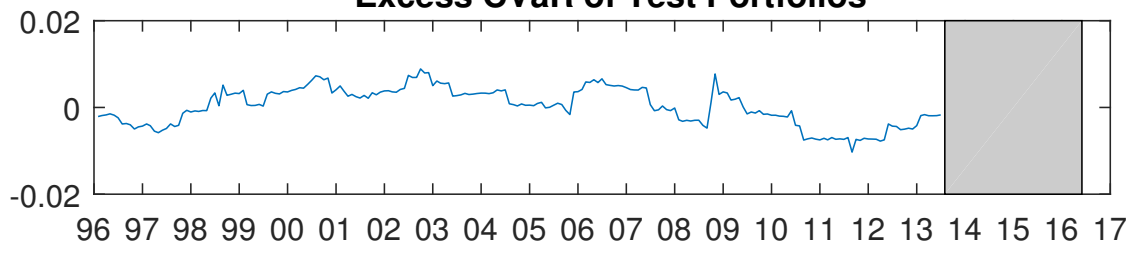

Net Count of Strictly Preferred Test Portfolios

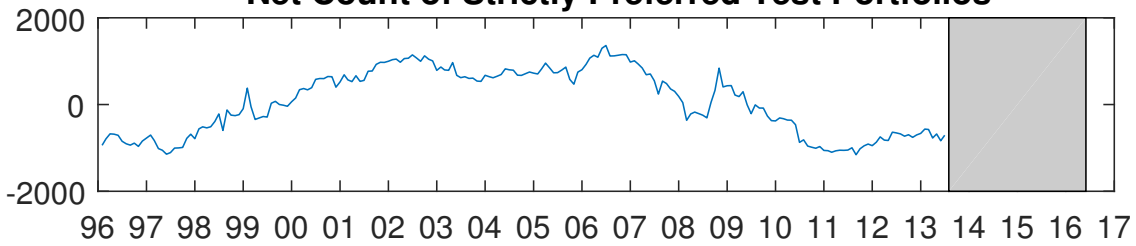

SEG

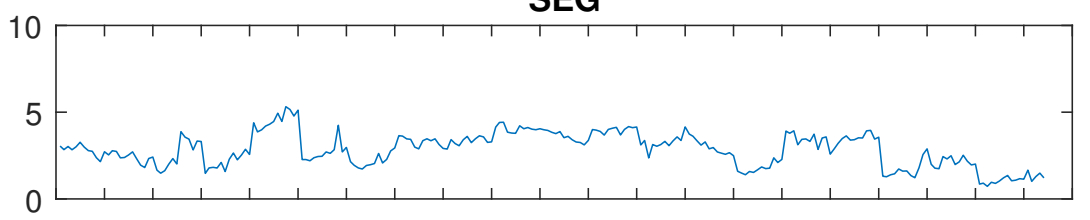

96979899000102030405060708091011121314151617 LGO (BLUE) and GGO (RED)

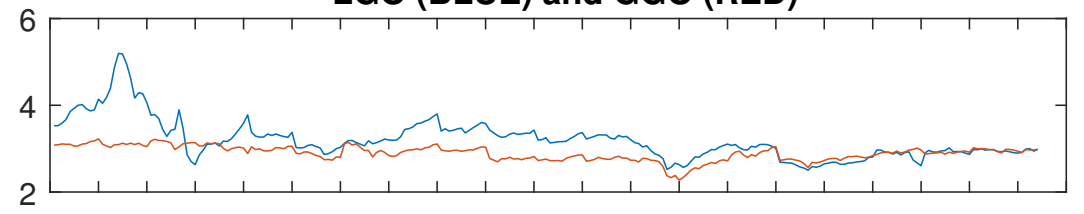

96979899000102030405060708091011121314151617

FigURE D.12: Random Portfolio Experiment Results for Latin America 


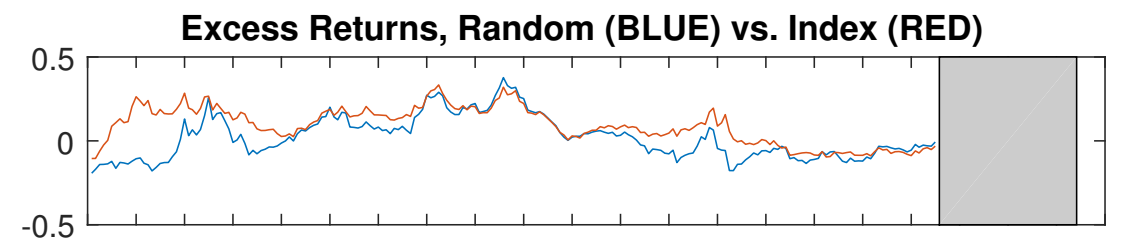

96979899000102030405060708091011121314151617

Excess Correlation of Test Portfolios

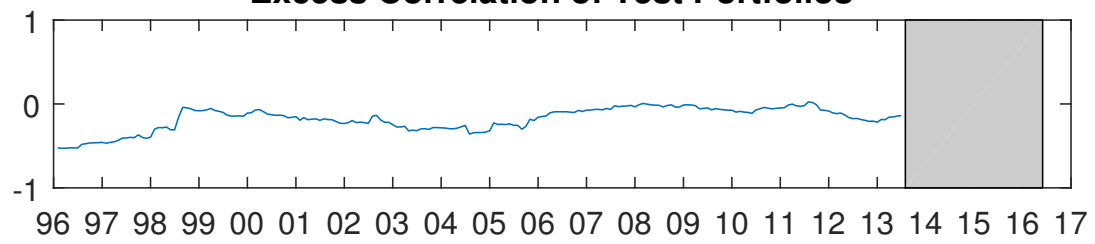

Excess CVaR of Test Portfolios

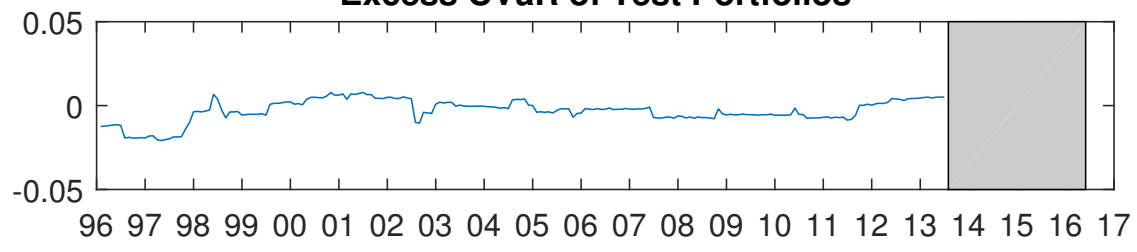

Net Count of Strictly Preferred Test Portfolios

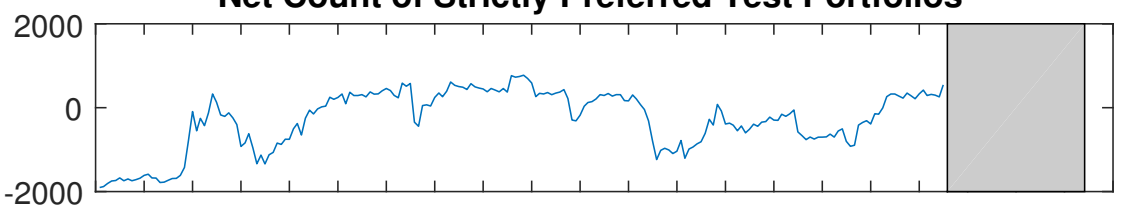

$9697989900010203040506070809101112131415 \quad 1617$

SEG

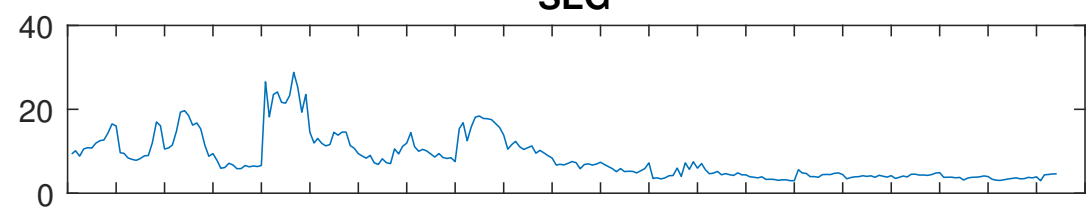

96979899000102030405060708091011121314151617

LGO (BLUE) and GGO (RED)

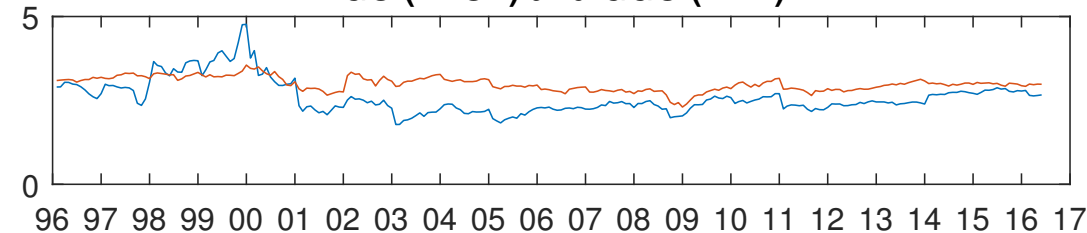

FiguRE D.13: Random Portfolio Experiment Results for Korea 


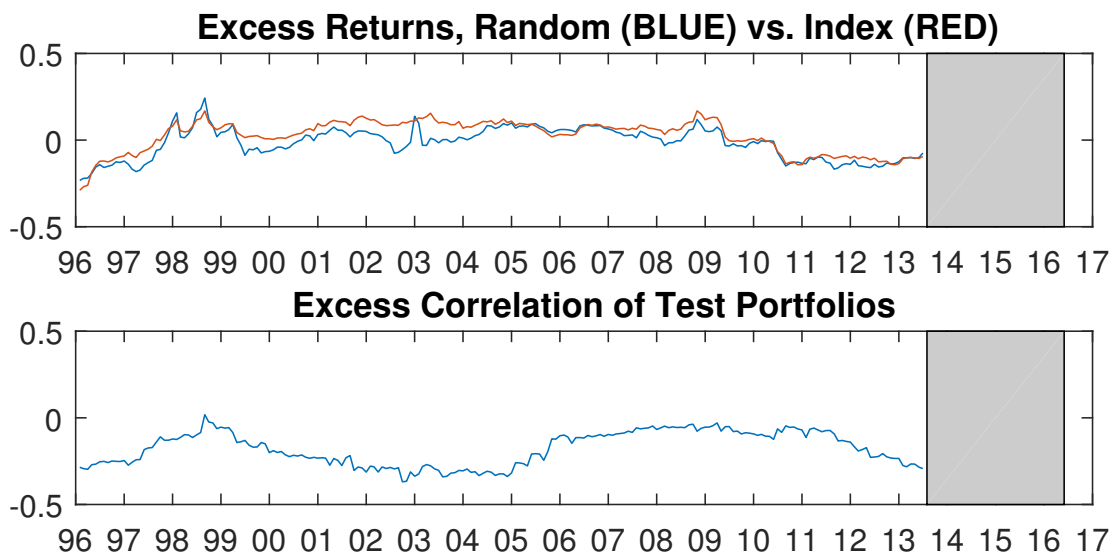

Excess CVaR of Test Portfolios

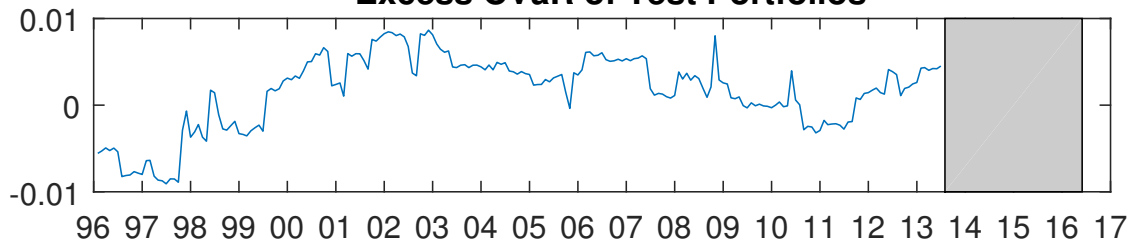

Net Count of Strictly Preferred Test Portfolios

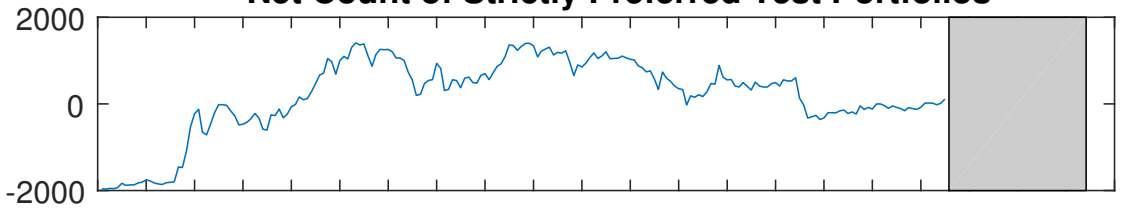

$969798990001020304050607080910111213141516 \quad 17$

SEG
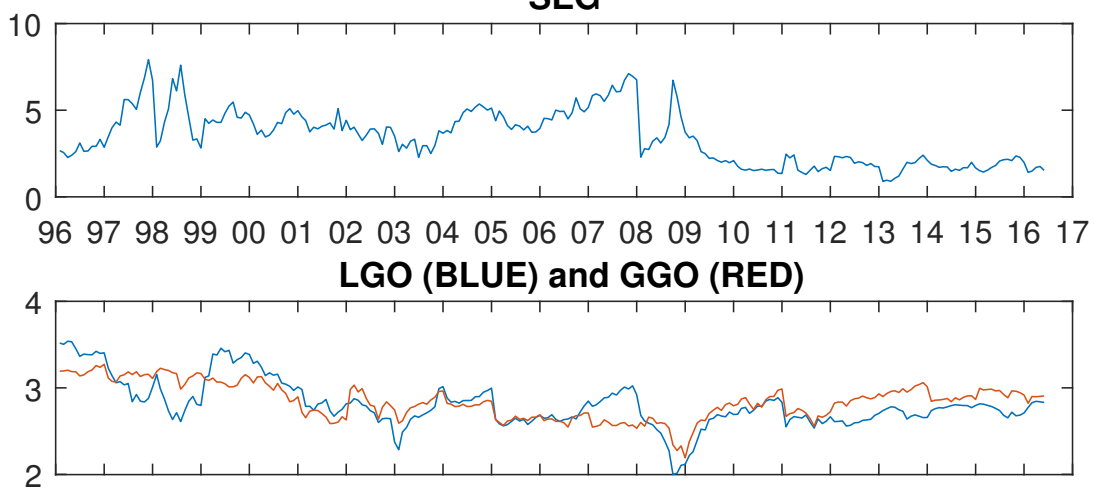

$969798990001020304050607080910111213141516 \quad 17$

FIGURE D.14: Random Portfolio Experiment Results for emerging Asia 


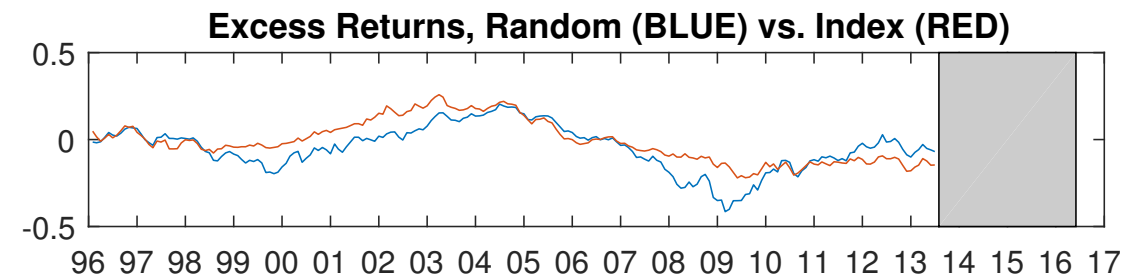

Excess Correlation of Test Portfolios

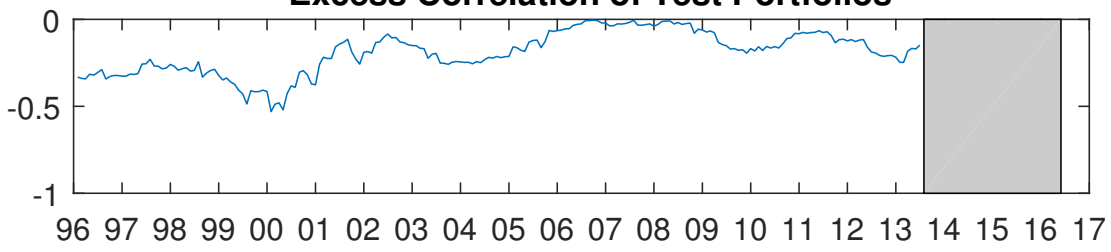

Excess CVaR of Test Portfolios

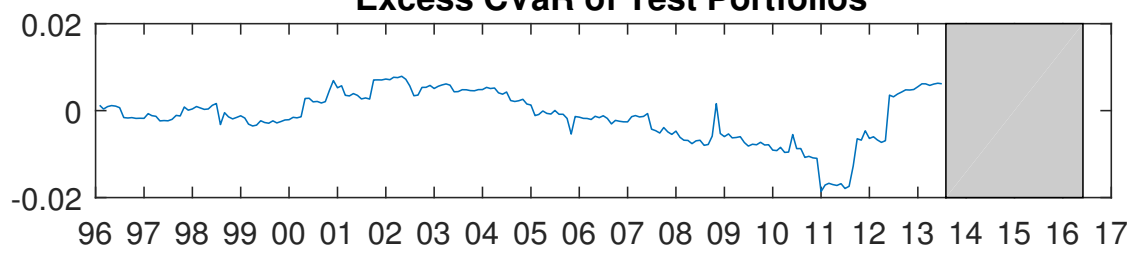

Net Count of Strictly Preferred Test Portfolios

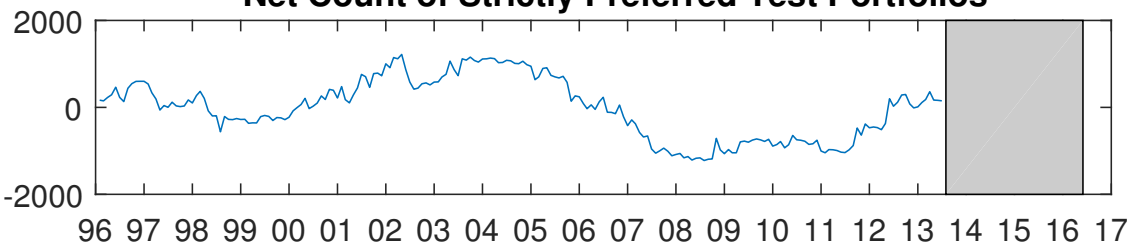

SEG

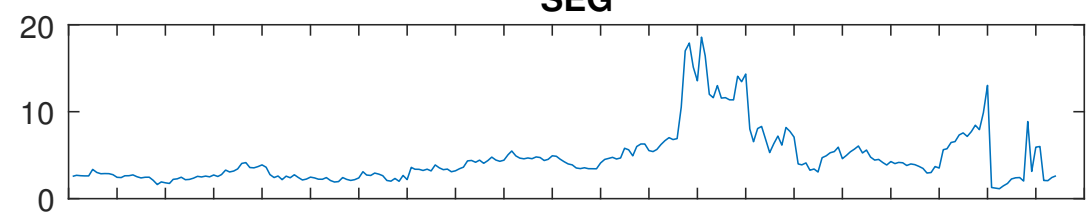

96979899000102030405060708091011121314151617

LGO (BLUE) and GGO (RED)

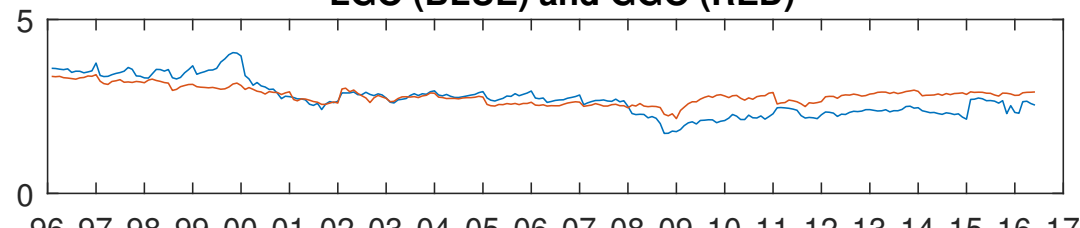

96979899000102030405060708091011121314151617

FIGURE D.15: Random Portfolio Experiment Results for emerging EU 

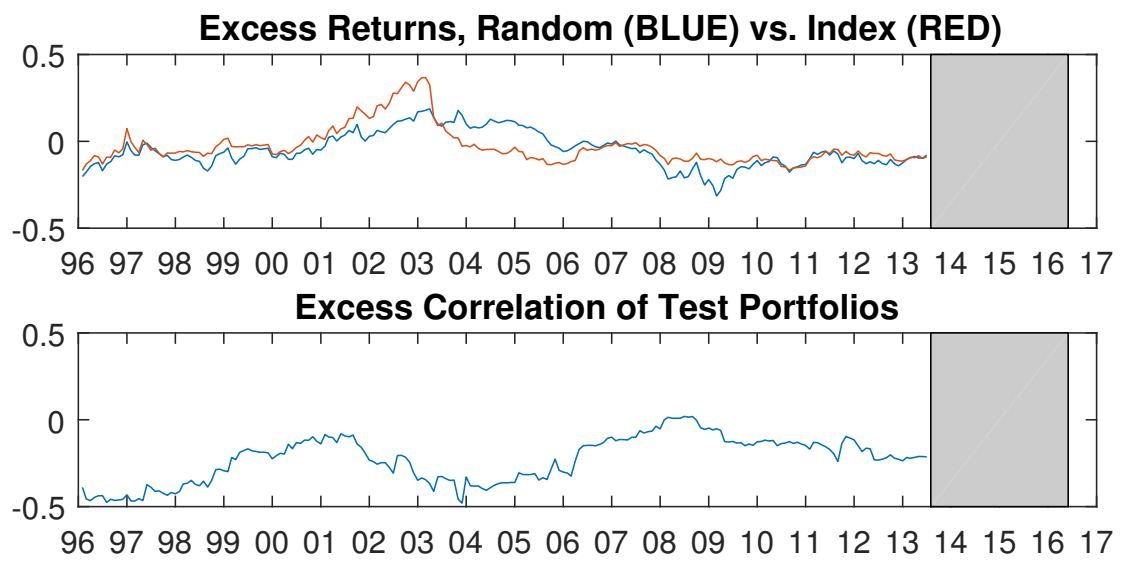

Excess CVaR of Test Portfolios

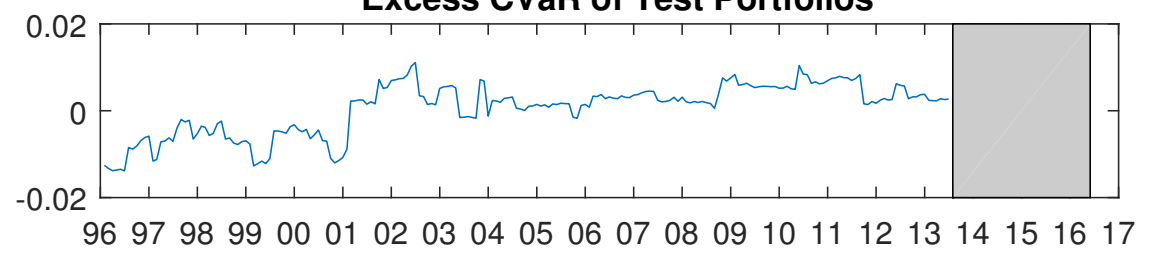

Net Count of Strictly Preferred Test Portfolios

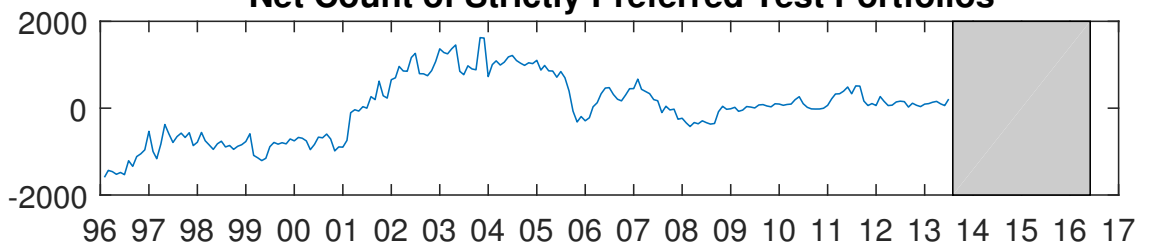

SEG
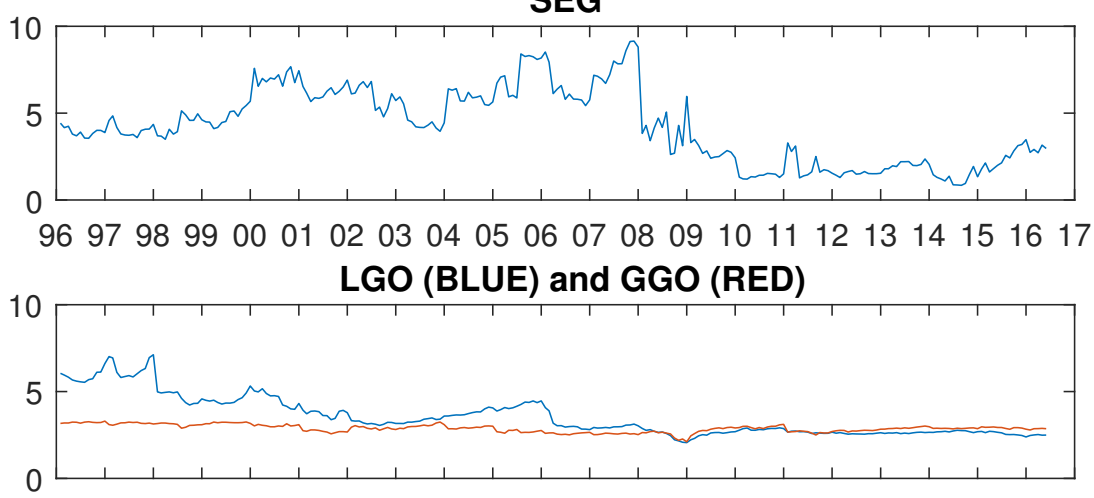

96979899000102030405060708091011121314151617

FIGURE D.16: Random Portfolio Experiment Results for Middle East/North Africa 


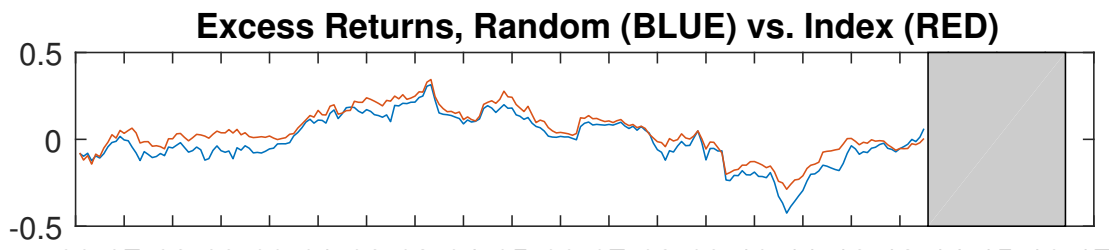

$96979899000102030405060708091011 \quad 121314151617$

Excess Correlation of Test Portfolios

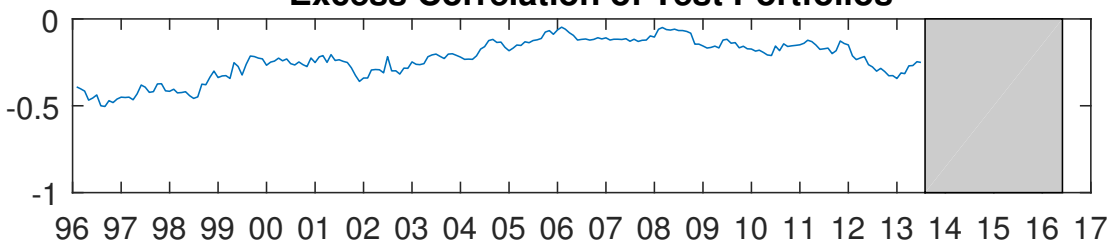

Excess CVaR of Test Portfolios

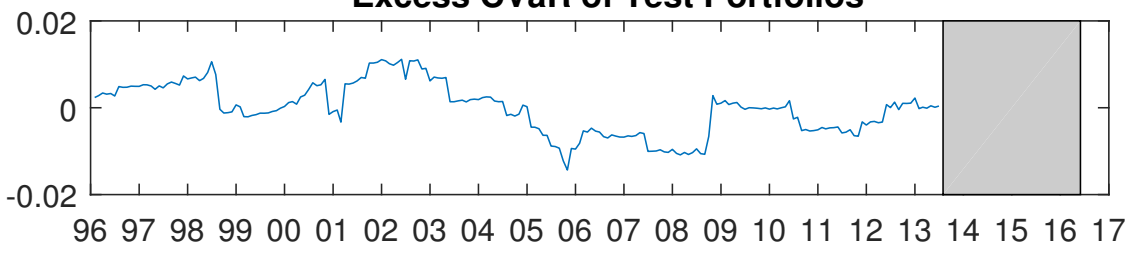

Net Count of Strictly Preferred Test Portfolios

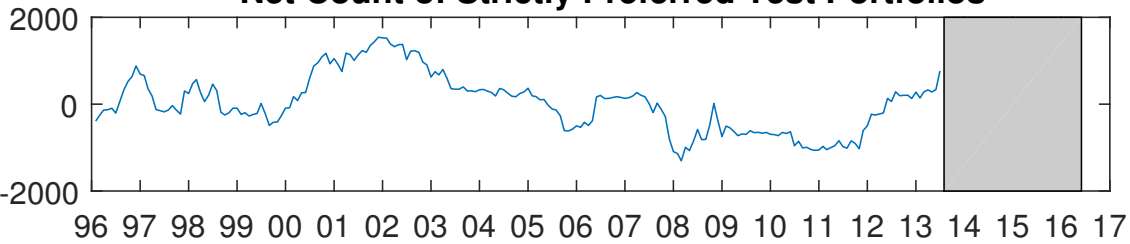

SEG
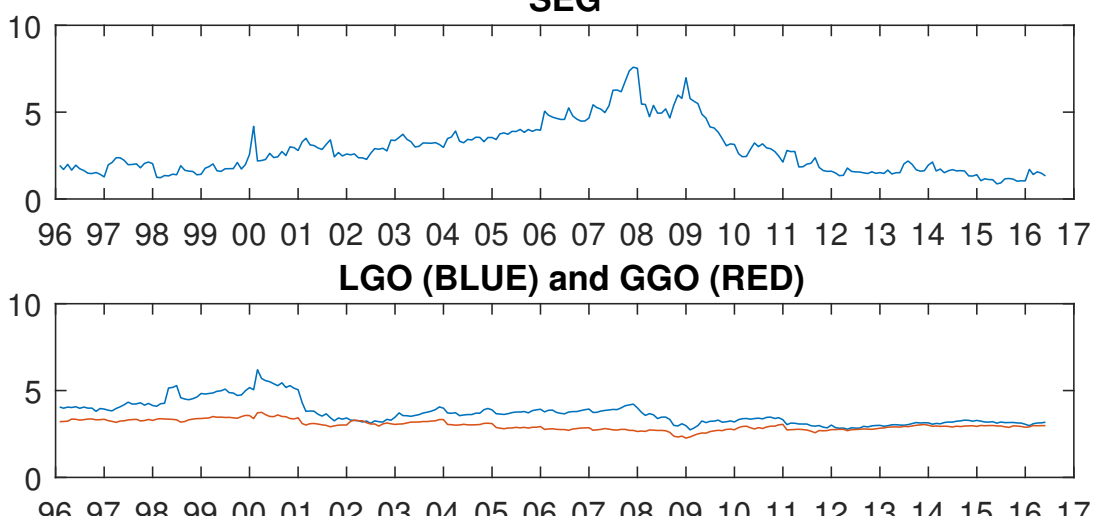

96979899000102030405060708091011121314151617

FiguRE D.17: Random Portfolio Experiment Results for India/Sri Lanka 


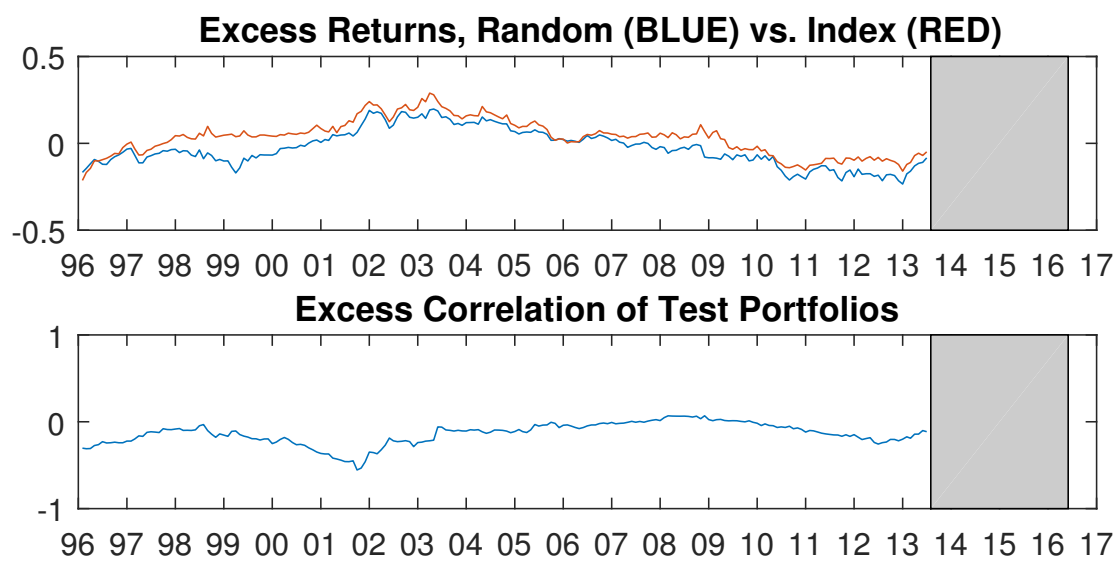

Excess CVaR of Test Portfolios

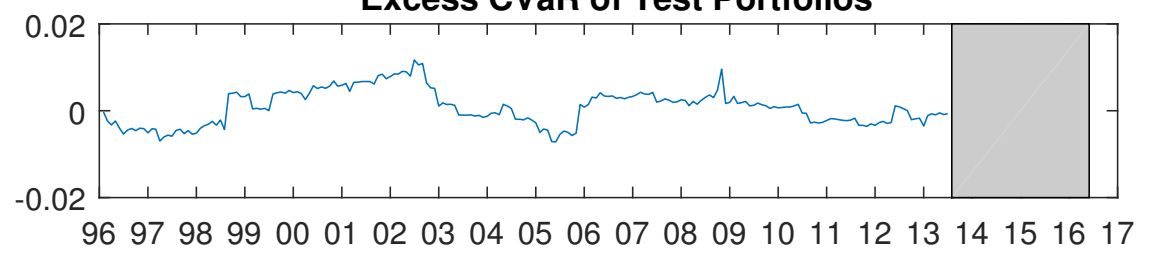

Net Count of Strictly Preferred Test Portfolios

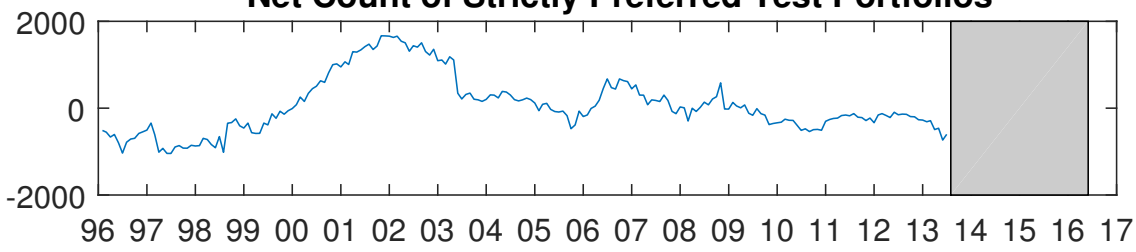

SEG
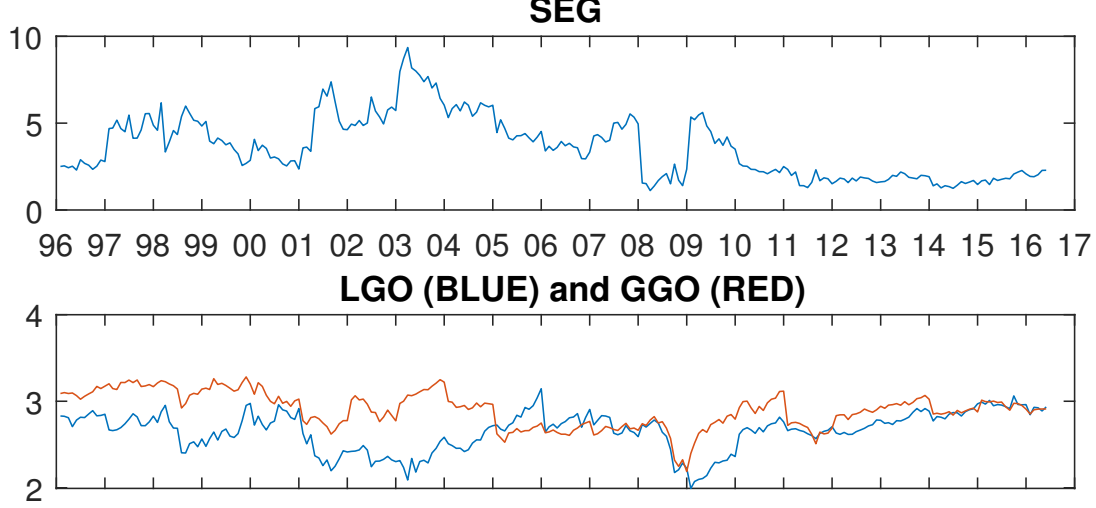

96979899000102030405060708091011121314151617

FIGURE D.18: Random Portfolio Experiment Results for South Africa 


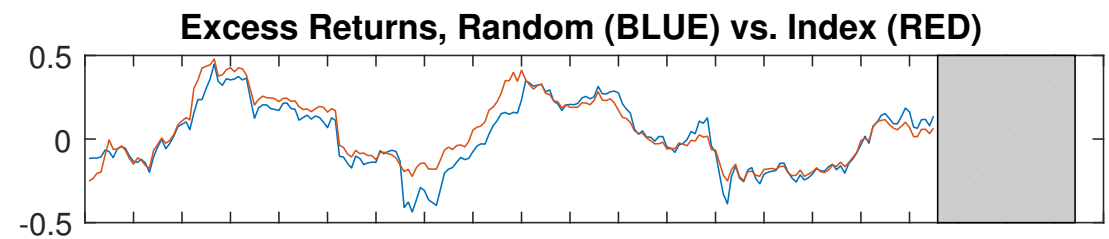

$969798990001020304050607080910111213141516 \quad 17$

Excess Correlation of Test Portfolios

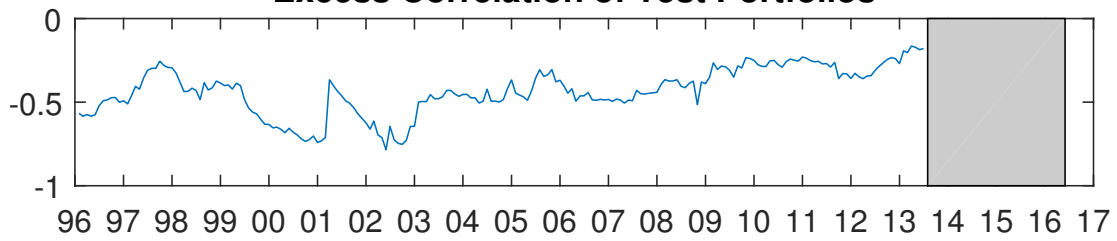

Excess CVaR of Test Portfolios

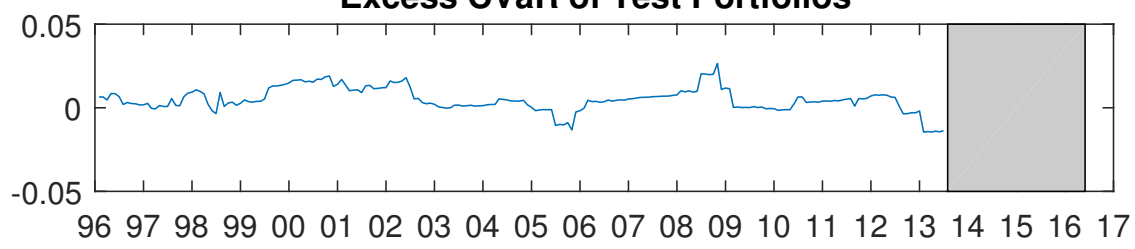

Net Count of Strictly Preferred Test Portfolios

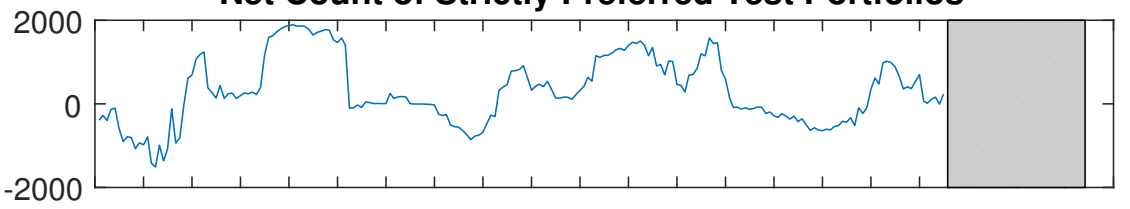

$969798990001020304050607080910111213141516 \quad 17$

SEG

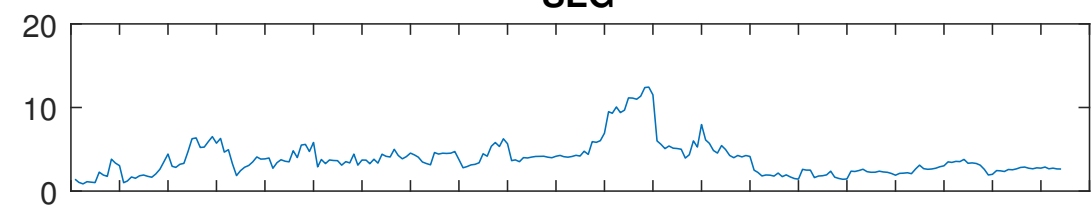

96979899000102030405060708091011121314151617

LGO (BLUE) and GGO (RED)

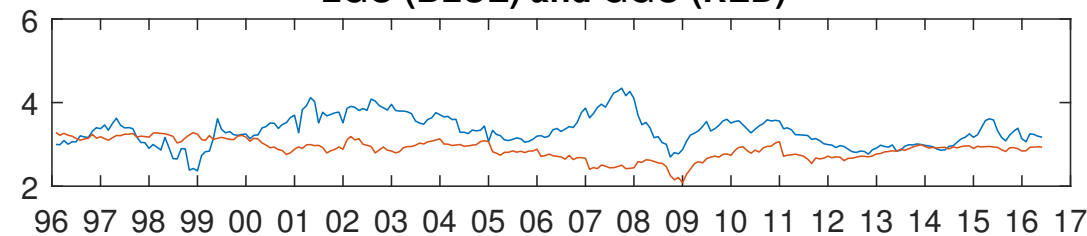

FIgURE D.19: Random Portfolio Experiment Results for China 


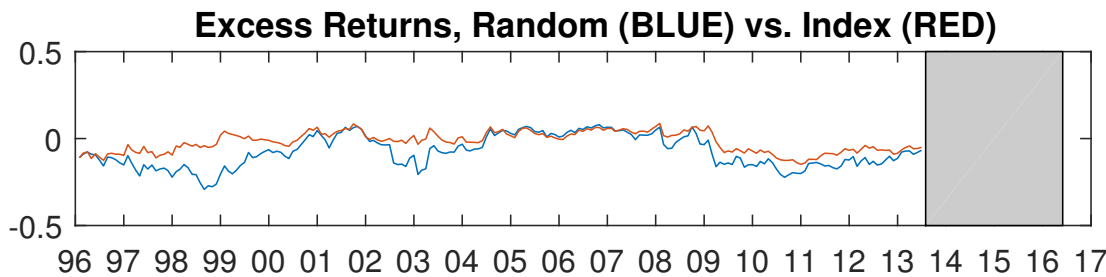

\section{Excess Correlation of Test Portfolios}

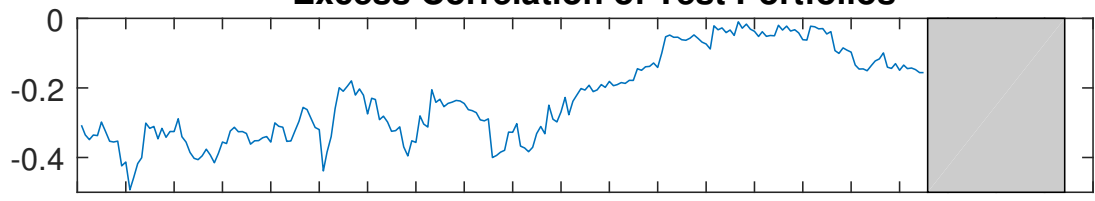

96979899000102030405060708091011121314151617

Excess CVaR of Test Portfolios

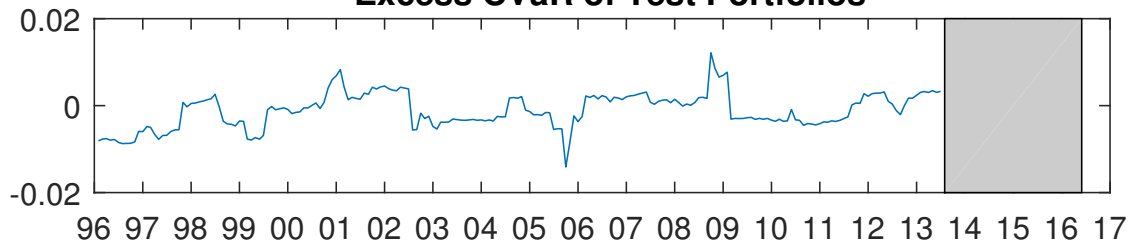

Net Count of Strictly Preferred Test Portfolios

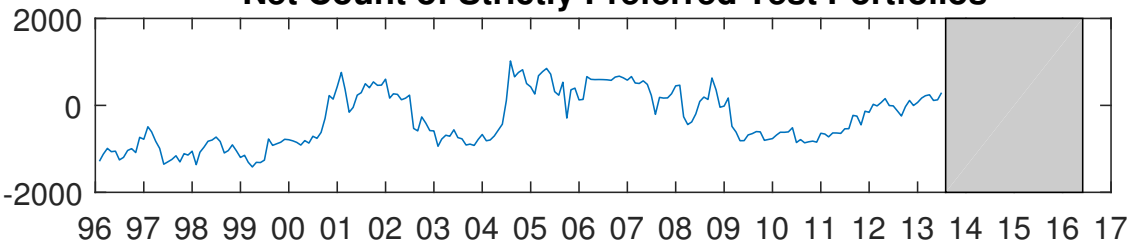

SEG

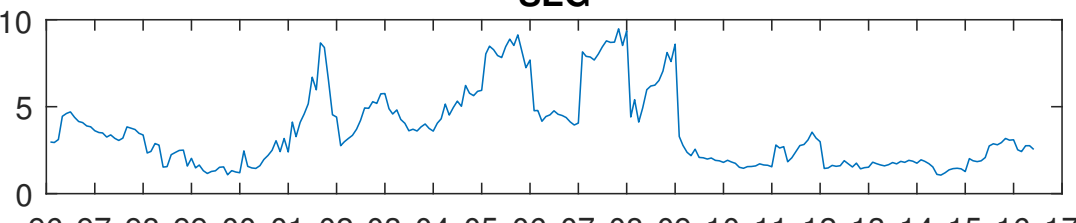

96979899000102030405060708091011121314151617

LGO (BLUE) and GGO (RED)

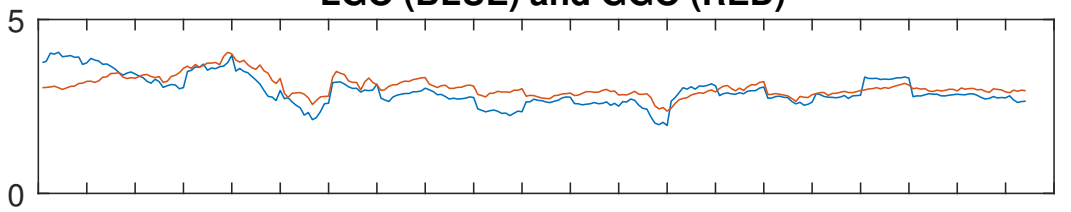

96979899000102030405060708091011121314151617

FIGURE D.20: Random Portfolio Experiment Results for Tai- 



\section{Bibliography}

Acerbi, Carlo and Dirk Tasche (2002). "Expected shortfall: a natural coherent alternative to value at risk". In: Economic notes 31.2, pp. 379-388.

Aggarwal, R., B. Lucey, and C. Muckley (2009). Dynamics of Equity Market Integration in Europe: Evidence of Changes with Events and Over Time. Tech. rep. Institute for International Integration Studies at Trinity College, Dublin. URL: http: / / fmwww.bc . edu/repec/mmfc05/paper48.pdf.

Ang, A. and X. Zhang (2011). Price-Earnings Ratios: Growth and Discount Rates. Tech. rep. Columbia University and Purdue University. URL: https : / / www0.gsb. columbia.edu/faculty/aang/papers/PEratio.pdf.

Arnott, R. et al. (2013). The Surprising "Alpha" from Malkiel's Monkey and Upside-Down Strategies. Tech. rep. Research Affiliates. URL: http: / / rvwinvesting.com/RAFI_Monkey_Paper.pdf.

Asness, C. (2003). Fight the Fed Model: The Relationship Between Stock Market Yields, Bond Market Yields, and Future Returns. Tech. rep. URL: http: / / dx . doi.org/10.2139/ssrn.381480.

Bekaert, G. and C. Harvey (1995). "Time-Varying World Market Integration". In: Journal of Finance 50.2. URL: http: / / papers.ssrn.com/sol3/ papers.cfm?abstract_id=274249.

Bekaert, G. et al. (2007). "Global Growth Opportunities and Market Integration". In: Journal of Finance 62.3. URL: http: / / www . nber . org/ papers/w10990.

- (2011). "What Segments Equity Markets?" In: The Review of Financial Studies 24.12. URL: http: / / www. jstor.org/stable/41302003.

Bierens, Herman J. and Luis F. Martins (2010). "Time-Varying Cointegration". In: Econometric Theory 26.5, pp. 1453-1490. URL: http: / / www . jstor. org/stable/40800889.

Bollerslev, Tim, Robert F. Engle, and Jeffrey M. Wooldridge (1988). "A Capital Asset Pricing Model with Time-Varying Covariances". In: Journal of Political Economy 96.1, pp. 116-131. URL: http: / / dx . doi .org/10 . $1086 / 261527$.

Burns, P. (2004). Performance Measurement via Random Portfolios. Tech. rep. URL: http://dx.doi.org/10.2139/ssrn.630123.

Campbell, John Y. and Robert J. Shiller (2001). Valuation Ratios and the Long-Run Stock Market Outlook: An Update. Working Paper 8221. National Bureau of Economic Research. DOI: 10.3386/w8221. URL: http: / /www . nber. org/papers/w8221.

Carrieri, F., V. Errunza, and K. Hogan (2007). "Characterizing World Market Integration Through Time". In: Journal of Financial and Quantitative Analysis 42.4, pp. 915-940. URL: http: / /papers.ssrn.com/sol3/papers. cfm?abstract_id=274249. 
Engle, Robert F., David M. Lilien, and Russell P. Robins (1987). “Estimating Time Varying Risk Premia in the Term Structure: The Arch-M Model". In: Econometrica 55.2, pp. 391-407. ISSN: 00129682, 14680262. URL: http: / / www. jstor.org/stable/1913242.

Errunza, V. and E. Losq (1985). "International Asset Pricing under Mild Segmentation: Theory and Test". In: Journal of Finance 40.1. URL: http: / / www. jstor.org/stable/2328050.

Errunza, Vihang, Etienne Losq, and Prasad Padmanabhan (1992). “Tests of integration, mild segmentation and segmentation hypotheses". In: Journal of Banking and Finance 16.5, pp. 949-972. URL: http: / / EconPapers. repec.org/RePEc:eee: jofina:v:16:y:1992:i:5:p:949-972.

Gow, I., G. Ormazabal, and D. Taylor (2010). “Correcting for Cross-Sectional and Time-Series Dependence in Accounting Research". In: The Accounting Review 85.2. URL: http://dx.doi.org/10.2308/accr.2010.85.2. 483.

Irons, R. and T. Wu (2013). "Will the market P/E ratio revert to its mean?" In: Investment Management and Financial Innovations 10.4. URL: https: / / businessperspectives.org/journals_free/imfi/2013/imfi_ en_2013_04cont_Irons.pdf.

Jayasuriya, Shamila A. and William Shambora (2009). “Oops, we should have diversified!" In: Applied Financial Economics 19.22, pp. 1779-1785. DOI: $10.1080 / 09603100903035947$. URL: http: / / dx.doi.org/10 . $1080 / 09603100903035947$.

Jensen, M., F. Black, and M. Scholes (1972). “The Capital Asset Pricing Model: Some Empirical Tests". In: Studies in the THeory of Capital Markets. URL: https://ssrn.com/abstract $=908569$.

Kearney, C. and B. Lucey (2004). "International equity market integration: Theory, evidence and implications". In: International Review of Financial Analysis 13.5. URL: http://dx.doi.org/10.1016/j.irfa.2004.02. 013.

Lisi, F. (2009). Dicing with the Market: Randomized Procedures for Evaluation of Mutual Funds. Tech. rep. 9-2008. Department of Statistical Sciences of the University of Padua, Italy. URL: http: / / papers.ssrn.com/sol3/ papers.cfm?abstract_id=1375730.

Longin, F. and B. Solnik (1995). "Is the correlation in international equity returns constant: 1960-1990?" In: Journal of International Money and Finance 14.1. URL: http: //dx.doi.org/10.1016/0261-5606 (94)00001-H.

Malkiel, B.G. (2011). A Random Walk Down Wall Street: The Time-Tested Strategy for Successful Investing (Tenth Edition). W. W. Norton. ISBN: 9780393081695. URL: https: / /books.google.com/books?id=08x1YpBp6WYC.

Markowitz, Harry (1952). "Portfolio Selection". In: The Journal of Finance 7.1, pp. 77-91. URL: http: / /www. jstor.org/stable/2975974.

Petersen, Mitchell A. (2009). "Estimating Standard Errors in Finance Panel Data Sets: Comparing Approaches". In: The Review of Financial Studies 22.1. URL: http://dx.doi.org/10.1093/rfs/hhn053. 
Rangvid, J. (1995). “Increasing convergence among European stock markets? A recursive common stochastic trends analysis". In: Economics Letters 71.3. URL: http://dx.doi.org/10.1016/s0165-1765 (01)00361-5.

Sharpe, William F. (1964). “Capital Asset Prices: A Theory of Market Equilibrium under Conditions of Risk". In: The Journal of Finance 19.3, pp. 425-442. URL: http: / / www . jstor.org/stable/2977928.

Speidell, L. and A. Khrone (2007). "The Case for Frontier Equity Markets". In: The Journal of Investing 16.3, pp. 12-22. URL: http: / / www. i i journals. com/doi/abs/10.3905/joi.2007.694758? journalcode=joi.

Stein, R (2014). "Not fooled by randomness: Using random portfolios to analyse investment funds". In: Investment Analysts Journal 43.79, pp. 1-15. DOI: $10.1080 / 10293523.2014 .11082564$. URL: http: / / www. tandfonline.com/doi/abs/10.1080/10293523.2014.11082564.

Thomas, J. and F. Zhang (2008). Don't Fight the Fed Model! Tech. rep. Yale University. URL: http: / / faculty.som.yale.edu/ jakethomas / papers / fedmodel.pdf.

Thompson, S. (2011). "Simple formulas for standard errors that cluster by both firm and time". In: Journal of Financial Economics 99.1, pp. 1 -10. ISSN: 0304-405X. URL: http://dx.doi.org/10.1016/j.jfineco.2010. 08.016.

Weigand, R. and R. Irons (2006). "Does the Market P/E Ratio Revert Back to Average?" In: Investment Management and Financial Innovations 3.3. URL: https://businessperspectives.org/journals_free/imfi/ 2006/imfi_en_2006_03_Weigand.pdf.

White, Halbert (1980). "A Heteroskedasticity-Consistent Covariance Matrix Estimator and a Direct Test for Heteroskedasticity". In: Econometrica 48.4, pp. 817-838. URL: http: / / www. jstor.org/stable/1912934.

Wilcoxon, Frank (1945). "Individual Comparisons by Ranking Methods". In: Biometrics Bulletin 1.6, pp. 80-83. URL: http: / / www. jstor.org/ stable/3001968.

Yardeni, E. (2003). Stock Valuation Models. Tech. rep. Prudential Financial Research. URL: http: / / quantlabs . net/academy / download/free_ quant_instituitional_books_/[Prudential\%20Financial $\div 20$ Research] $\div 20$ Stock 20 Valuation 20 Models.pdf. 